\title{
Diversity and Function of Fungi Associated with the Fungivorous Millipede, Brachycybe lecontii
}

Angie M. Macias

Follow this and additional works at: https://researchrepository.wvu.edu/etd

\section{Recommended Citation}

Macias, Angie M., "Diversity and Function of Fungi Associated with the Fungivorous Millipede, Brachycybe lecontii" (2017). Graduate Theses, Dissertations, and Problem Reports. 6132.

https://researchrepository.wvu.edu/etd/6132

This Thesis is protected by copyright and/or related rights. It has been brought to you by the The Research Repository @ WVU with permission from the rights-holder(s). You are free to use this Thesis in any way that is permitted by the copyright and related rights legislation that applies to your use. For other uses you must obtain permission from the rights-holder(s) directly, unless additional rights are indicated by a Creative Commons license in the record and/ or on the work itself. This Thesis has been accepted for inclusion in WVU Graduate Theses, Dissertations, and Problem Reports collection by an authorized administrator of The Research Repository @ WVU. For more information, please contact researchrepository@mail.wvu.edu. 
Diversity and function of fungi associated with the fungivorous millipede, Brachycybe lecontii

Angie M. Macias

Thesis submitted to the Davis College of Agriculture, Natural Resources and Design at West Virginia University in partial fulfillment of the requirements for the degree of

\author{
Master of Science \\ in \\ Plant Pathology
}

Dr. Matthew T. Kasson, Ph. D., Chair

Dr. Daniel Panaccione, Ph. D.

Dr. Ember Morrissey, Ph. D.

Dr. Rita Rio, Ph. D.

Division of Plant and Soil Sciences

Morgantown, West Virginia

2017

Keywords: (Brachycybe, millipede, fungivory, biodiversity)

Copyright 2017 Angie Macias 


\section{ABSTRACT \\ Uncovering the diversity and function of fungi associated with the fungivorous millipede, Brachycybe lecontii}

Angie M. Macias

Brachycybe (Wood) is a genus of fungivorous millipedes. To date, the fungal associates of these millipedes have never been characterized. In an attempt to resolve these relationships, culture-based approaches combined with DNA barcode sequencing were used. Sampling of 313 individuals collected from three of four $B$. lecontii clades and 20 sites across seven states uncovered at least 183 genera in 40 orders from four fungal phyla. At least seven putative new species were recovered in this study, despite the use of more classical culture-based approaches. Three of these fungi were phylogenetically resolved using ITS + LSU and include two new species, aff. Fonsecaea sp., Mortierella aff. ambigua, and a new genus related to Apophysomyces. Overall, the results of this study highlight the vast amount of undescribed fungal biodiversity associated with millipedes. Twelve fungal genera from nine orders showed high connectivity across the entire $B$. lecontii-associated fungal network, indicating a central role for these fungi in their association with these millipedes. These twelve include the two putative new species described above. The ecology of these and other fungal associates were also explored, using fungal cohort pairings and entomopathogenicity trials. Over $40 \%$ of all fungal pairings resulted in competitive interactions, a majority of which involved inhibition or overgrowth by fungi in the Hypocreales and Polyporales, respectively. The abundance of these competitive interactions in these two orders indicate differing ecological strategies. Hypocreales used chemical warfare to competitively exclude other fungi, while Polyporales physically overgrew their competitors. Mucoromycotan fungi used a similar strategy to the Polyporales. Results of a series of entomopathogenicity trials indicated that $B$. lecontii was less susceptible to entomopathogenic Hypocreales than an insect model (Galleria mellonella), even though these fungi are known to attack several classes of arthropods. Furthermore, the absence of a negative interaction between $B$. lecontii and entomopathogenic Hypocreales may indicate a beneficial relationship. When challenged with Polyporales, $B$. lecontii exhibited high mortality, while G. mellonella was unaffected. This stands in sharp contrast to previous casual observations of the feeding behavior of $B$. lecontii. Recent discoveries of previously overlooked fungal diversity have been groundbreaking and hint at substantial cryptic fungal biodiversity across the globe. The 200-300 million-year-old association between fungi and the Colobognatha, which includes Brachycybe lecontii, provides an ideal system to uncover biodiversity and examine function of these fungi in a highly understudied and ancient association. 


\section{ACKNOWLEDGEMENTS}

To thank those who have helped me get to where I am today, I have to go back well over a decade. It has been a long road to travel, and I would not be here, finishing my thesis, without all these people and organizations I want to thank. I thank my guidance counselors Lori Coone and Jan Phillips, who helped me learn to plan my academic future, even though I was only in middle school. I also thank all the staff of my middle school, who together, helped fund my living expenses for a boarding school summer program that steered me into higher education. I thank Ell Close, my friend and sponsor, for making sure that I could pursue my education without worrying about the costs. I thank the Asheville School, for being a nurturing environment where my passion for science grew and flourished. I thank my friend Bill, for encouraging me to apply to challenging academic programs. I thank the Cornell Plant Pathology Herbarium and its staff, Scott LaGreca, Torben Russo, and Kathie Hodge, for giving me my first job and teaching me about the intricacies of systematics and evolution of fungi. I thank my parents, Clarence and Dianna, for inviting me into their home before they had even met me, and for supporting me in all my adventures since. Their patience and tolerance for my ranting on and on about how cool bugs and spiders are is well-appreciated!

I must also thank all the members of the Kasson Lab Crew (Matt Kasson, Mark Double, Kristen Wickert, Cameron Stauder, Matt Berger, Amy Metheny, Dylan Short, and Nicole Utano) for their undying enthusiasm for science, and for their willingness to let me take over the Brachcybe project that they began before I arrived. I thank my many academic friends on Twitter, for their humor, willingness to share knowledge, and willingness to help a young woman in academia see all the nuances of being a scientist, mentor, and professor. I thank my committee members, Matt Kasson, Dan Panaccione, Ember Morrissey, and Rita Rio, for helping me through this research, and for encouraging me to apply for Ph.D. fellowships to continue working with Brachycybe. I thank my collaborators on this research project: Tappey Jones, Derek Hennen, Victoria Wong, Paul Marek, Michael Brewer, and many others. I thank Matt Kasson, for going well above and beyond what is expected of an academic advisor, and for being a great friend. I will never forget the many weekends I have spent cruising West Virginia in the lab Jeep, blasting music as we search for dead cicadas, beetle-infested logs, and little pink millipedes. 
TABLE OF CONTENTS

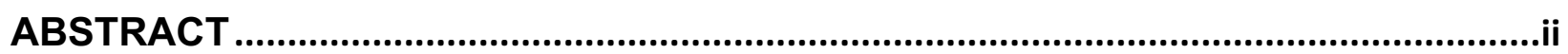

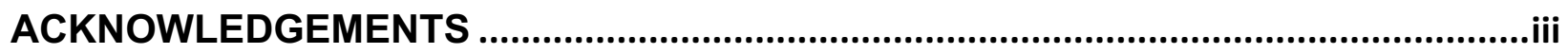

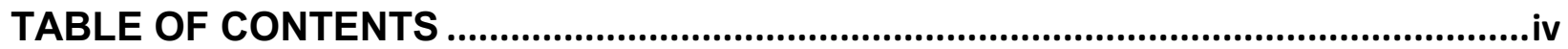

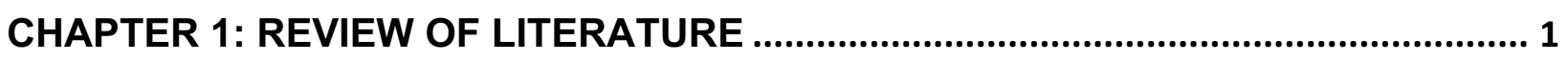

Millipede evolution, biology, and ecology ………...............................................................

Introduction to Brachycybe...................................................................................................

Animal-fungal symbioses ………………………….......................................................

Basidiomycete Fungi and Sociality in Insects ....................................................................

Literature Cited ..........................................................................................................................

CHAPTER 2: IDENTIFYING FUNGAL ASSOCIATES OF THE MILLIPEDE

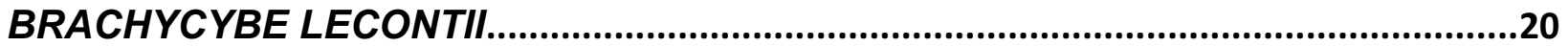

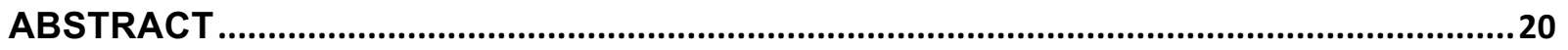

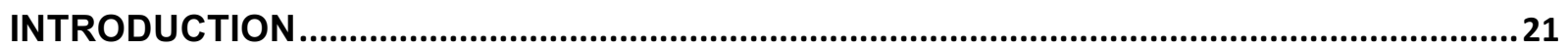

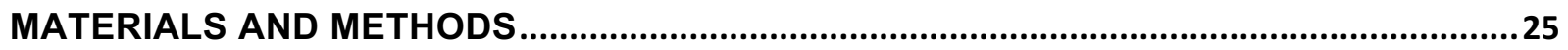

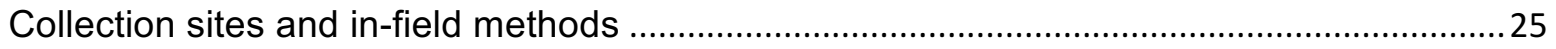

In-lab millipede processing \& isolate collection .................................................................2.

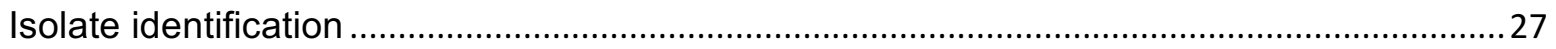

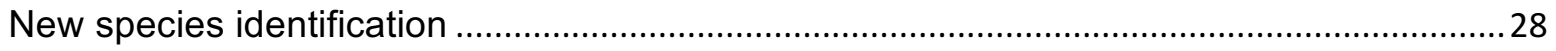

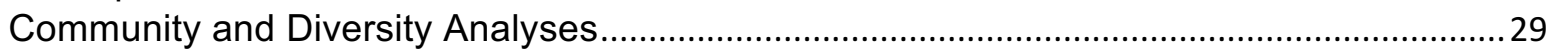

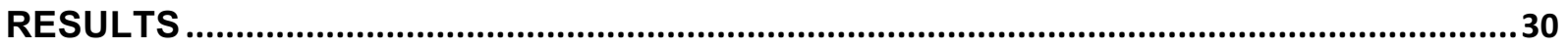

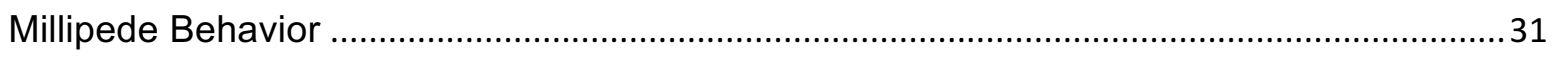

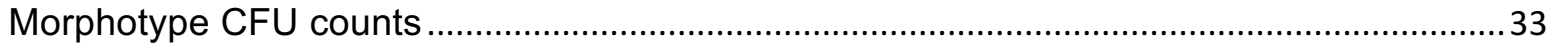

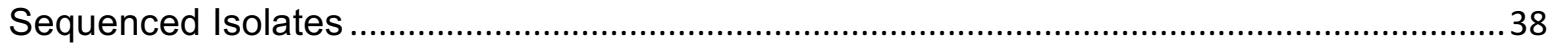

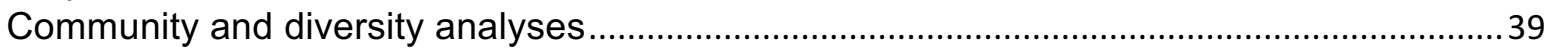

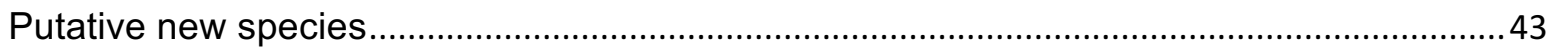

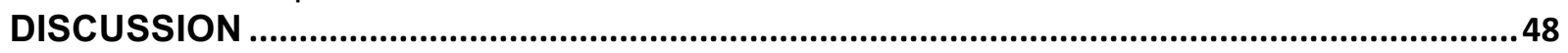

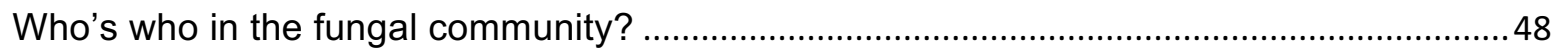

The role of white filamentous fungi............................................................................. 49

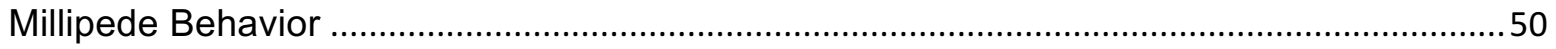

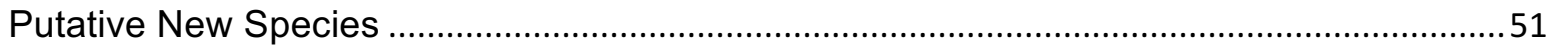

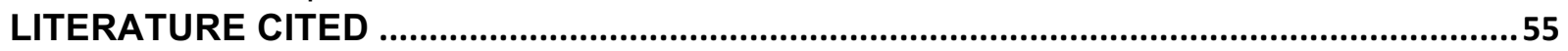

SUPPLEMENTAL TABLES .................................................................................................6

CHAPTER 3: IDENTIFYING FUNCTIONAL ROLES OF BRACHYCYBE LECONTII-

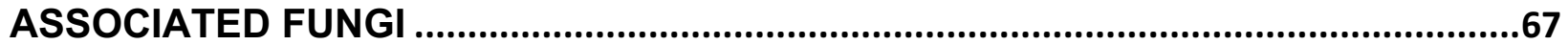

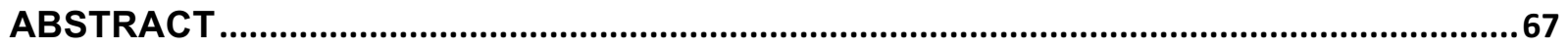

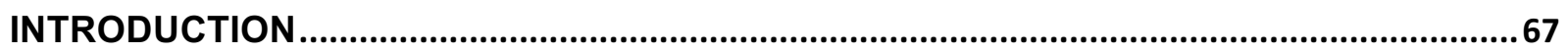




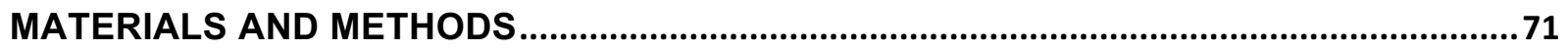

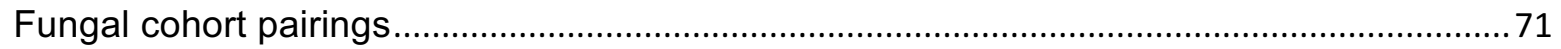

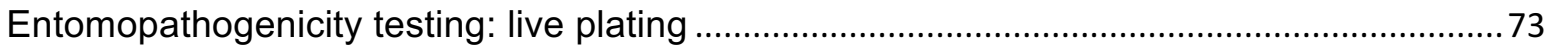

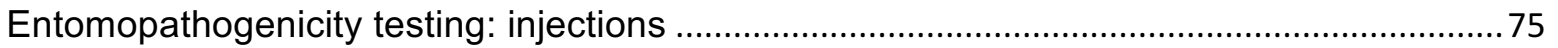

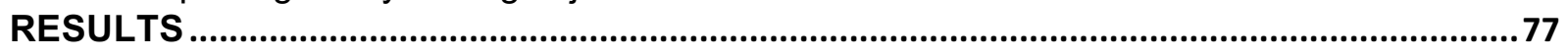

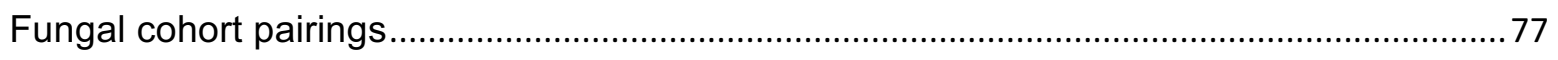

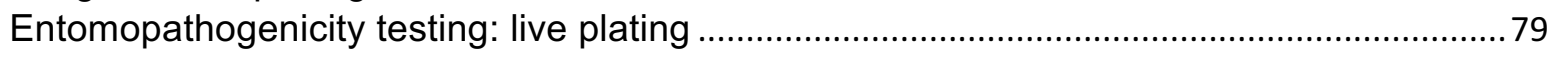

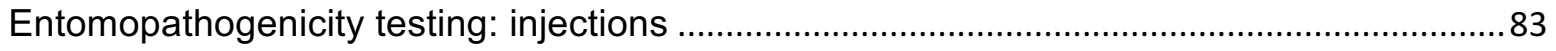

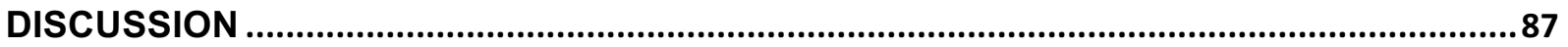

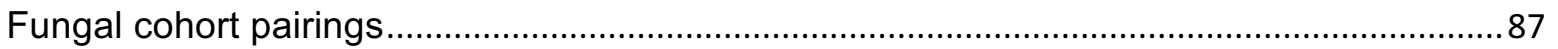

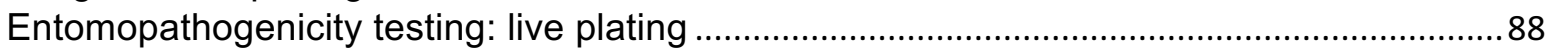

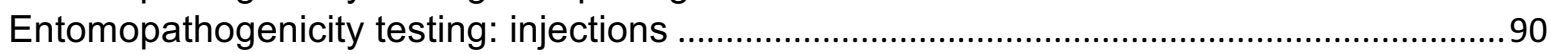

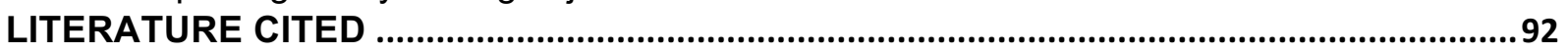

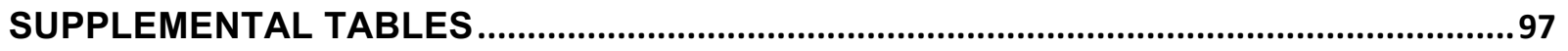

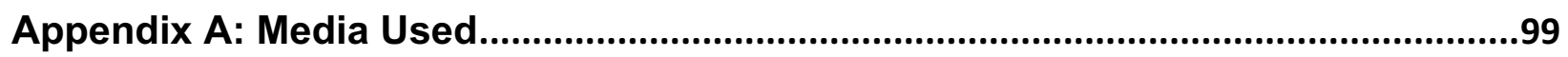

Appendix B: DNA Extraction Protocol................................................................99 


\section{CHAPTER 1: REVIEW OF LITERATURE}

\section{Millipede evolution, biology, and ecology}

Millipedes (Arthropoda: Myriapoda: Diplopoda) are non-insect arthropods with many body segments, and two pairs of legs per body segment. Other morphological characteristics include short elbowed antennae, a single fused maxilla, and large mandibles (Hopkin and Read 1992). The earliest fossil evidence of millipedes consists of trace fossils from the Ordovician, though the first body fossil, Pneumodesmus newmanii, dates to the Silurian (Wilson and Anderson 2004). This millipede fossil is also the earliest record of air-breathing in any animal. However, a recent molecular clock study of the evolution of air-breathing places the divergence of subphylum Myriapoda (containing millipedes and centipedes) at 554 MYA, in the mid- to late Cambrian (Lozano-Fernandez et al. 2016), although the reliability of molecular clock assumptions becomes questionable in deep phylogenetic time.

Millipedes are a relatively diverse group of animals, with approximately 12,000 millipede species described to date, in 16 orders and 140 families (Shear 2011). They are generally solitary animals, interacting with others only to reproduce. Millipede reproductive organs are located near the head, and males clasp the female with their legs while copulating. Some cases of geographic or complete parthenogenesis have been reported (Pinheiro et al. 2009). Females typically lay their eggs in an underground brooding chamber constructed of frass, soil, and decayed plant material (Hopkin and Read 1992). Eggs are abandoned after laying, except in a few rare cases of parental care (Kudo et al. 2009, 2011). 
The smallest known millipede is 2 millimeters long, while the largest can reach 35 centimeters (Hopkin and Read 1992). The majority are detritivores, feeding on dead and decaying plant material and animal waste on the forest floor, though observations or hypotheses of herbivory (Marek et al. 2012), fungivory (Brewer et al. 2012, Marek et al. 2012), and predation (Srivastava and Srivastava 1967) exist. Detritivorous millipedes play a crucial role in nutrient cycling, particularly in nutrient-poor areas (Mattson 2012, Lawrence and Samways 2003, Bonkowski et al. 1998). Nearly all millipedes are burrowers that live underground or inside wet, rotting substrate, and as such, have poor to non-existent vision (Manton 1961). The exoskeleton of millipedes lacks a waxy cuticle, so they must stay in damp environments to maintain body moisture (CloudsleyThompson 1950).

The only defenses millipedes possess are curling into a spiral to protect head and legs, and chemical defense through a wide variety of compounds secreted from repugnatorial glands along the body. It is believed that all millipedes synthesize these compounds themselves, but it is possible that some may sequester compounds from fungi (Shear 2015). These compounds include cyanogenics, terpenes, alkaloids, and phenols (Shear 2015). Defensive compounds may also have antibacterial (Williams and Singh 1997) and antifungal (Roncadori et al. 1985) properties, in addition to warding off vertebrate and arthropod predators, but some parasites use millipede secretions to home in on suitable hosts (Hash et al. 2017). Capuchin monkeys and other primates seek out millipedes to rub onto their bodies to repel insect pests like mosquitos (Valderrama et al. 2000).

Millipedes are regularly reported in association with fungi, likely due to their 
detritivorous habit. Most records of fungal-millipede interactions are cases where the millipede occasionally grazes on fungi in the environment, or where a parasitic fungus is attacking the millipede (Lilleskov and Bruns 2005, Bultman and Mathews 1996, Hodge et al. 2017). Several species of specialist ectoparasitic fungi in the Laboulbeniales have been recorded from millipedes (Santamaria et al 2014, Enghoff and Santamaria 2015). In the millipede pet trade, fungal infection due to poor husbandry is a widespread issue, especially of Archispirostreptus gigas (McMonigle 2012). Opportunistic saprotrophs may take advantage of weakened millipedes, but true entomopathogenic fungal attack on healthy animals is uncommon in the literature (Brito 1994, Chitty 2006). At least two species of trichomycetes, obligate arthropod gut-associated fungi, have been reported from millipedes (Wright 1979).

Introduction to Brachycybe

Brachycybe (Wood) is a genus of millipedes in the family Andrognathidae (Diplopoda: Platydesmida) with eight described species and two awaiting description (Brewer et al. 2012). In the United States, there are two species in the Appalachian Mountains and three (plus two undescribed) in northern California. The remaining three species are in China, Taiwan, Japan, and South Korea (Brewer et al. 2012). Interestingly, the two species in the eastern US (B. petasata and B. lecontii) are most distantly related to each other, with their closest relatives living in California and Japan, respectively (Brewer et al. 2012). This phylogenetic evidence indicates that the genus likely originated in the California mountains, and expanded its range at least twice into eastern North America, and at least once into Asia (Brewer et al. 2012). 
Brachycybe are small millipedes, with some individuals reaching $\sim 40 \mathrm{~mm}$ in length (pers. obs.). They are one of the few groups of arthropods that exhibit paternal care of their offspring. Evidence from B. nodulosa (Kudo et al. 2011) indicates that females choose to mate with the male with the widest body, which would provide the most protection to the eggs and hatchlings. After mating, the female lays her eggs in a sticky mound, which the male then wraps his body around, forming a basket. Males groom the eggs with their legs and mouthparts until they hatch, though it is unclear exactly what role this behavior plays. However, if the males are removed, the eggs quickly become overgrown by fungus and may fail to hatch (Kudo et al. 2011, pers. obs. in B. lecontii).

Brachycybe millipedes are most frequently found living on rotten logs and branches with visible fungal growth. They are subsocial, forming a pinwheel-like colony around crust-forming fungi such as Irpex, Peniophora, and Ceriporia. Individuals of all age groups will live in the same colony, and individuals freely move from one colony to another (Paul Marek, pers. comm.). They are believed to be fungivorous, as evidenced by their diminutive mouthparts (Paul Marek, pers. comm.), their clustering around fungi, and the visual damage they leave behind on crust fungi after they move.

This study will focus on the species Brachycybe lecontii, which ranges from eastern Oklahoma to Louisiana, and north to Missouri and mid-West Virginia. B. petasata overlaps in range with $B$. lecontii in the mountains on the border of North Carolina and Tennessee, and reaching into northern Georgia (Brewer et al. 2012). The mitochondrial genome of $B$. lecontii has been sequenced (Spruill 2010). This species has four distinct evolutionary clades, restricted by geography (Brewer et al. 2012). Their 
defensive secretions have been identified as the chemical deoxybuzonamine (Shear 2015), a heterocyclic nitrogen-containing compound related to buzonamine.

Buzonamine has been determined to have antipredator effects, but has only been tested against one ant species (Wood et al. 2000).

Historically, only one study reported the identity of a crust fungus fed upon by Brachycybe, and it was determined to be a species of Peniophora (Gardner 1975). More recently, five Polyporalean fungi have been reported directly from $B$. lecontii, and five others were isolated from B. lecontii-associated wood (Kasson et al. 2016).

$\underline{\text { Animal-fungal symbioses }}$

A wide variety of animals depend on fungi for food, shelter, and defense. The following is an exhaustive summary of known cases of animal-fungal symbioses. Eusocial termites and leaf-cutter ants, and subsocial ambrosia beetles are covered in the next section.

Ambrosia beetles (Coleoptera: Curculionidae: Scolytinae) have a nutritional symbiosis with various Ascomycotan fungi (one known exception, see next section). These fungi include Fusarium and Geosmithia (Hypocreales), Raffaelea and Afroraffaelea (Ophiostomatales), Ambrosiella, Meredithiella, and Phialophoropsis (Microascales) (Hulcr and Stelinski 2017). These beetles bore tunnels into dead or dying trees, or less commonly, pith, seeds, fruits, and petioles (Mueller et al. 2005). These tunnels serve as fertile ground for the beetles' fungal symbiont, which is transported inside a specialized pouch called a mycangium. The beetle inoculates her tunnel and soon after fungal growth appears, lays her eggs. The offspring feed on the 
fungus, and once mature, carry it away in their mycangia to start their own galleries (Hulcr and Stelinski 2017). Beetles obtain necessary vitamins, amino acids, and sterols from their fungus, in exchange for helping transport the fungus to new substrate (Mueller et al. 2005).

Sirex noctilio wood wasps (Hymenoptera: Siricidae) have a nutritional symbiosis with the fungus Amylostereum areolatum (Basidiomycota: Russulales) (Gaut 1969). These wasps oviposit their eggs up to $1.2 \mathrm{~cm}$ deep on their host plant, typically a member of the Pinaceae (Coutts and Dolezal 1969). These oviposition sites often have multiple tunnels, the last of which is injected with fungal arthrospores contained in sacs at the base of the female's ovipositor (Coutts and Dolezal 1969). Amylostereum is able to kill off a healthy tree, thus making it suitable for larval development, and in fact, the larvae depend on the fungus to condition the wood for their use (Coutts 1969, Coutts and Dolezal 1969). Other members of the Siricidae also have mutualistic fungi that perform similar roles (Coutts and Dolezal 1969).

Ship-timber beetles (Coleoptera: Lymexylidae) have a suspected nutritional symbiosis with the fungus Endomyces (Ascomycota: Saccharomycetales) (De Fine Licht and Biedermann 2012). Females carry inoculum in a mycangium near the ovipositor, and eject the fungus when eggs are laid. The larvae then carry spores into the wood as they begin boring (Arnett et al 2002). Like ambrosia beetles, ship-timber beetles remove wood dust and frass from their galleries, allowing their symbiotic fungus to grow on the tunnel walls (Henry 1967). Gut dissections have indicated that the larvae are indeed consuming fungus, though wood fragments were present as well (Henry 1967, Casari and Teixeira 2011). No studies on the nutritional content of the fungus, nor 
the question of whether or not the larvae required the fungus to survive, have been performed.

The marsh periwinkle, Littoraria irrorata (Mollusca: Littorinidae), has a nutritional symbiosis with several fungi, most frequently Mycosphaerella (Ascomycota: Mycosphaerellales) and Phaeosphaeria (Ascomycota: Pleosporales) (Silliman and Newell 2003, Sieg et al. 2013). These snails live on Spartina (Poaceae) in salt marshes, where they scrape the grass blades with their radula to create open wounds for fungi to colonize. In addition, these snails defecate onto the wounds, providing extra nitrogen for fungi, and additionally inoculating the wound with fungal spores present in the feces (Silliman and Newell 2003). After the fungus develops on the plant wounds, the snails consume it. Young snails require fungi to survive, and will die if left on Spartina with no fungal inoculum (Silliman and Newell 2003).

The Brazilian stingless bee, Scaptotrigona depilis (Hymenoptera: Apidae), has a nutritional symbiosis with the fungus Monascus sp. (Ascomycota: Eurotiales) (Menezes et al. 2015). Worker bees provision nest cells with a liquid food mass prior to egg-laying, and seal the cell when laying is complete (Menezes et al. 2015). Monascus then grows out from the walls of the cell, coating the food mass before the egg hatches. The larva then eats the fungus and the remaining food mass (Menezes et al. 2015). Without fungus, larval survival was only $8 \%$ (Menezes et al. 2015). When building new nests, bees carry a piece of nest material with them, suggesting that the bees actively transmit a single cultivar of Monascus to new nests (Menezes et al. 2015).

Some gall midges (Diptera: Cecidomyiidae: Lasiopterini and Asphondyliini) have a nutritional symbiosis with the fungi Macrophoma (Ascomycota: Botryosphaeriales), 
Ramichloridium (Ascomycota: Mycosphaerellales), and Aureobasidium (Ascomycota: Dothideales) (Rohfritsch 2008). These midges lay an egg on a plant tissue, and within a few hours of hatching, the host plant's cells become activated and a gall begins to form (Rohfritsch 2008). In most gall midges, the gall is filled with nutritive plant tissue, but in galls caused by the Lasiopterini and Asphondyliini, the gall is lined with fungal tissue. The fungus is deposited by the female at the time of egg-laying (Rohfritsch 1997, 2008). Females pick up new inoculum by rubbing specialized pouches on old, mature galls (Rohfritsch 2008).

Carton-inhabiting ants (Hymenoptera: Formicidae) have a structural symbiosis with several fungi in the Chaetothyriales, Capnodiales, and Pleosporales (Ascomycota), most of which do not yet have names (Voglmayr et al. 2011, Schlick-Steiner et al. 2008). Each ant species has its own community of structural fungi that help hold the nest wall together and allow the ants to climb the vertical wall surface (Voglmayr et al. 2011). It is not yet understood how the fungi are transmitted from nest to nest.

Domatia-inhabiting ants (Hymenoptera: Formicidae) have an unknown type of symbiosis with Chaetothyrialean fungi (Ascomycota) (Voglmayr et al. 2011, Defossez et al. 2009). Domatia are structures provided by plants as nesting-places for mutualistic ants that defend the plant from herbivory (Voglmayr et al. 2011). The fungal communities in domatia are much less diverse than those in ant carton, only containing one or two species of fungi (Defossez et al. 2009). These fungi are present in a thick, uniform, cushiony patch inside the domatium, and are never present without the mutualistic ant (Defossez et al. 2009). Parasitic ants living in domatia never had a fungus patch (Defossez et al. 2009). In addition, the fungi from domatia never 
sporulated, suggesting that they may be dependent on the ant for transportation (Defossez et al. 2009). Much more remains to be learned about this relationship between Chaetothyrialean fungi and their ant partners.

The arboreal ant Allomerus decemarticulatus (Hymenoptera: Formicidae) uses the hyphae of an undescribed fungus to build a trap that captures large insect prey (Dejean et al. 2005). These ants require supplemental nitrogen in their diets, and obtain it from the trapped prey, while the fungus consumes food material that is bound up in the trap.

Basidiomycete Fungi and Sociality in Insects

In at least three cases of insect-fungal symbioses, the fungal partner is a basidiomycete that converts otherwise indigestible plant material into a food source for the insect. Access to these recalcitrant materials has allowed these animals to specialize and develop communal social structures that otherwise could not be supported by their environment.

Ambrosiophilus is an ambrosia beetle (Coleoptera: Curculionidae: Scolytinae) that cultivates the fungus Flavodon ambrosius (Basidiomycota: Polyporales) (Kasson et al. 2016). Ambrosia beetles are well-known for their symbiotic association with fungi, but the fungal partner has always been reported as a member of the Ascomycota, with the exception of the sister genus to Ambrosiophilus, Ambrosiodmus (Li et al. 2015, Simmons et al. 2016), which also cultivates F. ambrosius. Compared to Ascomycotan ambrosial fungi like Fusarium and Raffaelea, Flavodon is much more aggressive at colonizing woody tissue (Kasson et al. 2016). Even when compared to known white-rot 
fungi, isolates of Flavodon caused significantly more loss of mass and hardness in wood tester blocks (Kasson et al. 2016). In nature, this results in a large proportion of the recalcitrant nutrients in wood being "claimed" by the beetle and its fungus. As a result of these traits, Ambrosiophilus beetles can stay in the same log for more than one generation without running out of resources. This freedom to persist allowed Ambrosiophilus to develop large, long-lived, communal colonies with multiple generations dwelling together, a social habit contrary to nearly all other ambrosia beetles (Kasson et al. 2016).

Another insect, the termite (Blattodea: Termitoidae: Macrotermitinae), has developed a symbiosis with fungi that allows it to utilize wood, in addition to other plant detritus. Well over 300 species of these widespread insects all cultivate the fungus Termitomyces sp. (Basidiomycota: Agaricales: Lyophyllaceae) (Mueller et al. 2005), though not all are obligately dependent on it. Termitomyces is able to convert wood and decaying plant material brought into the nest by the termites into a concentrated highnitrogen, high-carbohydrate form (Mueller et al. 2005). Termites can have colonies of up to one million individuals divided into two social castes with many-sub-castes, where each individual serves a particular role in the survival of the colony (Abe et al. 2000). Access to the nutrients locked away in wood and decaying plant material has allowed termites to inhabit a large suite of ecological niches around the world (Abe et al. 2000). Across their range, no other animal utilizes wood to the same extent as termites, with the aid of Termitomyces, and it is likely that the near-exclusive access termites enjoy has allowed them to develop the complex social behaviors seen in the obligately mutualistic species (Abe et al. 2000). 
Leafcutter ants (Hymenoptera: Formicidae: Attini) have also developed a similar mutualism with basidiomycete fungi. Members of genera Atta and Acromyrmex are obligate mutualists with species-specific strains of Agaricaceae fungi (Mueller et al. 2005). These ants have some of the most large and complex societies of any animal ever recorded, with counts ranging from over 100,000 individuals per colony to several million (Schultz and Brady 2008, Murakami et al. 2000, Hölldobler and Wilson 2008). Each colony can have up to four social castes, each with their own specialized roles in defense, resource-gathering, and offspring care (Mueller et al. 2005). While adult ants may supplement their fungus diet with plant sap, the larvae are entirely dependent on the fungus for nutrition (Mueller et al. 2005). Because of this mutualism, leaf-cutter ants are able to access the incredibly abundant rainforest resource of fresh leaves, and may utilize up to $17 \%$ of this resource in some ecosystems (Aylward et al. 2012). Access to this super-abundant but under-utilized resource likely helped fuel the sophistication and complexity seen in leaf-cutter ant societies today (Aylward et al. 2012). 


\section{Literature Cited}

Abe, T., D. E. Bignell, and M. Higashi (Eds.). 2000. TermitesL evolution, sociality, symbioses, ecology. Spriner Science and Business Media, New York, U. S. 95.

Arnett, R. H., M. C Thomas., P. E. Skelley, andJ. H. Frank (Eds.). 2002. American beetles, volume II: Polyphaga: Scarabaeoidea through Curculionoidea. CRC Press, New York, U.S.

Aylward, F. O., C. R. Currie, and G. Suen. 2012. The evolutionary innovation of nutritional symbioses in leaf-cutter ants. Insects. 3(1): 41-61.

Bonkowski, M., S. Scheu, and M. Schaefer. 1998. Interactions of earthworms (Octolasion lacteum), millipedes (Glomeris marginata), and plants (Hordelymus europaeus) in a beechwood on a basalt hill: implications for litter decomposition and soil formation. Applied Soil Ecology. 9(1): 161-166.

Brewer, M. S., C. L. Spruill, N. S. Rao, and J. E. Bond. 2012. Phylogenetics of the millipede genus Brachycybe Wood, 1864 (Diplopoda: Platydesmida:

Andrognathidae): patterns of deep evolutionary history and recent speciation. Molecular Phylogenetics and Evolution. 64(1): 232-242.

Brito, J. M. 1994. The millipede of Santo Antao, Spinotarsus caboverdus: survey for pathogenic microorganisms, bioassay tests of fungal pathogens against $S$. caboverdus and Melanoplus sanguinipes. Dissertation, Montana State University-Bozeman, College of Agriculture.

Bultman, T. L. and P. L. Mathews. 1996. Mycophagy by a millipede and its possible impact on an insect-fungus mutualism. Oikos. 75(1): 67-74. 
Casari, S. A. and É. P. Teixeira. 2011. Larva of Atractocerus brasiliensis (Lepeletier \& Audinet-Serville, 1825) (Lymexylidae, Atractocerinae). Papéis Avulsos de Zoologia (São Paulo). 51(12): 197-205.

Chitty, J. R. 2006. Myriapods (centipedes and millipedes). In: Lewbart, G. A. (Ed.) “Invertebrate medicine." Blackwell Publishing, lowa, U.S. 200-201.

Cloudsley-Thompson, J. L. 1950. The water relations and cuticle of Paradesmus gracilis (Diplopoda, Strongylosomidae). Journal of Cell Science. 3(16): 453-464.

Coutts, M. P. 1969. The mechanism of pathogenicity of Sirex noctilio on Pinus radiata I. Effects of the symbiotic fungus Amylostereum. Australian Journal of Biological Sciences. 22(4): 915-924.

Coutts, M. P., and J. E. Dolezal. 1969. Emplacement of fungal spores by the woodwasp, Sirex noctilio, during oviposition. Forest Science. 15(4): 412-416.

De Fine Licht, H. H. and P. H. Biedermann. 2012. Patterns of functional enzyme activity in fungus farming ambrosia beetles. Frontiers in Zoology. 9(13): 1-11.

Defossez, E., M. A. Selosse, M. P. Dubois, L. Mondolot, A. Faccio, C. DjietoLordon, D. McKey, and R. Blatrix. 2009. Ant-plants and fungi: a new threeway symbiosis. New Phytologist. 182(4): 942-949.

Dejean, A., P. J. Solano, J. Ayroles, B. Corbara, and J. Orivel. 2005. Insect behavior: arboreal ants build traps to capture prey. Nature. 434(7036): 973.

Enghoff, H. and S. Santamaria. 2015. Infectious intimacy and contaminated cavesthree new species of ectoparasitic fungi (Ascomycota: Laboulbeniales) from blaniulid millipedes (Diplopoda: Julida) and inferences about their transmittal mechanisms. Organisms Diversity \& Evolution. 15(2): 249-263. 
Gardner, M. R. 1975. Revision of the millipede family Andrognathidae in the Nearctic region. Memoirs of the Pacific Coast Entomological Society. 5: 19-38.

Gaut, I. P. C. 1969. Identity of the fungal symbiont of Sirex noctilio. Australian Journal of Biological Sciences. 22(4): 905-914.

Hash, J. M., J. G. Millar, J. M. Herati, J. F. Harwood, and B. V. Brown. 2017. Millipede defensive compounds are a double-edged sword: Natural history of the millipede-parasitic genus Myriophora Brown (Diptera: Phoridae). Journal of Chemical Ecology. 43(2): 198-206.

Henry, S. M. (Ed.). 2013. Symbiosis: associations of invertebrates, birds, ruminants, and other biota. Academic Press, New York, U.S.

Hodge, K. T., A. E. Hajek, and A. Gryganskyi. 2017. The first entomophthoralean killing millipedes, Arthrophaga myriapodina n. gen. n. sp., causes climbing before host death. Journal of Invertebrate Pathology. 149: 135-140.

Hölldobler, B., and E. O. Wilson. 2009. The superorganism: the beauty, elegance, and strangeness of insect societies. WW Norton \& Company, New York, U.S. 91-97.

Hopkin, S. P. and H. J. Read. 1992. The biology of millipedes. Oxford University Press, Oxford, England. 1-24.

Hulcr, J. and L. L. Stelinski. 2017. The ambrosia symbiosis: from evolutionary ecology to practical management. Annual Review of Entomology. 62: 285-303.

Kasson, M. T., K. L. Wickert, C. M. Stauder, A. M. Macias, M. C. Berger, D. R. Simmons, D. P. Short, D. B. DeVallance, and J. Hulcr. 2016. Mutualism with aggressive wood-degrading Flavodon ambrosius (Polyporales) facilitates niche 
expansion and communal social structure in Ambrosiophilus ambrosia beetles. Fungal Ecology. 23: 86-96

Kudo, S. I., C. Koshio, and T. Tanabe. 2009. Male egg-brooding in the millipede Yamasinaium noduligerum (Diplopoda: Andrognathidae). Entomological Science. 12(3): 346-347.

Kudo, S. I., Y. Akagi, S. Hiraoka, T. Tanabe, and G. Morimoto. 2011. Exclusive male egg care and determinants of brooding success in a millipede. Ethology. 117(1): $19-27$.

Lawrence, J. M. and M. J. Samways. 2003. Litter breakdown by the Seychelles giant millipede and the conservation of soil processes on Cousine Island, Seychelles. Biological Conservation. 113(1): 125-132.

Lilleskov, E. A. and T. D. Burns. 2005. Spore dispersal of a resupinate ectomycorrhizal fungus, Tomentella sublilacina, via soil food webs. Mycologia. 97(4): 762-769.

Lozano-Fernandez, J., R. Carton, A. R. Tanner, M. N. Puttick, M. Blaxter, J. Vinther, J. Olesen, G. Giribet, G. D. Edgecombe, and D. Pisani. 2016. A molecular palaeobiological exploration of arthropod terrestrialization. Philosophical Transactions of the Royal Society B. 371(1699).

Manton, S. M. 1961. The evolution of arthropodan locomotory mechanisms, part 7. Functional requirements and body design in Colobognatha (Diplopoda), together with a comparative account of diplopod burrowing techniques, trunk musculature, and segmentation. Zoological Journal of the Linnean Society. 44(299): 383-462. 
Marek, P., W. Shear, and J. Bond. 2012. A rediscription of the leggiest animal, the millipede Illacme plenipes, with notes on its natural history and biogeography (Diplopoda, Siphonophorida, Siphonorhinidae). ZooKeys. 241: 77-112.

Mattson, W. J. (Ed.) 2012. The role of arthropods in forest ecosystems. Springer Science \& Business Media, New York, U.S. 96-97.

McMonigle, O. 2012. Millipeds in captivity: diplopodan husbandry and reproductive biology. Coachwhip Publications, Ohio, U.S.

Menezes, C., A. Vollett-Neto, A. J. Marsaioli, D. Zampirei, I. C. Fontoura, A. D. Luchessi, and V. L. Imperatriz-Fonseca. 2015. A Brazilian social bee must cultivate fungus to survive. Current Biology. 25(21): 2851-2855.

Mueller, U. G., N. M. Gerardo, D. K. Aanen, D. L. Six, and T. R. Schultz. 2005. The evolution of agriculture in insects. Annual Review of Ecology, Evolution, and Systematics. 36: 563-595.

Murakami, T., S. Higashi, and D. Windsor. 2000. Mating frequency, colony size, polyethism, and sex ratio in fungus-growing ants (Attini). Behavioral Ecology and Sociobiology. 48(4): 276-284.

Pinheiro, T. G., M. I. Marques, and L. D. Battirola. 2009. Life cycle of Poratia salvator (Diplopoda: Polydesmida: Pyrgodesmidae). Zoologia (Curitiba). 26(4): 658-662.

Rohfritsch, O. 1997. Morphological and behavioural adaptations of the gall midge Lasioptera arundinis (Schiner) (Diptera, Cecidomyiidae) to collect and transport conidia of its fungal symbiont. Tijdschrift voor Entomologie. 140(1): 59-66.

Rohfritsch, O. 2008. Plants, gall midges, and fungi: a three-component system. Entomologia Experimentalis et Applicata. 128(1): 208-216. 
Roncadori, R. W., S. S. Duffey, and M. S. Blum. 1985. Antifungal activity of defensive secretions of certain millipedes. Mycologia. 77(2): 185-191.

Santamaria, S., H. Enghoff, and A. S. P. S. Reboleira. 2014. Laboulbeniales on millipedes: Diplopodomyces and Troglomyces. Mycologia. 106(5): 1027-1038.

Schlick-Steiner, B. C., F. M. Steiner, H. Konrad, B. Seifert, E. Christian, K. Moder, C. Stauffer, and R. H. Crozier. 2008. Specificity and transmission mosaic of ant nest-wall fungi. Proceedings of the National Academy of Sciences. 105(3): 940943.

Schultz, T. R. and S. G. Brady. 2008. Major evolutionary transitions in ant agriculture. Proceedings of the National Academy of Sciences. 105(14): 5435-5440.

Shear, W. 2011. Class Diplopoda de Blainville in Gervais, 1844. In: Zhang, Z. (ed.) "Animal biodiversity: an outline of higher-level classification and survey of taxonomic richness". Magnolia Press, Auckland, New Zealand, 2011.

Shear, W. A. 2015. The chemical defenses of millipedes (Diplopoda): biochemistry, physiology, and ecology. Biochemical Systematics and Ecology. 61: 78-117.

Sieg, R. D., D. Willey, K. Wolfe, and J. Kubanek. 2013. Multiple chemical defenses produced by Spartina alterniflora deter farming snails and their fungal crop. Marine Ecology Progress Series. 488: 35-49.

Silliman, B. R. and S. Y. Newell. 2003. Fungal farming in a snail. Proceedings of the National Academy of Sciences. 100(26): 15643-15648.

Simmons, D. R., Y. Li, C. C. Bateman, and J. Hulcr. 2016. Flavodon ambrosius sp. nov., a basidiomycetous mycosymbiont of Ambrosiodmus ambrosia beetles. Mycotaxon. 131(2): 277-285. 
Spruill, C. L. 2010. Phylogenetics and systematics of the millipede genus Brachycybe Wood, 1864 (Platydesmida: Andrognathidae). Thesis, East Carolina University.

Srivastava, P. D. and Y. N. Srivastava. 1967. Orthomorpha sp.-a new predatory millipede on Achatina fulica in Andamans. Cellular and Molecular Life Sciences. 23(9): 776.

Valderrama, X., J. G. Robinson, A. B. Attygalle, and T. Eisner. 2000. Seasonal anointment with millipedes in a wild primate: a chemical defense against insects? Journal of Chemical Ecology. 26(12): 2781-2790.

VogImayr, H, V. Mayer, U. Maschwitz, J. Moog, C. Djieto-Lordon, and R. Blatrix. 2011. The diversity of ant-associated black yeasts: insights into a newly discovered world of symbiotic interactions. Fungal Biology. 115(10): 1077-1091.

Williams, L. A., P. D. A. Singh, and L. S. Caleb-Williams. 1997. Biology and biological action of the defensive secretion from a Jamaican millipede. Naturwissenschaften 84(4): 143-144.

Wilson, H. M. and L. I. Anderson. 2004. Morphology and taxonomy of Paleozoic millipedes (Diplopoda: Chilognatha: Archipolypoda) from Scotland. Journal of Paleontology. 78(1): 169-184.

Wood, W. F., F. J. Hanke, I. Kubo, J. A. Carroll, and P. Crews. 2000. Buzonamine, a new alkaloid from the defensive secretion of the millipede, Buzonium crassipes. Biochemical Systematics and Ecology. 28(4): 305-312.

Wright, K. A. 1979. Trichomycetes and oxyuroid nematodes in the millipede, Narceus annularis. Proceedings of the Helminthological Society of Washington. 46: 213223. 
You, L., D. R. Simmons, C. C. Bateman, D. P. Short, M. T. Kasson, R. J. Rabaglia, and J. Hulcr. 2015. New fungus-insect symbiosis: culturing, molecular, and histological methods determine saprophytic Polyporales mutualists of Ambrosiodmus ambrosia beetles. PLoS ONE. 10(9). 


\title{
CHAPTER 2: IDENTIFYING FUNGAL ASSOCIATES OF THE MILLIPEDE BRACHYCYBE LECONTII
}

\begin{abstract}
Brachycybe (Wood) is a genus of millipedes known to be fungivorous, but, to date, their fungal associates have never been characterized. In an attempt to resolve these relationships, culture-based approaches combined with DNA sequencing were used. Sampling of 313 individuals collected from 3 of 4 Brachycybe lecontii clades and 20 sites across 7 states revealed at least 183 genera in 40 orders from 4 fungal phyla. Of the genera found, $40 \%$ were recovered only once, and only $13 \%$ had 10 or more isolates recovered, many of which were found across numerous sampling locations. Twelve fungal genera from nine orders showed high connectivity across the whole fungal network, indicating a central role for these fungi in their association with $B$. lecontii. In the literature, only a single genus of fungus (Peniophora) has been reported in association with Brachycybe, but systematic examination of photos available on websites such as Flickr.com indicated that many more types of fungus associate with these millipedes. Results of this study do not support the limited previous observations of the feeding behavior of $B$. lecontii - instead, it appears that these millipedes feed on a wide variety of fungi, not just Polyporales. At least seven putative new species were recovered in the study despite the use of more classical culture-based approaches. Overall, the results of this study highlight the vast amount of undescribed fungal biodiversity associated with millipedes.
\end{abstract}




\section{INTRODUCTION}

Millipedes (Arthropoda: Myriapoda: Diplopoda) are non-insect arthropods with many body segments, and two pairs of legs per body segment. The first millipede body fossil, Pneumodesmus newmanii, dates to the Silurian (420-440 million years ago), and presents the earliest evidence for air-breathing in any animal (Wilson and Anderson 2004).

Millipedes are a relatively diverse group of animals, with approximately 12,000 millipede species described to date, in 16 orders and 140 families (Shear 2011). The majority are detritivores, feeding on dead and decaying plant material and animal waste on the forest floor, though anecdotal evidence supports herbivorous (Marek et al. 2012), fungivorous (Brewer et al. 2012, Marek et al. 2012), and carnivorous lifestyles (Srivastava and Srivastava 1967). Detritivorous millipedes play a crucial role in nutrient cycling, particularly in nutrient-poor areas (Mattson 2012, Lawrence and Samways 2003, Bonkowski et al. 1998). Nearly all millipedes have a subterranean lifestyle, living in decomposing leaf litter, in the soil, or inside wet, rotting wood substrates.

Millipedes are regularly reported in association with fungi, likely due to their detritivorous habit. Most records of fungal-millipede interactions are cases where millipedes occasionally graze on fungi in the environment, or where a parasitic fungus is attacking the millipede (Lilleskov and Bruns 2005, Bultman and Mathews 1996, Hodge et al. 2017). Several species of specialist ectoparasitic fungi in the Laboulbeniales have been recorded from millipedes (Santamaria et al. 2014, Enghoff and Santamaria 2015). In the millipede pet trade, fungal infection due to poor animal husbandry is a widespread issue, especially in the most notable pet species, the giant African millipede 
(Archispirostreptus gigas) (McMonigle 2012). Opportunistic saprotrophs may take advantage of weakened millipedes, but confirmed entomopathogenicity of healthy animals is uncommon in the literature (Brito 1994, Chitty 2006). At least two species of trichomycetes, obligate arthropod gut-associated fungi, also have been reported from millipedes (Wright 1979).

Brachycybe (Wood) is a genus of millipedes in the family Andrognathidae (Diplopoda: Platydesmida) with eight described species and at least two additional new species awaiting description (Brewer et al. 2012). In the United States, there are two species in the Appalachian Mountains and three (plus two undescribed) in northern California. All Brachycybe are small millipedes, with some individuals reaching $4 \mathrm{~cm}$ in length (pers. obs.). They are one of the few groups of arthropods that exhibit paternal care of their offspring (Kudo et al. 2011) (Figure 1). Brachycybe are most frequently found living on rotten logs and branches with visible fungal growth (Shelley et al. 2005). They exhibit various social behaviors including overlapping adult generations and reproductive division of labor. They also form pinwheel-like multigenerational colonies around resupinate fungi underneath downed woody substrates (Gardner 1975) (Figure 1). All members of the millipede subterclass Colobognatha, which includes Brachycybe, are believed to be strict fungivores (Gardner 1975), as evidenced by their diminutive mouthparts (Paul Marek, pers. comm.) their clustering around fungi, and the visual damage (i.e. divots) they leave behind on fungi (Figure 1). 


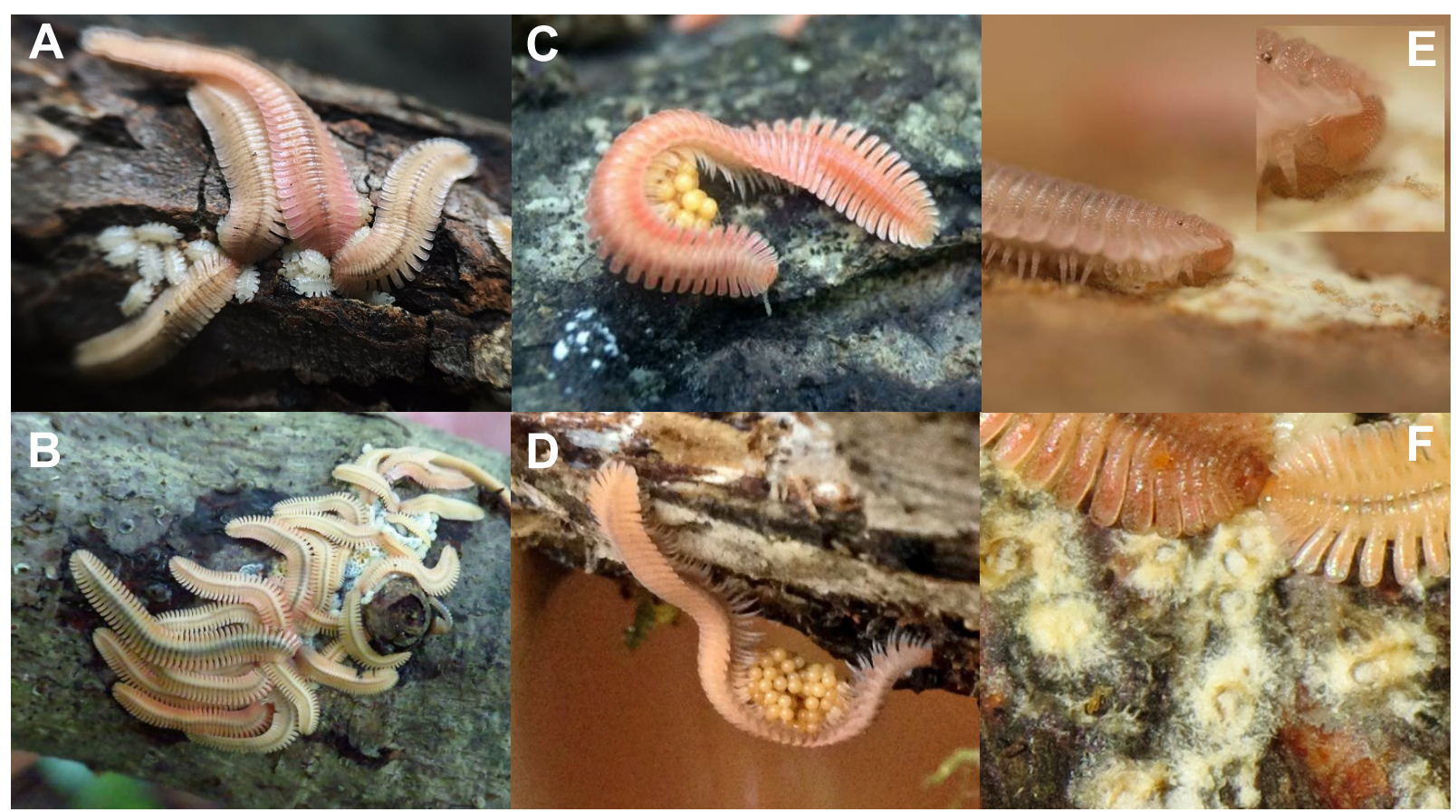

FIGURE 1: Brachycybe lecontii behaviors. A: B. lecontii forming a multigenerational partial pinwheel around a food source embedded in bark. B: Several adults forming a full pinwheel around a fungus on wood. C: Male caring for eggs. D: Male transporting eggs to underside of log, after log was flipped. E: Millipede feeding on fungus. F: Millipedes sharing a feeding site. Several feeding divots visible.

The known geographic range of Brachycybe lecontii extends across 13 states from eastern Oklahoma to western South Carolina, south to Louisiana, and north to southern West Virginia (Shelley et al. 2005, Brewer et al. 2012). Their range encompasses five Level III and nine Level IV Ecoregions (as defined in 2013 report from U.S. EPA). The five Level III Ecoregions include: "Ouachita Mountains" (AR, OK), "Arkansas Valley" (AR), "Piedmont" (SC), "Blue Ridge" (GA, SC), "Ridge and Valley" (VA), and "Central Appalachians" (TN, VA, WV). The nine Level IV Ecoregions were as follows: "Central Mountain Ranges", "Central Hills, Ridges, and Valleys", and "Fourche Mountains" (“Ouachita Mountains"); "Scattered High Ridges and Mountains" (“Arkansas Valley”); “Northern Inner Piedmont” (“Piedmont”); “Southern Crystalline Ridges and 
Mountains" ("Blue Ridge"); "Southern Sandstone Ridges" and "Southern Dissected Ridges and Knobs" ("Ridge and Valley"); and "Dissected Appalachian Plateau" ("Central Appalachians"). Within this known range, five subpopulations have been identified (Shelley et al. 2005), four of which were recently validated using sequence data (Brewer et al. 2012).

Historically, only one study reported the identity of a resupinate fungus fed upon by Brachycybe, and it was determined to be a species of Peniophora (Russulales) (Gardner 1975). More recently, five Polyporalean fungi (Irpex lacteus, Phanerochaete sp., Trametopsis cervina, Junghuhnia nitida, and Gloeoporus pannocinctus) have been reported directly from $B$. lecontii, and five other Polyporales were isolated from $B$. lecontii associated wood (Kasson et al. 2016). However, the overwhelming number of casual observations in websites such as Arachnoboards.net (2 observations), Bugguide.net (6), Flickr.com (3), Instagram.com (6), and iNaturalist.org (3) of Brachycybe interacting with various fungi supports a much more diverse fungal community than has been formally identified.

In an attempt to address this knowledge gap, this study aims to identify fungal associates of Brachycybe lecontii across its known geographic range using culturebased approaches. The use of DNA sequencing will permit in-depth examination of culturable fungal communities including taxa with diagnostically informative morphology as well as morphologically cryptic taxa. 


\section{MATERIALS AND METHODS}

$\underline{\text { Collection sites and in-field methods }}$

Millipede collection sites were primarily identified through Brewer et al. 2012 and Gardner 1975, and additional sites were also identified. Sampling was targeted to collect millipedes from all four $B$. lecontii clades. Based on previous work by Brewer and colleagues (2012), individual sites were expected to contain millipedes from a single clade, with no previously reported overlap. In total, 20 sites were examined, with 18 yielding colonies and individuals, and 2 yielding individuals only. These sites were in Arkansas, Georgia, Oklahoma, South Carolina, Tennessee, Virginia, and West Virginia (Table 1).

TABLE 1: Brachycybe lecontii collection sites and associated information for each.

\begin{tabular}{|c|c|c|c|c|}
\hline $\begin{array}{l}\text { SITE } \\
\text { NAME }\end{array}$ & $\begin{array}{l}\text { COLLECTION } \\
\text { REFERENCES }\end{array}$ & $\begin{array}{l}\text { MILLIPEDE } \\
\text { CLADE }\end{array}$ & BRIEF DESCRIPTION & $\begin{array}{l}\text { LEVEL } 3 \& 4 \\
\text { ECOREGION }^{\dagger}\end{array}$ \\
\hline AR1 & Gardner 1975 & 4 & Mount Magazine & $37 \mathrm{~A}$ \\
\hline AR2 & None & 4 & Power Line Elm & $36 \mathrm{~B}$ \\
\hline AR3 & None & 4 & Serendipity Trail & $36 \mathrm{C}$ \\
\hline AR4 & Brewer et al. 2012 & $4^{*}$ & Mount Nebo & $37 \mathrm{~A}$ \\
\hline AR5 & None & 4 & Lake Ouachita & $36 \mathrm{~B}$ \\
\hline AR6 & None & 4 & Charlton Campground & $36 \mathrm{~B}$ \\
\hline GA1 & Gardner 1975 & 1 & Moccasin Creek & $66 \mathrm{D}$ \\
\hline OK1 & Brewer et al. 2012 & 4 & Hodgen & $36 \mathrm{D}$ \\
\hline SC1 & $\begin{array}{l}\text { Brewer et al. 2012, } \\
\text { Gardner } 1975\end{array}$ & 1 & Cassidy Bridge & $66 \mathrm{D}$ \\
\hline SC2 & Gardner 1975 & 1 & Stumphouse Tunnel & $45 \mathrm{E}$ \\
\hline TN1 & Gardner 1975 & 3 & Caryville & $69 \mathrm{D}$ \\
\hline VA1 & $\begin{array}{l}\text { Brewer et al. 2012, } \\
\text { Gardner } 1975\end{array}$ & 3 & Shortts Road & $69 D$ \\
\hline VA2 & None & 3 & Pinnacle & 671 \\
\hline VA3 & Gardner 1975 & 3 & Breaks & $69 D$ \\
\hline VA4 & None & 1 & Pulaski & $67 \mathrm{H}$ \\
\hline WV1 & $\begin{array}{l}\text { Brewer et al. 2012, } \\
\text { Gardner } 1975\end{array}$ & 3 & War & 69D \\
\hline WV2 & None & 3 & Berwind Lake & $69 D$ \\
\hline
\end{tabular}




\begin{tabular}{l|llll} 
WV3 & None & 3 & Panther & $69 \mathrm{D}$ \\
WV4 & None & 3 & Cabwaylingo & $69 \mathrm{D}$ \\
WV5 & None & 3 & Chief Logan & $69 \mathrm{D}$
\end{tabular}

*AR4 was expected to have Clade 2 (Brewer et al. 2012) but millipedes collected there were determined to be from Clade 4.

${ }^{\dagger}$ Ecoregions are defined in Supplemental Table 1.

At each site, decaying logs on the forest floor were overturned until colonies of $B$. lecontii were located. Colonies are defined as groupings of two or more individuals, and were typically found on or near resupinate fungi covering the underside of the logs. When a suitable colony was found, individuals from single colonies were placed together inside $25 \mathrm{ml}$ sterile collection vials, often with a piece of the fungus-colonized wood they were observed feeding on, and stored in a cooler until processing. In addition, cross-sections of wood from which colonies were collected were taken to permit their identification once back in the lab.

$\underline{\text { In-lab millipede processing \& isolate collection }}$

All millipedes were maintained at $4^{\circ} \mathrm{C}$ until processed, which typically occurred within three days. After surface sterilization in $70 \%$ ethanol, individuals were sexed, sectioned with a sterilized scalpel, and tail portions preserved in $70 \%$ ethanol for millipede genotyping in the Marek Lab using custom markers previously described by Brewer and colleagues (2012). Gonopods were also preserved from males to permit anatomical study in the Marek Lab. The remainder of the millipede was macerated in $500 \mu \mathrm{l}$ of sterile distilled water, and $50 \mu \mathrm{l}$ was spread on glucose yeast extract agar (GYEA) amended with streptomycin sulfate and tetracycline hydrochloride antibiotics to isolate fungi (Appendix A). Cultures were parafilmed and allowed to grow at room 
temperature until growth was observed. Each colony-forming unit (CFU) was categorized by morphotype, counted, and recorded. One representative of each morphotype from each plate was retained and assigned an isolate number. Culture plates were retained for up to three weeks to ensure that slow-growing fungi were counted and sampled. Depending on how rapidly fungi grew in pure culture, isolates were either grown on potato dextrose broth (Appendix A) prior to DNA extraction, or mycelium was scraped directly from plates. DNA was extracted from all isolates using a modified Wizard kit (Promega, Madison, WI, USA) (Appendix B). For long-term storage, isolates were kept on potato dextrose agar slants (PDA, Appendix $\mathrm{A}$ ) at $4^{\circ} \mathrm{C}$.

Wood samples were dried at room temperature for up to several weeks depending on the size of the sampled section and sanded for visual identification using an orbital sander equipped with 220-grit paper. Identifications were made by examining anatomical features in cross section with the aid of a dissecting microscope, based on descriptions by Panshin and de Zeeuw (1980).

$\underline{\text { Isolate identification }}$

All isolates were identified using the universal fungal barcoding gene, the ribosomal internal transcribed spacer region (ITS), which includes ITS1, 5.8S, and ITS2 (Schoch et al. 2012). All primers used in this study were obtained from Integrated DNA Technologies (IDT, Coralville, IA, USA). PCR was conducted in $25.5 \mu \mathrm{L}$ reactions with the following reagents: $12.5 \mu \mathrm{L}$ Bioline PCR Master Mix (Bioline USA Inc, Taunton, MA), $10 \mu \mathrm{L}$ sterile distilled water, $1 \mu \mathrm{L}$ reverse primer (ITS4, 5'TCCTCCGCTTATTGATATGC-3'), $1 \mu \mathrm{L}$ forward primer (ITS5, 5'- 
GGAAGTAAAAGTCGTAACAAGG-3'), and $1 \mu \mathrm{L}$ fungal DNA (White et al. 1990). Reactions were performed on an MJ Research PTC-200 Peltier Thermal Cycler (GMI, Ramsey, MN). PCR conditions were as follows: initial denaturation at $95^{\circ} \mathrm{C}$ for 2 minutes, 35 cycles of denaturation at $95^{\circ} \mathrm{C}$ for 30 seconds, annealing at $56^{\circ} \mathrm{C}$ for 30 seconds, and elongation at $72^{\circ} \mathrm{C}$ for 1 minute, and final elongation at $72^{\circ} \mathrm{C}$ for 7 minutes.

Products were visualized via gel electrophoresis on a $1.5 \% \mathrm{w} / \mathrm{v}$ agarose (Amresco, Solon, OH, USA) gel with 0.5\% Tris-Borate-EDTA buffer (Amresco, Solon, $\mathrm{OH}$, USA). SYBR Gold (Invitrogen, Grand Island, NY, USA) was used as the nucleic acid stain, and bands were visualized on a UV transilluminator (Syngene, Frederick, MD, USA). PCR products were purified using ExoSap-IT (Affymetrix, Santa Clara, CA). Products were Sanger sequenced with the same primers used for PCR (Eurofins, Huntsville, AL, USA). Resulting sequences were searched in the NCBI GenBank BLASTn database, and identifications recorded for each isolate.

\section{New species identification}

Isolates were considered to be a putative new species (PNS) if three or more identical sequences were recovered with identical low percentage ( $95 \%$ or less) BLASTn matches. When a PNS was identified, the large subunit of the ribosomal ITS region (LSU) was also sequenced using primers LROR (5'-ACCCGCTGAACTTAGC-3') and LR5 (5'-TCCTGAGGGAAACTTCG-3') (Vilgalys and Hester 1990). PCR conditions were as follows: initial denaturation at $95^{\circ} \mathrm{C}$ for 2 minutes, 35 cycles of denaturation at $95^{\circ} \mathrm{C}$ for 30 seconds, annealing at $51.1^{\circ} \mathrm{C}$ for 45 seconds, and elongation at $72^{\circ} \mathrm{C}$ for 90 
seconds, and final elongation at $72^{\circ} \mathrm{C}$ for 5 minutes. PCR products were visualized, purified, and sequenced as above. The LSU gene was also sequenced for known relatives of the PNS (as identified by BLAST matches of the ITS sequence).

Putative new species were resolved phylogenetically by constructing an ITS+LSU concatenated maximum likelihood (ML) tree for the new species and its known relatives based on a combination of BLAST matches and previously published literature. MEGA7 (Kumar et al. 2016) was used to align (CLUSTAL-W, Larkin et al. 2007), select a model for estimating evolutionary distance, and construct an ML tree for each PNS. Reference sequences used for each phylogeny are listed in Supplemental Tables 2, 3, and 4.

Community and Diversity Analyses

Community and diversity analyses were used to answer two key questions: 1) Are $B$. lecontii fungal communities stable across millipede clade and/or wood host?; and 2) What fungal genera are core/central in the Brachycybe fungal food web, regardless of clade and/or wood host?

Diversity indices were used to provide information about rarity and commonness of genera associated with the fungal community of $B$. lecontii by site. Three indices were used: alpha diversity, Shannon's diversity index, and Shannon's equitability (evenness) index.

The effects of $B$. lecontii clade and wood host on the community structure were analyzed by PerMANOVA using the vegan package in $R$ (Oksanen et al. 2017). Tukey's HSD (honest significant difference) test was used as a post-hoc test to permit pairwise 
comparisons of significant dependent variables (i.e., clade and wood host).

A co-occurrence network was constructed for fungal isolates obtained from $B$. lecontii based on fungal genus presence/absence data. Betweenness-centrality was used to measure relative contribution of each node (single fungal genus) to connectivity across the whole network. High betweenness-centrality values are typically associated with nodes located in the core of the network, which in this system are defined as fungal genera with multiple edges connecting Brachycybe clades and multiple wood hosts.

Low betweenness-centrality values indicate fungal genera with a more peripheral location in the network, with fewer edges connecting clades and substrates (Greenblum et al. 2011).

To further investigate patterns in the network, network modularity was characterized. A module is a group of nodes (i.e. fungal genera) that are highly connected within the module with few connections outside the module (Shi et al. 2016). Modularity ranges from -1 to 1 . Positive values indicate the number of edges inside the group is greater than that expected by chance. In this study, modules were detected using the Louvain algorithm, which aims to determine the optimal number of partitions that maximize the modularity index (Blondel et al. 2008).

\section{RESULTS}

In total, 313 individuals were collected from 3 of 4 B. lecontii clades, distributed among 60 colonies at 20 sites in 7 states. Some sites were not used in the analysis due to containing only singletons (VA1, WV3) or being collected under non-standard sampling methods (VA4). Colonies were obtained from 10 genera of wood hosts. From 
these 313 individual millipedes, 5,154 CFUs were counted, and 1,310 isolates retained. Of these, 1,002 isolates were resolved to Kingdom Fungi, and 965 to at least genus. The remaining 308 isolates did not yield usable DNA templates, possibly due to slow growth, contamination, or both, and were excluded from this study. The isolates that were included represent a large amount of diversity, including at least 183 genera in 40 fungal orders from 4 phyla.

\section{Millipede Behavior}

In general, $B$. lecontii were found in forested areas under downed woody material of various sizes. Some individuals were found in leaf litter near logs, and these individuals were primarily adult males. Most colonies included 15 or fewer individuals, but numerous logs yielded several colonies. Colonies were multi-generational, containing a mix of hatchlings, juveniles, adults, and older adults that were several years old based on their number of segments. In a few cases, single-sex colonies were found, but most colonies contained a mixture of sexes. Our study recovered 102 males and 146 females.

Most millipedes were engaged in feeding behavior, with their heads buried in fungus growing on the log. Some millipedes were feeding alone, but most were in a partial or complete pinwheel formation (Figure 1A-B) Multigenerational colonies frequently had adults and hatchlings or juveniles sharing a single feeding site (Figure 1A).

Males were observed caring for eggs in close proximity to the main colony, particularly if collecting was done in early summer (May-June) (Figure 1C). Males with 
eggs were not immobile, however, and would transport the eggs to a safe location if the log was overturned (Figure 1D).

Three sites, WV4, SC1, and AR2, had millipedes that displayed atypical behaviors. In WV4, the site as a whole was very moist, and a group of millipedes was observed climbing a standing Carpinus caroliniana snag (Figure 2A). The tree was covered in moss and had evidence of fungal colonization. The snag was positioned on a steep west-facing slope. Millipedes were observed as high as fifteen feet off the ground. In SC1, a large fallen Liriodendron log was observed with several hundred millipedes gathered on the top of the log (Figure 2B). Conditions at this site were also wet, but the log was not flooded. Aside from the exposed location, these millipedes were forming typical pinwheel aggregations and feeding on fungal mycelium. In AR2, 10 millipedes were found at an extremely arid site, next to a power line clearing without cover or wood debris (Figure 2C). These millipedes were a foot off the ground, in a healthy UImus alatus tree. There were no signs of moisture or fungus on the tree.

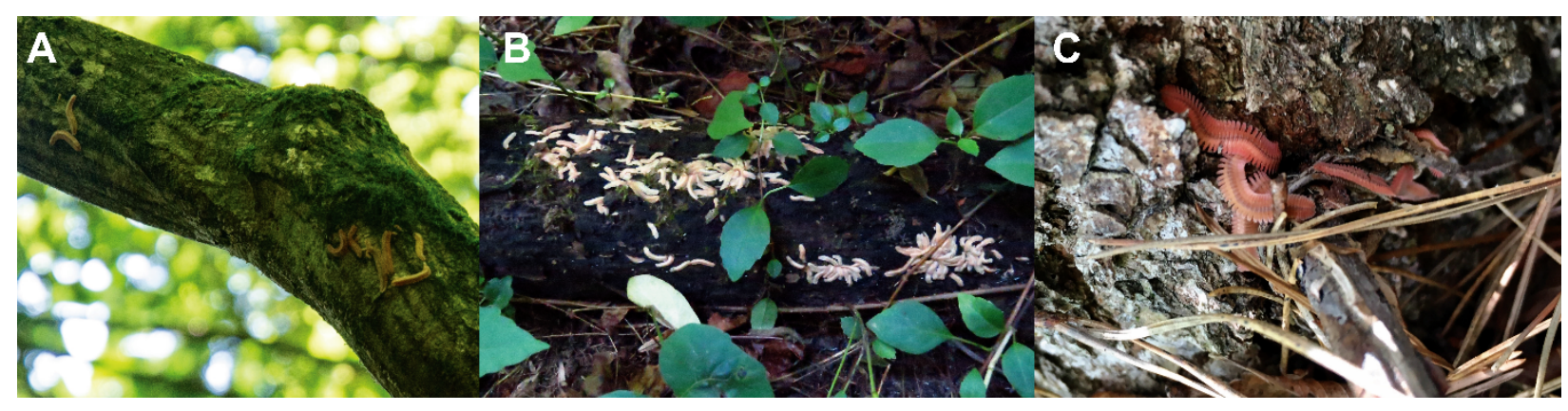

FIGURE 2: B. lecontii displaying atypical behaviors. A: Colony from site WV4, climbing a rotting snag. B: Exposed colony from site SC1, sitting on top of log. C: Colony from site AR2, climbing a living tree in an arid site. 


\section{Morphotype CFU counts}

All colony-forming units on millipede macerate plates were quantified and sorted into one of six broad morphological classes: (non-Hypocreales) white filamentous fungi, entomopathogenic Hypocreales, dematiaceous yeasts, zygomycetes, miscellaneous yeasts, and "Other." The "Other" class included more than a dozen recognizable morphotypes, including Penicillium sp., Acremonium sp., and Pestalotiopsis sp. Many of these genera were quantified separately to ensure that they were not overlooked beneficial fungi, but were later combined.

White filamentous fungi were characterized by white hyphae spread thinly in a loose colony with no other outwardly identifiable characteristics. Entomopathogenic Hypocreales formed a tight, dense colony of white to yellow hyphae, sometimes stained the media red or yellow, or in other cases, formed thin mats that produced crusts of dry conidia. Dematiaceous yeasts had slow-growing, heavily melanized colonies that frequently formed a raised mound in the center of the colony. Zygomycetes were identified by their characteristic sporangia, or by a Mortierella-like morphology (roseate growth appressed to the media, garlic odor, rare sporangia). All colonies that appeared creamy and non-hyphal were grouped into the miscellaneous yeast category. All other morphotypes were placed in the "Other" category. Similar to the 'Other' category, morphologically unique yeasts were tallied separately to ensure that these fungi were not inadvertently overlooked, and later combined.

Of the defined morphotypes, miscellaneous yeasts and entomopathogenic Hypocreales dominated across all Brachycybe lecontii colonies (18.8\% and $17.4 \%$ of all 
CFUs, respectively). Zygomycetes accounted for $7.6 \%$ of all CFUs, followed by white filamentous fungi $(7.4 \%)$ and dematiaceous yeasts $(6.7 \%)$. The "Other" category accounted for $41.9 \%$ of all CFUs.

At the colony level (Figure 3), entomopathogenic Hypocreales were present in $75 \%$ of colonies (mean: $17.2 \mathrm{CFUs,}$ median: 5 ). Likewise, dematiaceous yeasts were present in $75 \%$ of colonies (mean: 6.7 CFUs, median: 3 ). Miscellaneous yeasts were present in $66.7 \%$ of colonies (mean: 21 CFUs, median: 6.5 ), followed by $61.7 \%$ for zygomycetes (mean: 9.1 CFUs, median: 7 ), and $48.3 \%$ for white filamentous fungi (mean: 11.4 CFUs, median: 5). The "Other" morphotype was present in all colonies (mean: 31.6 CFUs, median: 13).

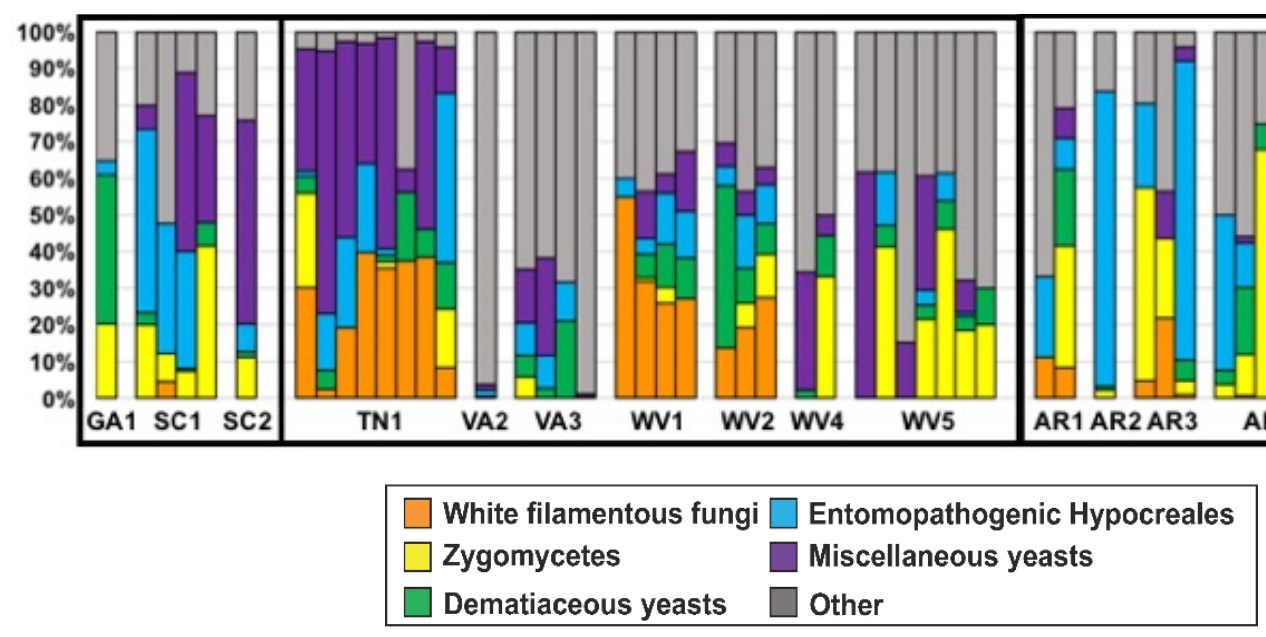

FIGURE 3: Stacked bar chart showing the percentage of CFUs from each colony (=individual bar) from each fungal morphotype. Each cluster of bars represents a site, and larger boxes indicate which millipede clade the sites are from (Clade 1, 3, 4).

At the site level (Figure 4), dematiaceous yeasts and the "Other" morphotype were recovered from all sites, zygomycetes from $94.1 \%$ of sites, entomopathogenic Hypocreales from $94.1 \%$ of sites, miscellaneous yeasts from $88.2 \%$ of sites, and white 
filamentous fungi from $58.8 \%$ of sites.

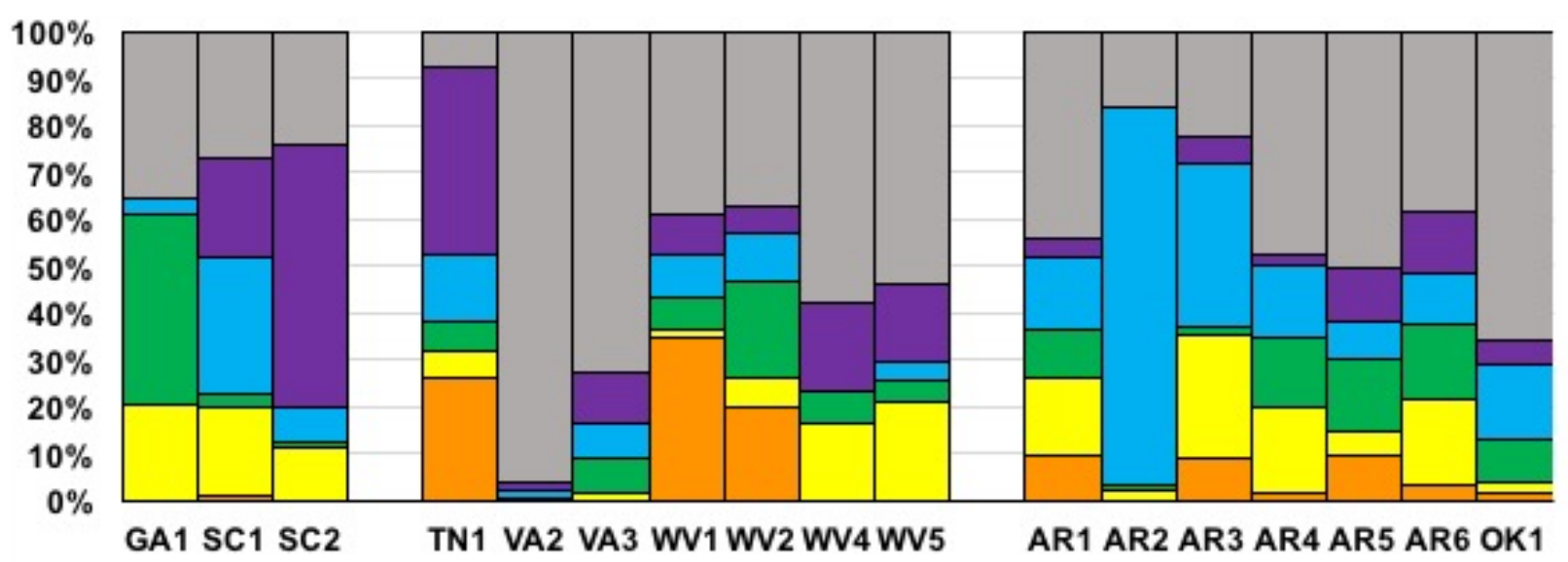

White filamentous fungi $\square$ Entomopathogenic Hypocreales
Zygomycetes
Dematiaceous yeasts $\quad \square$ Miscellaneous yeasts

FIGURE 4: Stacked bar chart showing what percentage of CFUs from each site were from each fungal morphotype. Each cluster of bars indicates millipede clade 1, 3 and 4 .

Next, the data were partitioned by millipede clade, millipede sex, and wood host, at the colony level. Three millipede clades were sampled. Clade 1 contained 53 individuals from 6 colonies in 3 sites, Clade 3 contained 156 individuals from 29 colonies in 7 sites, and Clade 4 contained 104 individuals from 24 colonies in 7 sites. Incidence of fungal morphotypes varied by clade (Table 2): Entomopathogenic Hypocreales represented almost a third of all CFUs from Clade 4 yet were less than one-tenth of the total CFUs from Clade 3. Likewise, white filamentous fungi varied considerably across clades, representing $12.5 \%$ of total CFUs from Clade 3 , but below $3 \%$ for the other two clades. Miscellaneous yeasts represented one-third to one-fifth of total CFUs from Clade 1 and Clade 3, but less than one-tenth for Clade 4. The remaining fungal morphotypes have, in general, equal representation across clades. 
TABLE 2: Table indicating what percentage of CFUs from each millipede clade were from each fungal morphotype.

\begin{tabular}{|c|c|c|c|}
\hline Morphotype & Clade 1 & Clade 3 & Clade 4 \\
\hline Wh. fila. Fungi & $0.5 \%$ & $12.5 \%$ & $2.0 \%$ \\
\hline Entomo. Hypo. & $17.7 \%$ & $9.0 \%$ & $31.6 \%$ \\
\hline Demat. Yeasts & $4.9 \%$ & $5.5 \%$ & $9.7 \%$ \\
\hline Zygomycetes & $13.4 \%$ & $4.9 \%$ & $9.5 \%$ \\
\hline Misc. Yeasts & $39.1 \%$ & $20.8 \%$ & $6.5 \%$ \\
\hline Other & $24.4 \%$ & $47.3 \%$ & $40.8 \%$ \\
\hline
\end{tabular}

Millipedes were separated into four life stages: male (gonopods visible), female (adult size, no gonopods), juvenile (not adult size, no gonopods visible), and hatchlings (white colored, extremely small). For analyses by millipede sex, juveniles and hatchlings were excluded because they could belong to either sex. The only dramatic difference between males and females was in the abundance of white filamentous fungi, where $13.1 \%$ of CFUs from males were white filamentous fungi, compared to $5.8 \%$ of females (Table 3).

TABLE 3: Table indicating what percentage of CFUs from each millipede sex were from each fungal morphotype

\begin{tabular}{|c|c|c|}
\hline Morphotype & Male & Female \\
\hline Wh. fila. fungi & $13.1 \%$ & $5.8 \%$ \\
\hline Entomo. Hypo. & $21.7 \%$ & $20.0 \%$ \\
\hline Demat. Yeasts & $11.4 \%$ & $6.4 \%$ \\
\hline Zygomycetes & $6.5 \%$ & $9.1 \%$ \\
\hline Misc. Yeasts & $15.1 \%$ & $20.2 \%$ \\
\hline Other & $32.1 \%$ & $38.5 \%$ \\
\hline
\end{tabular}

Millipedes were collected from 10 different genera of wood hosts. The most common wood hosts were Liriodendron (23 colonies) and Quercus (17), followed by Acer (4), Carya (4), Fagus (3), Pinus (3), Betula (2), Ulmus (2), Fraxinus (1), and Carpinus (1). 
There was only one notable difference between the two most common wood hosts. In Liriodendron, $21.8 \%$ of CFUs were from miscellaneous yeasts, compared to $6.0 \%$ in Quercus. The remaining morphotypes did not vary strongly between the two hosts (Figure 5).

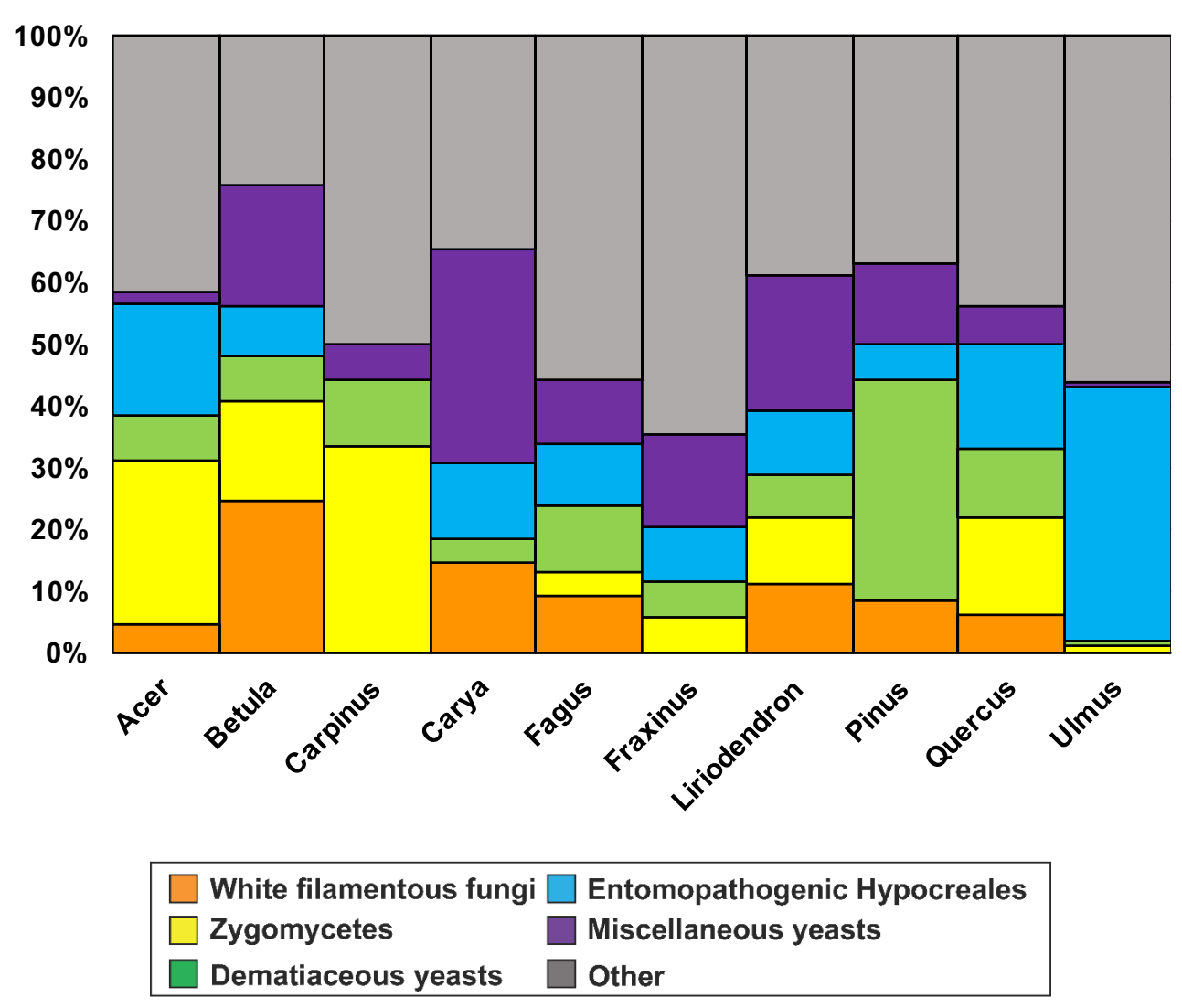

FIGURE 5: Stacked bar chart showing percentages of CFUs from each wood host represented by each fungal morphotype.

The number of colonies sampled across all the uncommon hosts (20) was similar to the number of colonies sampled from each of the common hosts ( 23 for Liriodendron, 17 for Quercus), so the percentages of each morphotype across the three classes Liriodendron, Quercus, and 'Other hosts' were compared. There were no notable differences between the three classes for any morphotype (Table 4). Individually, the 
uncommon hosts had widely varying percentages for all the morphotypes, as shown in Figure 5.

TABLE 4: Table indicating what percentage of CFUs from Liriodendron, Quercus, or other substrates (combined) were from each fungal morphotype.

\begin{tabular}{|c|c|c|c|}
\hline Morphotype & Liriodendron & Quercus & Other (combined) \\
\hline Wh. fila. fungi & $11.1 \%$ & $6.2 \%$ & $7.8 \%$ \\
\hline Entomo. Hypo. & $10.6 \%$ & $16.8 \%$ & $13.0 \%$ \\
\hline Demat. Yeasts & $6.9 \%$ & $11.1 \%$ & $10.3 \%$ \\
\hline Zygomycetes & $10.7 \%$ & $16.0 \%$ & $10.9 \%$ \\
\hline Misc. Yeasts & $21.8 \%$ & $6.0 \%$ & $12.6 \%$ \\
\hline Other & $38.6 \%$ & $44.0 \%$ & $45.4 \%$ \\
\hline
\end{tabular}

\section{$\underline{\text { Sequenced Isolates }}$}

Across all millipedes, 1,310 fungal isolates were collected and retained. Of these, 1,002 isolates were sequenced and resolved to Kingdom Fungi, and 965 to at least genus. These isolates represent a large amount of diversity, including at least 183 genera in 40 fungal orders from 4 phyla.

After sequencing, it became clear that the defined morphotypes (see previous section) were not always taxonomically restricted and often contained members from more than one order of fungi. "White filamentous fungi" often included members of the Polyporales, Xylariales, Pleosporales, and occasionally a (non-entomopathogenic) member of the Hypocreales. "Entomopathogenic Hypocreales" only contained fungi from the well-documented entomopathogenic families of the Hypocreales, Cordycipitaceae, Clavicipitaceae, and Ophiocordycipitaceae. "Dematiaceous yeasts" contained members from the Chaetothyriales, Chaetosphaeriales, Capnodiales, Mycosphaerellales, and Coniochaetales. Zygomycetes contained members of the 
Mortierellales, Mucorales, and Umbelopsidales. "Misc. yeasts" contained Tremellales, Saccharomycetales, and Dothideales. The remaining 24 orders generally fell into the "Other" morphotype, with individual isolates occasionally falling into the other defined morphotypes. Since the morphotypes were taxonomically heterogeneous, analyses were conducted at the order or genus level.

The most common order was the Hypocreales, containing $25.9 \%$ of all isolates resolved to at least order. Of that $25.9 \%, 42.6 \%$ of isolates were from the three entomopathogenic families listed previously. The five next most common orders were the Polyporales (8.6\%), Chaetothyriales (8.2\%), Xylariales (6.2\%), Capnodiales (5.8\%), and Eurotiales (5.6\%). All other orders contained fewer than 50 isolates $(<5 \%)$.

The most common genus was Trichoderma (45 isolates), followed by Verticillium (44), Umbelopsis (35), Penicillium (34), and Mortierella (32). There were 74 genera with only a single isolate, and only 24 genera had 10 or more isolates.

\section{Community and diversity analyses}

Alpha diversity was assessed by millipede clade, wood host, and site. Clade 1 included 32 genera, Clade 3 included 148, and Clade 4 included 69. The number of fungal genera obtained from each wood host were as follows: Liriodendron (114 genera), Quercus (74), Betula (54), Carya (45), Fagus (33), Ulmus (19), Acer (18), Pinus (11), Carpinus (10), and Fraxinus (10).

At the site level, alpha diversity varied from 3 genera at SC2 to 63 genera at WV1 with a mean of 23 per site (Table 5). In addition to alpha diversity, Shannon's diversity index and Shannon's equitability were also calculated for each site. Shannon's 
diversity index ranged from 0.95 in SC2 to 3.79 in WV2. Shannon's equitability ranged from 0.977 in AR1 and VA2 to 0.848 in TN1 (Table 5). Sites with the five highest Shannon's diversity index values did not overlap with sites with the five highest site equitability values. Conversely, sites with the lowest diversity index values did overlap in at least two of five sites (Table 5).

TABLE 5: Collection information and diversity indices for each site.

\begin{tabular}{|c|c|c|c|c|}
\hline Site & $\begin{array}{c}\text { No. of Millipedes } \\
\text { sampled }\end{array}$ & $\begin{array}{c}\text { Alpha } \\
\text { diversity }\end{array}$ & $\begin{array}{c}\text { Shannon's } \\
\text { diversity index (H) }\end{array}$ & $\begin{array}{c}\text { Shannon's } \\
\text { equitability (EH) }\end{array}$ \\
\hline AR1 & 6 & 11 & 2.342 & 0.977 \\
\hline AR2 & 6 & 14 & 2.497 & 0.946 \\
\hline AR3 & 13 & 17 & 2.590 & 0.914 \\
\hline AR4 & 22 & 26 & 3.064 & 0.941 \\
\hline AR5 & 14 & 19 & 2.801 & 0.951 \\
\hline AR6 & 12 & 18 & 2.583 & 0.894 \\
\hline GA1 & 9 & 13 & 2.378 & 0.927 \\
\hline OK1 & 14 & 18 & 2.737 & 0.947 \\
\hline SC1 & 22 & 14 & 2.262 & 0.857 \\
\hline SC2 & 4 & 3 & 0.950 & 0.865 \\
\hline TN1 & 42 & 42 & 3.170 & 0.848 \\
\hline VA1 & 4 & 34 & 3.301 & 0.936 \\
\hline VA2 & 8 & 11 & 2.342 & 0.977 \\
\hline VA3 & 15 & 24 & 3.043 & 0.957 \\
\hline VA4 & 5 & 7 & 1.787 & 0.918 \\
\hline WV1 & 29 & 63 & 3.784 & 0.913 \\
\hline WV2 & 24 & 57 & 3.790 & 0.938 \\
\hline WV3 & 4 & 16 & 2.599 & 0.937 \\
\hline WV4 & 12 & 24 & 3.033 & 0.954 \\
\hline WV5 & 36 & 34 & 3.045 & 0.864 \\
\hline
\end{tabular}

Next, PerMANOVAs were used to check for significant differences among fungal communities by clade and wood host. For clade, pairwise comparisons indicated significant differences in communities between Clade 1 and Clade $3(p<0.001)$ and 
Clade 3 and $4(p<0.05)$, but not between Clade 1 and Clade $4(p>0.05)$. For wood host, pairwise comparisons indicated significant $(p<0.05)$ differences among 18 host combinations (Supplemental Table 5). Twenty additional pairwise comparisons were not significant (Supplemental Table 5). Two hosts, Ulmus sp., and U. alatus, accounted for 15 of 18 significant differences, and both hosts were significantly different $(p<.001)$ from Acer, Betula, Carya, Fagus, Liriodendron, Pinus, and Quercus. The remaining three significant $(p<0.05)$ interactions included pairings of Acer, Betula, Fagus, Liriodendron, and Quercus.

The network inferred from co-occurrence data revealed a complex topology with several co-dominant foci (Figure 6). As a whole, community structure was heterogeneous across millipede clades and wood hosts. However, some genera were consistently present in most clades and wood hosts as indicated by betweennesscentrality results. Twelve fungal genera showed high connectivity across the whole network (betweenness-centrality values $>0.5$ ) (Figure 7). These included Phialophora (1.55), Ramichloridium (1.44), Mortierella (1.28), Trichoderma (1.03), Mucor (1.02), Verticillium (0.90), Phanerochaete (0.89), Fonsecaea (0.84), Penicillium (0.75), Umbelopsis (0.73), Cosmospora (0.68), and Xylaria (0.63). All other fungal genera fell below the 0.5 threshold including 144 genera with a betweenness-centrality values of 0.0 (Figure 7). 


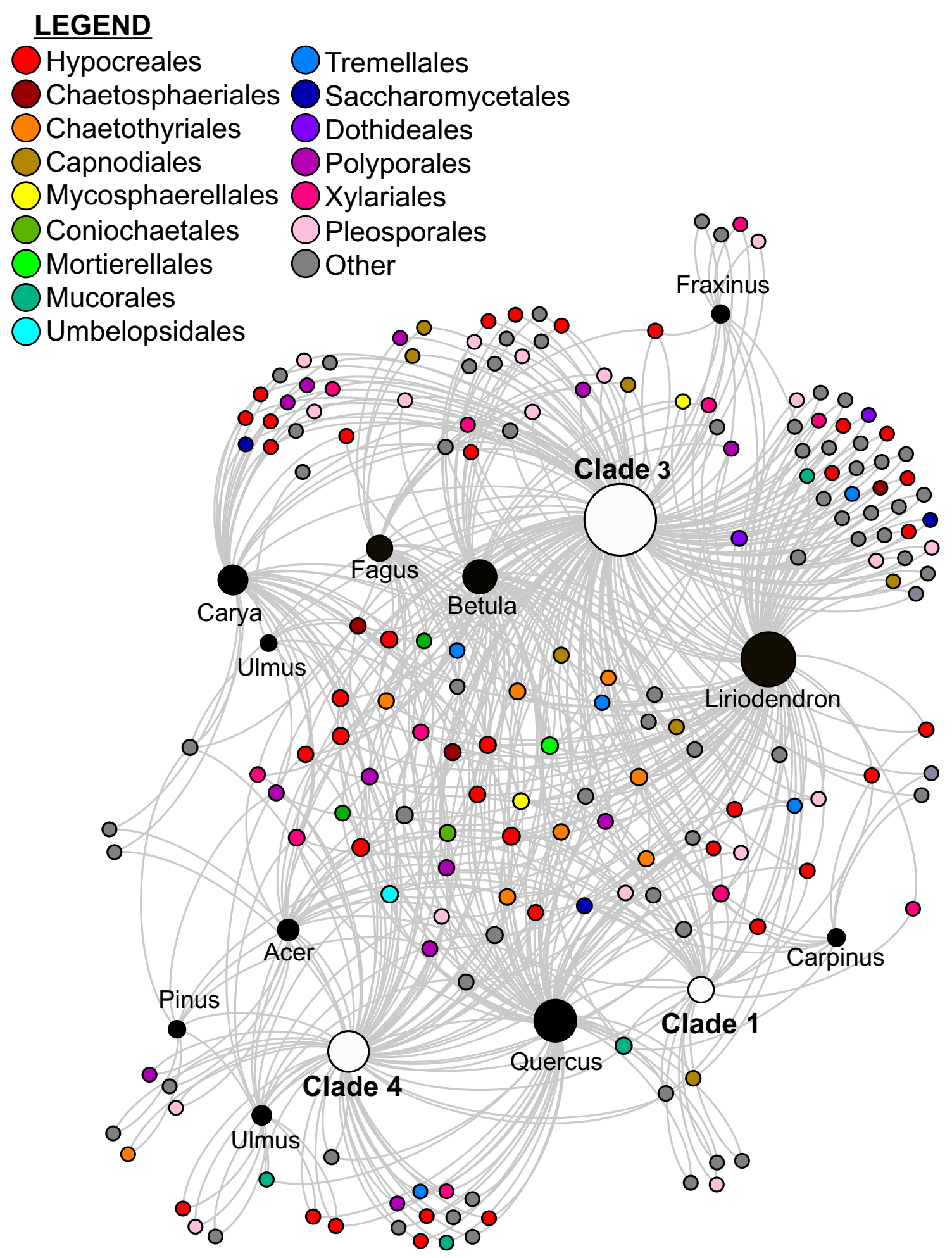

FIGURE 6: Fungal community connectivity network across $B$. lecontii clades and wood hosts. Unlabeled nodes represent unique fungal genera, color-coded by fungal order. White and black nodes represent clades and wood hosts. For these, the size of the circle represents the relative sample size for that group. 


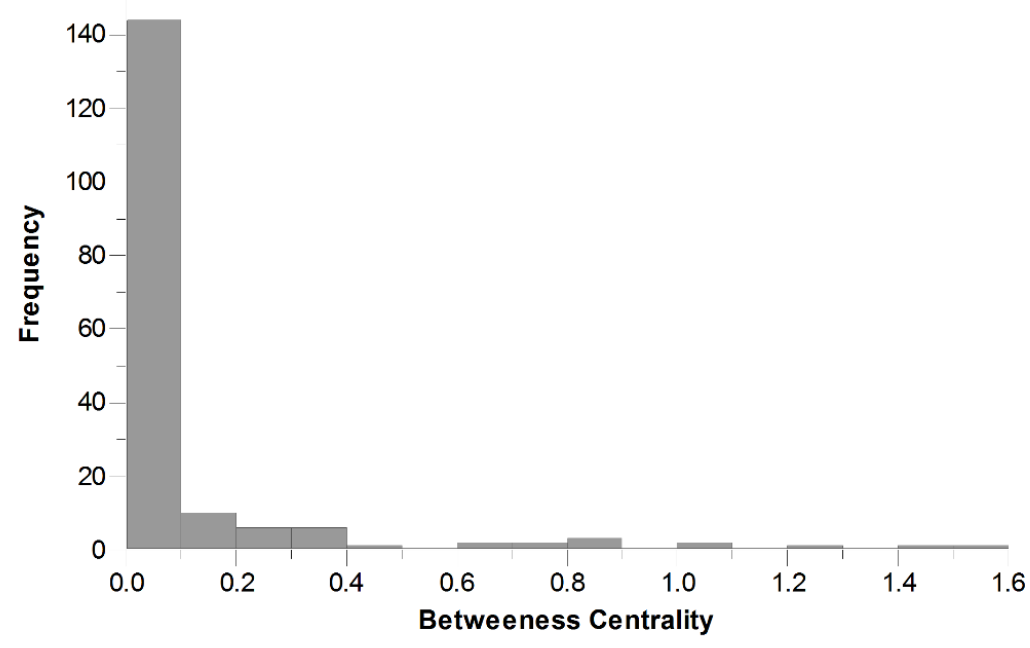

FIGURE 7: Histogram showing distribution of betweenness-centrality values for 183 fungal genera.

Modularity was assessed for the entire network and yielded a score of 0.239 . Six distinct modules were detected.

\section{Putative new species}

At least seven putative new species were identified based on previously established criteria, but only three were investigated. The four not examined are "aff. Coniochaeta" (Coniochaetales), "aff. Leptodontidium" (Helotiales), "Pseudonectria aff. buxi" (Hypocreales), and "aff. Oidiodendron" (Onygenales).

"Aff. Fonsecaea" is represented by 11 isolates from six collection sites (AR3, AR4, OK1, SC2, VA4, and WV1). These isolates are 95\% identical to strain "Fonsecaea sp. CBS 102252". The phylogenetic tree shown in Figure 8 was generated in MEGA7 (Kumar et al. 2016) and inferred by using the maximum likelihood method based on the Kimura 2-parameter model (Kimura 1980). The alignment contained 1,391 positions, but only 591 were retained in the final dataset. Fewer than $5 \%$ alignment gaps, missing 
data, and ambiguous bases were allowed at any position. Although there are 11 isolates of this PNS, only 9 were used in this phylogeny.

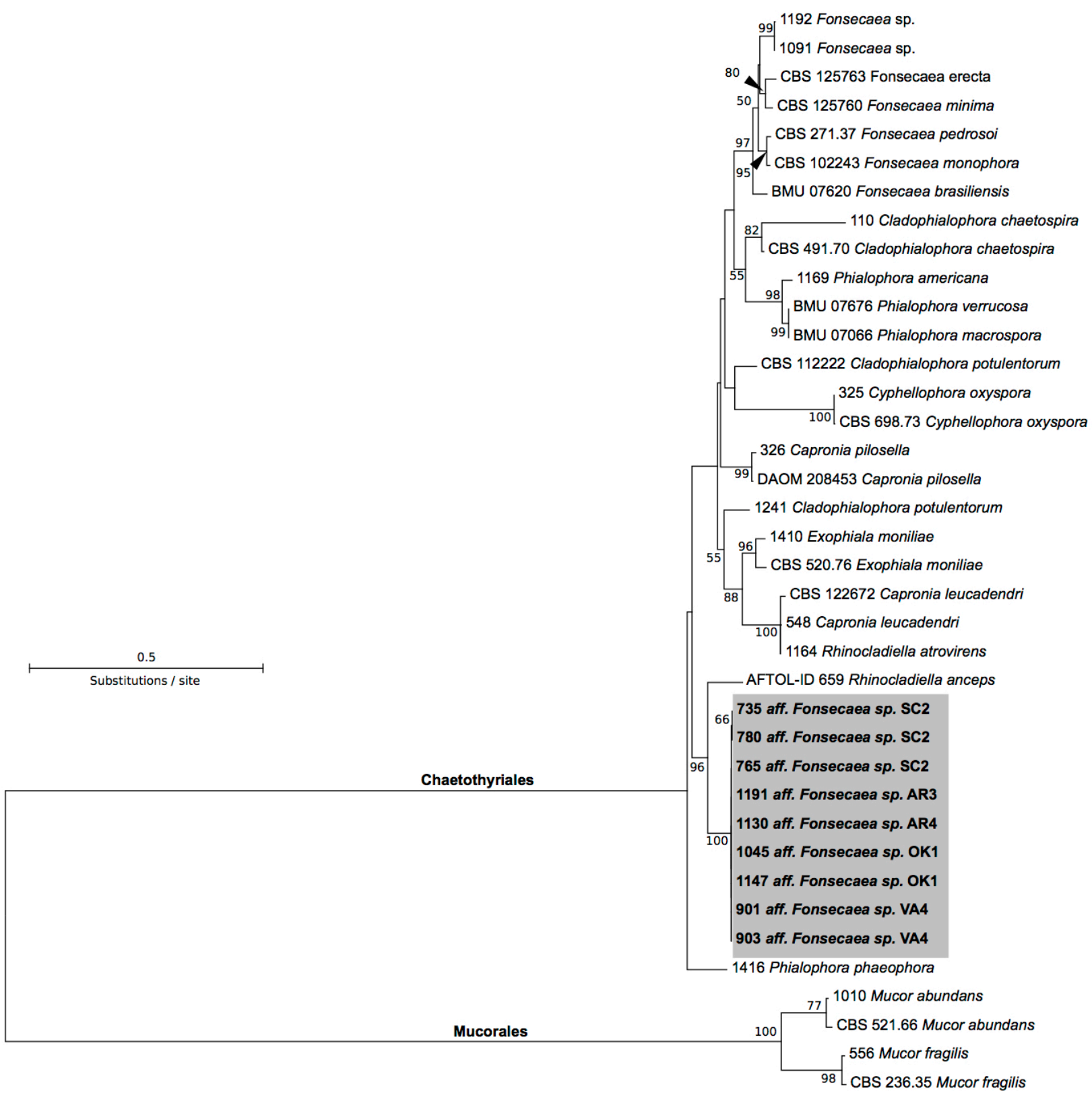

FIGURE 8: Concatenated ITS+LSU maximum likelihood phylogenetic tree for "aff. Fonsecaea," a putative new species. Bootstrap support is indicated near each node, and only values greater than $50 \%$ are shown. The grey box indicates the isolates belonging to aff. Fonsecaea sp.

"Mortierella aff. ambigua" is represented by 27 isolates from seven collection 
sites (AR1, AR3, AR4, VA3, WV2, WV4, and WV5). These isolates are 92\% identical to strain "Mortierella ambigua CBS 450.88". All isolates of "Mortierella aff. ambigua" produced large, granular, firm, lipid-rich structures as the cultures aged past $\sim 10$ days. These structures grew up to at most half a centimeter across, and were present on the surface and embedded in the media. When crushed, these structures appeared to be filled with large thin-walled cells, each filled with lipids and vacuoles (Figure 9). The function of these structures is unknown, and their presence has not been previously reported in the literature.
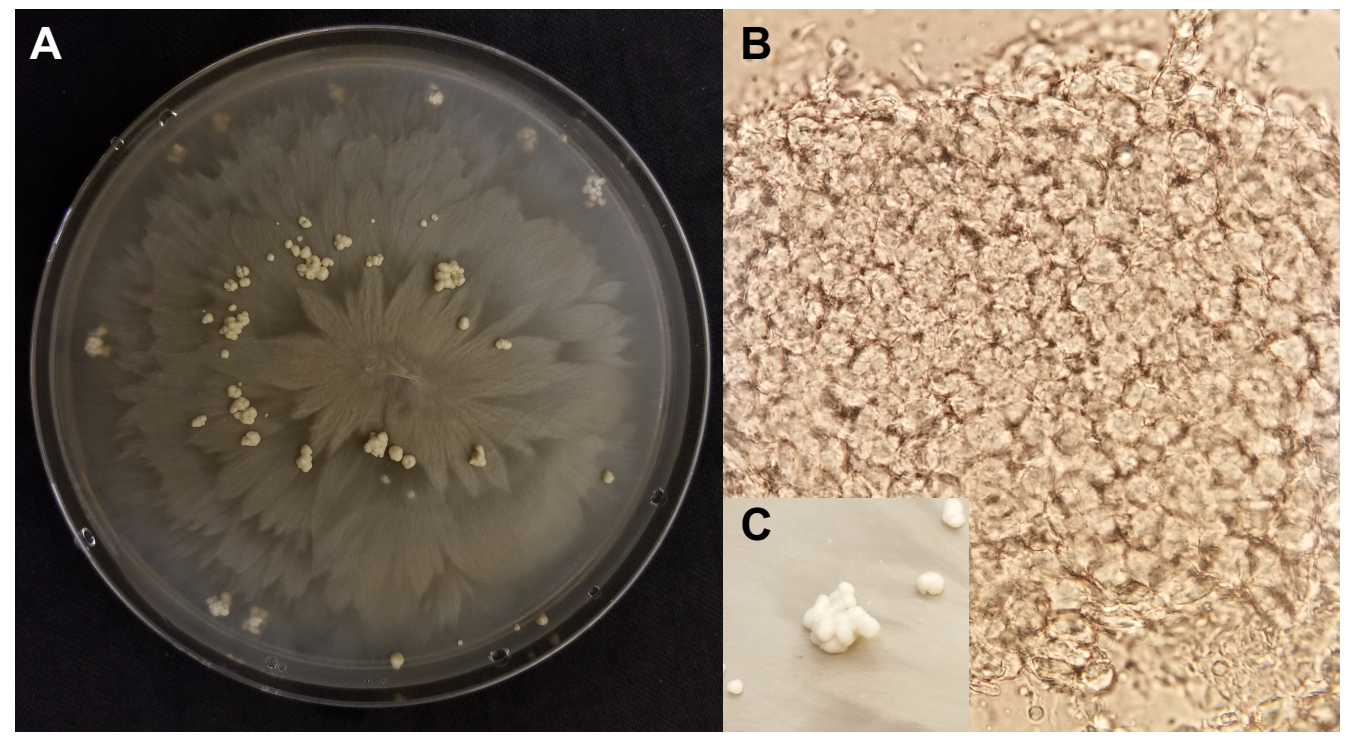

FIGURE 9: Colony morphology of PNS "Mortierella aff. ambigua", isolate 1150 after six weeks of growth on GYEA. A: Overall colony morphology, with surface and submerged structures. B: Magnification 40x, squash mount. C: Magnification 5x.

The phylogenetic tree shown in Figure 10 was generated in MEGA7 (Kumar et al. 2016) and inferred by using the maximum likelihood method based on the general time-reversible model (Nei and Kumar 2000). The alignment contained 1,234 positions, but only 918 were retained in the final dataset. Fewer than 5\% alignment gaps, missing 
data, and ambiguous bases were allowed at any position. Although there are 27 isolates

of this PNS, only 16 were used in this phylogeny.

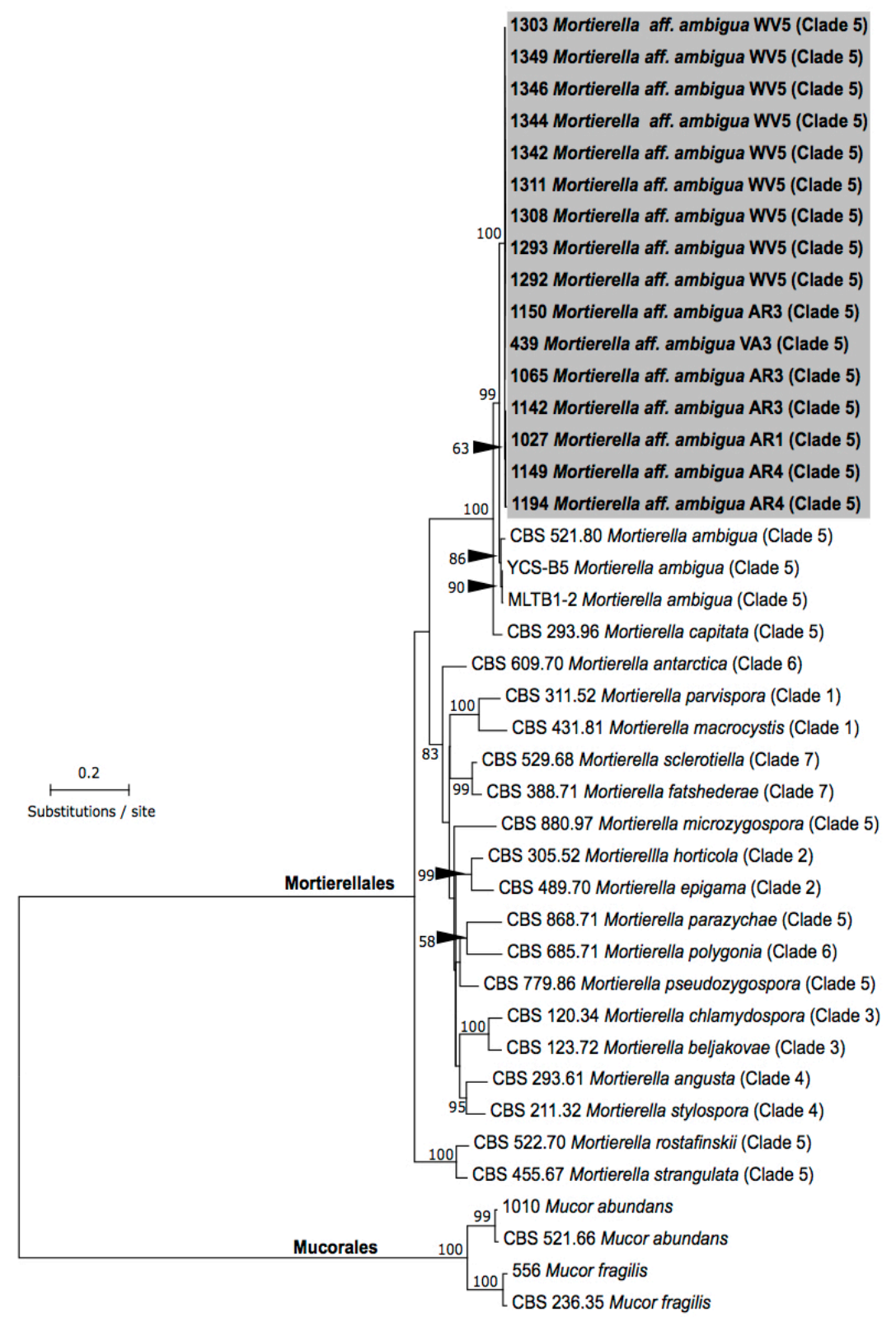

FIGURE 10: Concatenated ITS+LSU maximum likelihood phylogenetic tree for "Mortierella aff. ambigua," a putative new species. Bootstrap support is indicated near each node, and only values greater than $50 \%$ are shown. The grey box indicates the isolates belonging to Mortierella aff. ambigua.

Last, "aff. Apophysomyces sp." is represented by five isolates from one site 
(OK1). These isolates are $84 \%$ identical to strain "Apophysomyces ossiformis strain

UTHSC 04-838". Sporangial morphology of these isolates aligns with described features for this genus (Alvarez et al. 2010). The phylogenetic tree shown in Figure 11 was generated in MEGA7 (Kumar et al. 2016) and inferred by using the maximum likelihood method based on the Tamura 3-parameter model (Tamura 1992). The alignment contained 1,389 positions, but only 814 were retained in the final dataset. Fewer than $5 \%$ alignment gaps, missing data, and ambiguous bases were allowed at any position. Although there are 5 isolates of this PNS, only 3 were used in this phylogeny.

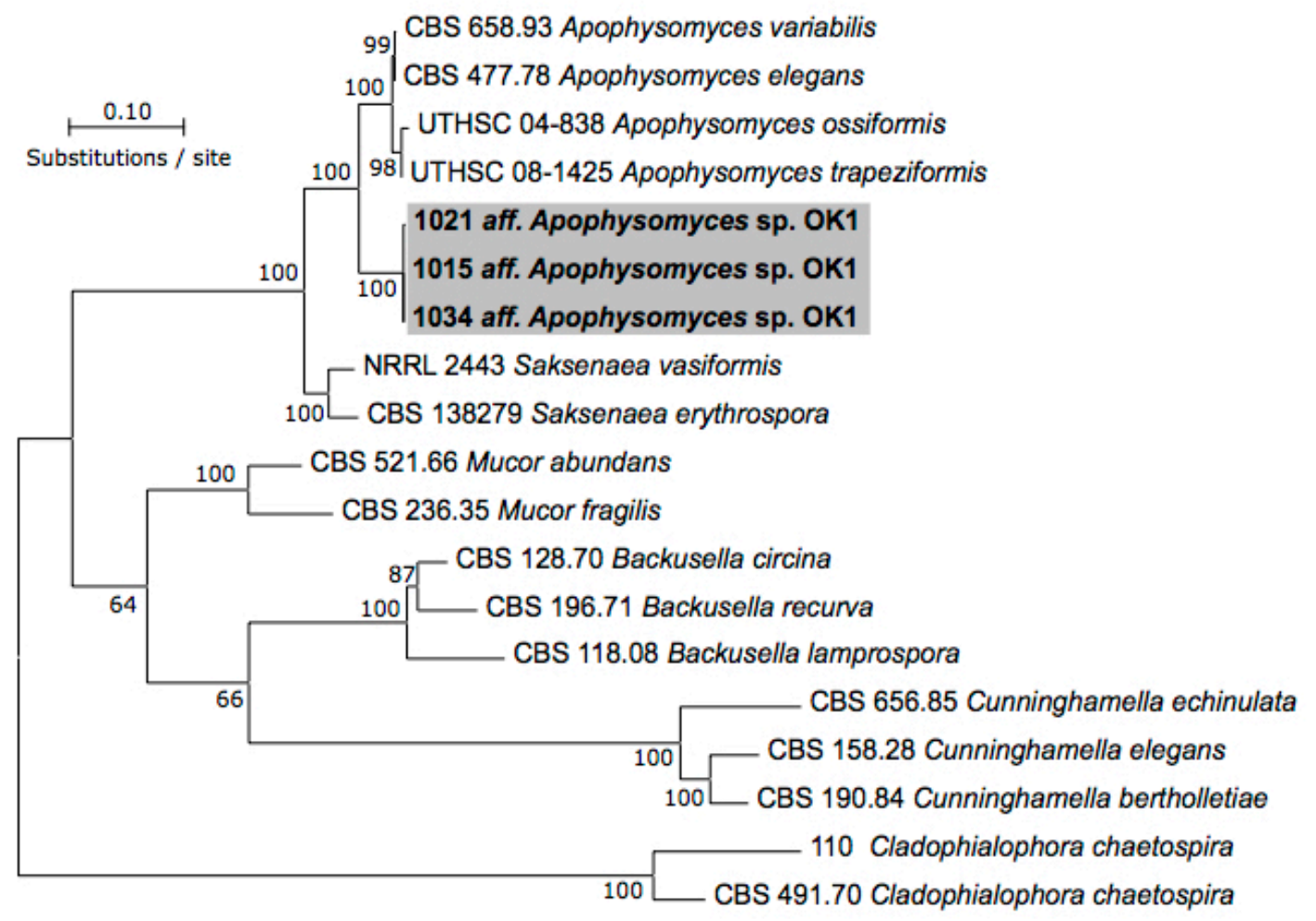

FIGURE 11: Concatenated ITS+LSU maximum likelihood phylogenetic tree for "aff. Apophysomyces," a putative new species. Bootstrap support is indicated near each node, and only values greater than $50 \%$ are shown. The grey box indicates the isolates belonging to aff. Apophysomyces. 


\section{DISCUSSION}

Who's who in the fungal community?

Brachycybe-associated fungi were sorted into five morphotypes, three of which were not taxonomically restricted. "White filamentous fungi" included members of four fungal orders, "Dematiaceous yeasts" had five orders and "Miscellaneous yeasts" had three orders spanning two fungal phyla. Quantification of CFUs provides a simplified coarse-scale approach to characterizing fungal communities. However, this method has several limitations, including morphological crypsis among distantly related taxa (Ko et al. 2011).

Based on sequencing results, Brachycybe lecontii associates with a large, diverse community of fungi, including at least 183 genera in 40 fungal orders from 4 phyla. Of all the genera of fungi found in this study, $40 \%$ were represented by a single isolate, and only $13 \%$ had 10 or more isolates. These genera are not evenly distributed among different sites, wood hosts, and millipede clades. But, across large groups of millipedes, certain genera appear more frequently than expected by chance.

Betweenness-centrality scores from the network analysis reveal that a small group of fungal genera make up the core of the fungal network. This core included two members of the Chaetothyriales, one Mycosphaerellales, one Mortierellales, three Hypocreales, one Mucorales, one Polyporales, one Eurotiales, one Umbelopsidales, and one Xylariales. The network analysis revealed that these fungi are consumed by many individuals across different lineages of $B$. lecontii and across many wood hosts, indicating that they may be the preferred fungal food source for these millipedes. 
The role of white filamentous fungi

Casual observations of naturally-occurring Brachycybe colonies led to the hypothesis that white filamentous fungi, mostly in the order Polyporales, are the primary food source for B. lecontii. However, both morphotype CFU counts and isolate sequencing data do not support this hypothesis. This morphotype was in extremely low incidence, compared to the other dominant morphotypes, and was recovered from only $48 \%$ of colonies. Since the Polyporales are only a subset of fungi in this morphotype, the true incidence of Polyporales is even lower. When investigated with cultureindependent sequencing, the proportion of Polyporales remained low at ca. 2\% (Michael Brewer, pers. comm.).

Although it is clear that $B$. lecontii are not consuming much of the white filamentous morphotype, that does not discount the possibility that these fungi may play a different but vital role during part of or throughout in the millipede life cycle. This study is designed to capture the fungi on or in B. lecontii, so fungi used in other ways, and not present on or in the millipede, would not be detected.

Unlike most fungi recovered during this study, Polyporales are perennial and can persist across many years, surviving through harsh conditions (Halme et al. 2009). In the field and in the laboratory colonies, $B$. lecontii displayed a marked preference for moister logs, and it is possible that in times of reduced moisture, the millipedes rely on moisture from Polyporales. Other arthropods use Polyporalean fruiting bodies for protection from changes in moisture (Mitgaard et al. 1998, Jonsell et al. 2001) Another possibility is that $B$. lecontii may only consume a liquid filtered extract of Polyporales. Ongoing studies by Wong et al. (in prep) support this hypothesis in that Brachycybe 
have a brush-like labrum, which would likely prevent ingestion of fungal hyphal fragments, but not spores. If no viable fungal propagules are present in the millipede, no fungi will be detected using the methods of this study. In addition, little is known of where the millipedes go or what they do in the winter (Gardner 1975, Shelley et al. 2005), and it is also possible that Polyporales and other white filamentous fungi may play some role during this period of time.

\section{Millipede Behavior}

Pinwheel formations were abundant at all sites in the field and in laboratory colonies. While documented in the literature for a half-century (referred to as starclusters, pinwheels or stellate arrangements) their function remains unknown (Gardner 1975, Manton 1961). These self-assembled formations may be a result of merely gathering around a common feeding site, or they may have another role, such as aiding in physical defense through aggregation (Dury et al. 2014, Curley et al. 2015) and/or concentrating millipede defensive compounds (Wood et al. 2000; Shear 2015). Another possibility is adults facilitate cooperative feeding that may benefit juveniles and hatchlings, who have smaller mouthparts. These hypotheses remain to be explored.

Observations made at three sites indicated atypical "summit-like" behavior (Hodge et al. 2017) in B. lecontii, with individuals exposing themselves to the elements and various predators. At two of those three sites, it was found that entomopathogenic Hypocreales dominated the fungal community. In site SC1, 29.3\% of all CFUs were entomopathogenic Hypocreales, and the site had an abundance of one genotype of Lecanicillium. Eighty-one percent of millipedes at SC1 harbored Lecanicillium, some of 
which were confirmed to be infected with the entomopathogenic nematode, Heterohabditis sp. (data not shown). In AR2, $80.2 \%$ of all CFUs were entomopathogenic Hypocreales, including Verticillium, Metarhizium, Pochonia, and Purpureocillium. Whether or not these fungi are the cause of the atypical behavior observed at these sites is unclear, but studies of entomopathogenic Hypocreales in insects indicate behavioral modification of the host is a possibility. For example, an arboreal carpenter ant (Camponotus leonardi) is occasionally parasitized by the Hypocrealean fungus Ophiocordyceps unilateralis. This fungus manipulates its host to travel to an optimum microclimate and clamp its mandibles onto a plant before death, improving the ability of the fungus to grow and reproduce (Andersen et al. 2009). Sexual behavior may also be manipulated by entomopathogens: male Ceratitis fruit flies infected with Metarhizium anisopliae delayed mating to groom, an activity that spreads spores all over the body (Dimbi et al. 2009). When females were infected, males found them highly attractive and attempted mating, even if the female was deceased.

Future studies should attempt to fulfull Koch's Postulates with fungi isolated from millipedes displaying unusual behaviors, to determine if these isolated fungi are the cause of the behaviors.

\section{Putative New Species}

In this study, evidence was found for at least seven putative new species (PNS), but only three were studied in detail. One of the three PNS studied was from the Ascomycota, in the order Chaetothyriales, and two were from the Mucoromycota, in the orders Mortierellales and Mucorales. 
Based on NCBI BLAST results, the PNS from the Chaetothyriales was called "aff. Fonsecaea sp." The Fonsecaea isolate most similar to isolates from this study matched at $95 \%$ of loci, but there was only a single isolate of Fonsecaea in the top matches. Most of the next closest matches were to Rhinocladiella/Ramichloridium anceps, and were accompanied by a significant drop in percent match from the Fonsecaea isolate. In addition, the fungus $R$. anceps belongs to a different order, either the Mycosphaerellales or the Capnodiales (still under debate, Crous et al. 2009). Many of the orders that contain dematiaceous fungi, like Chaetothyriales, Chaetosphaeriales, Capnodiales, and others, are not resolvable with just the ITS region, further complicating the issue (Crous et al. 2009). Many phylogenetic studies in the literature appear to have found some resolution of these orders, but other papers using fungi supposedly in the same genus as those in the first yield a different phylogenetic structure (Arzanlou et al. 2007).

Regardless of the exact identification and higher taxonomy for the PNS "aff. Fonsecaea sp.," our phylogenetic study indicates that it is not a close relative of Fonsecaea, and instead a close relative of Rhinocladiella anceps. All 11 isolates of "aff. Fonsecaea sp." are clonal and come from at least 6 sites and 3 wood hosts, spanning all three millipede clades. Future work will focus on morphological studies and phylogenetic analyses that will explicitly include additional loci and members of the Mycosphaerellales and Capnodiales. Once completed, a formal description will follow.

NCBI BLAST results from the two other PNS were not ambiguous, and the higher taxonomy for the Mucoromycota has already been clearly established (Spatafora et al. 2017). The PNS "Mortierella aff. ambigua" is represented by 27 clonal isolates from 7 
sites and 5 wood hosts, spanning 2 millipede clades (Clade 3 and 4). This PNS forms a clade with known reference sequences of Mortierella ambigua, but is also in its own clade sister to M. ambigua, indicating that "Mortierella aff. ambigua" is a new species of Mortierella closely related to Mortierella ambigua.

An attempt was made to use a subset of Mortierella references representing the seven identified clades in the genus (Wagner et al. 2013), but our phylogeny failed to recover the same topology. Future work for "Mortierella aff. ambigua" will focus on morphological studies, particularly the unique structures produced in pure culture. Once completed, a formal description will follow.

The last PNS, "aff. Apophysomyces sp.," is represented by five clonal isolates from one site, OK1, in Clade 4. The genus Apophysomyces includes four species, and is sister to the genus Saksenaea (Alvarez et al. 2010). This PNS forms a clade with known reference sequences of all four species known to exist in Apophysomyces, but is also in its own clade sister to the known species, indicating that "aff. Apophysomyces sp." is likely a new genus of closely related to Apophysomyces. The amount of divergence between the PNS and known species of Apophysomyces is greater than the divergence within known species of Apophysomyces, further supporting the PNS as a new genus.

Future work for "aff. Apophysomyces sp." will focus on morphological studies. Once completed, a formal description will follow.

Despite the use of more classical culture-based approaches, the recovery of seven putative new species highlights the vast amount of undescribed fungal biodiversity associated with millipedes. Culture-independent approaches will likely 
uncover many more new species, possibly including some from unculturable lineages of fungi. 


\section{LITERATURE CITED}

Alvarez, E., A. M. Stchigel, J. Cano, D. A. Sutton, A. W. Fothergill, J. Chander, V. Salas, M. G. Rinaldi, and J. Guarro. 2010. Molecular phylogenetic diversity of the emerging mucoralean fungus Apophysomyces: proposal of three new species. Revista Iberoamericana de Micologia. 27(2): 80-89.

Andersen, S. B., S. Gerritsma, K. M. Yusah, D. Mayntz, N. L. Hywel-Jones, J. Billen, J. J. Boomsma, and D. P. Hughes. 2009. The life of a dead ant: the expression of an adaptive extended phenotype. The American Naturalist. 174(3): 424-433.

Arzanlou, M., J. Z. Groenewald, W. Gams, U. Braun, H. D. Shin, and P. W. Crous. 2007. Phylogenetic and morphotaxonomic revision of Ramichloridium and allied genera. Studies in Mycology. 58: 57-93.

Bastian, M., S. Heymann, and M. Jacomy. 2009. Gephi: an open source software for exploring and manipulating networks. International AAAI Conference on Weblogs and Social Media.

Blondel, V. D., J. L. Guillaume, R. Lambiotte, and E. Lefebvre. 2008. Fast unfolding of communities in large networks. Journal of Statistical Mechanic: Theory and Experiment. 2008.

Bonkowski, M., S. Scheu, and M. Schaefer. 1998. Interactions of earthworms (Octolasion lacteum), millipedes (Glomeris marginata), and plants (Hordelymus europaeus) in a beechwood on a basalt hill: implications for litter decomposition and soil formation. Applied Soil Ecology. 9(1): 161-166. 
Brewer, M. S., C. L. Spruill, N. S. Rao, and J. E. Bond. 2012. Phylogenetics of the millipede genus Brachycybe Wood, 1864 (Diplopoda: Platydesmida: Andrognathidae): patterns of deep evolutionary history and recent speciation. Molecular Phylogenetics and Evolution. 64(1): 232-242.

Brito, J. M. 1994. The millipede of Santo Antao, Spinotarsus caboverdus: survey for pathogenic microorganisms, bioassay tests of fungal pathogens against $S$. caboverdus and Melanoplus sanguinipes. Dissertation, Montana State University-Bozeman, College of Agriculture.

Bultman, T. L. and P. L. Mathews. 1996. Mycophagy by a millipede and its possible impact on an insect-fungus mutualism. Oikos. 75(1): 67-74.

Chitty, J. R. 2006. Myriapods (centipedes and millipedes). In: Lewbart, G. A. (ed.) "Invertebrate medicine." Blackwell Publishing, lowa, U.S. 200-201.

Crous, P. W., C. L. Schoch, K. D. Hyde, A. R. Wood, C. Gueidan, G. S. De Hoog, and J. Z. Groenewald. 2009. Phylogenetic lineages in the Capnodiales. Studies in Mycology. 64: 17-47.

Curley, E. A., H. E. Rowley, and M. P. Speed. 2015. A field demonstration of the costs and benefits of group living to edible and defended prey. Biological Letters. 11(6).

Dimbi, S., N. K. Maniania, and S. Ekesi. 2009. Effect of Metarhizium anisopliae inoculation on the mating behavior of three species of African tephritid fruit flies, Ceratitis capitata, Ceratitis cosyra, and Ceratitis fasciventris. Biological Control. 50(2): 111-116. 
Dury, G. J., J. C. Bede, and D. M. Windsor. 2014. Preemptive circular defence of immature insects: definition and occurrences of cycloalexy revisited. Psyche: A Journal of Entomology.

Enghoff, H. and S. Santamaria. 2015. Infectious intimacy and contaminated cavesthree new species of ectoparasitic fungi (Ascomycota: Laboulbeniales) from blaniulid millipedes (Diplopoda: Julida) and inferences about their transmittal mechanisms. Organisms Diversity \& Evolution. 15(2): 249-263.

Gardner, M. R. 1975. Revision of the millipede family Andrognathidae in the Nearctic region. Memoirs of the Pacific Coast Entomological Society. 5: 19-38.

Greenblum, S., P. J. Turnbaugh, and E. Borenstein. 2012. Metagenomic systems biology of the human gut microbiome reveals topological shifts associated with obesity and inflammatory bowel disease. Proceedings of the National Academy of Sciences. 109(2): 594-599.

Halme, P., J. S. Kotiaho, A.L. Ylisirniö, J. Hottola, K. Junninen, J. Kouki, M. Lindgren, M. Mönkkönen, R. Penttilä., P. Renvall, and J. Siitonen. 2009. Perennial polypores as indicators of annual and red-listed polypores. Ecological Indicators. 9(2): 256-266.

Hodge, K. T., A. E. Hajek, and A. Gryganskyi. 2017. The first entomophthoralean killing millipedes, Arthrophaga myriapodina n. gen. n. sp., causes climbing before host death. Journal of Invertebrate Pathology. 149: 135-140.

Jonsell, M., G. Nordlander, and B. Ehnström. 2001. Substrate associations of insects breeding in fruiting bodies of wood-decaying fungi. Ecological Bulletins. 49: 173194. 
Kasson, M. T., K. L. Wickert, C. M. Stauder, A. M. Macias, M. C. Berger, D. R. Simmons, D. P. Short, D. B. DeVallance, and J. Hulcr. 2016. Mutualism with aggressive wood-degrading Flavodon ambrosius (Polyporales) facilitates niche expansion and communal social structure in Ambrosiophilus ambrosia beetles. Fungal Ecology. 23: 86-96

Kimura, M. 1980. A simple method for estimating evolutionary rate of base substitutions through comparative studies of nucleotide sequences. Journal of Molecular Evolution. 16: 111-120.

Ko, T. W., S. L. Stephenson, A. H. Bahkali, and K. D. Hyde. 2011. From morphology to molecular biology: can we use sequence data to identify fungal endophytes? Fungal Diversity. 50(1): 113-120.

Kudo, S. I., Y. Akagi, S. Hiraoka, T. Tanabe, and G. Morimoto. 2011. Exclusive male egg care and determinants of brooding success in a millipede. Ethology. 117(1): 19-27.

Kumar, S., G. Stecher, and K. Tamura. 2016. MEGA7: Molecular Evolutionary Genetics Analysis version 7.0 for bigger datasets. Molecular Biology and Evolution. 33(7): 1870-1874.

Larkin, M. A., G. Blackshields, N. P. Brown, R. Chenna, P. A. McGettigan, H. McWilliam, F. Valentin, I. M. Wallance, A. Wilm, R. Lopez, J. D. Thompson, T. J. Gibson, and D. G. Higgins. 2007. Clustal W and Clustal X version 2.0. Bioinformatics. 23(21): 2947-2948. 
Lawrence, J. M. and M. J. Samways. 2003. Litter breakdown by the Seychelles giant millipede and the conservation of soil processes on Cousine Island, Seychelles. Biological Conservation. 113(1): 125-132.

Lilleskov, E. A. and T. D. Burns. 2005. Spore dispersal of a resupinate ectomycorrhizal fungus, Tomentella sublilacina, via soil food webs. Mycologia. 97(4): 762-769.

Manton, S. M. 1961. The evolution of arthropodan locomotory mechanisms, part 7. Functional requirements and body design in Colobognatha (Diplopoda), together with a comparative account of diplopod burrowing techniques, trunk musculature, and segmentation. Zoological Journal of the Linnean Society. 44(299): 383-462.

Marek, P., W. Shear, and J. Bond. 2012. A rediscription of the leggiest animal, the millipede Illacme plenipes, with notes on its natural history and biogeography (Diplopoda, Siphonophorida, Siphonorhinidae). ZooKeys. 241: 77-112.

Mattson, W. J. (ed.) 2012. The role of arthropods in forest ecosystems. Springer Science \& Business Media, New York, U.S. 96-97.

McMonigle, O. 2012. Millipeds in captivity: diplopodan husbandry and reproductive biology. Coachwhip Publications, Ohio, U.S.

Midtgaard, F., B. A. Rukke, and A. Sverdrup-Thygeson. 1998. Habitat use of the fungivorous beetle Bolitophagus reticulatus (Coleoptera: Tenebrionidae): effects of basidiocarp size, humidity and competitors. European Journal of Entomology. 95(4): 559-570. 
Nei, M. and S. Kumar. 2000. Molecular evolution and phylogenetics. Oxford University Press, Oxford, England. 147-164.

Oksanen, J., F. G. Blanchet, M. Friendly, R. Kindt, P. Legendre, D. McGlinn, P. R. Minchin, R. B. O’Hara, G. L. Simpson, P. Solymos, M. H. M. Stevens, E. Szoecs, and H. Wagner. 2017. Vegan: community ecology package. Version 2.4-2.

Panshin, A. J. and C. de Zeeuw. 1980. Textbook of wood technology. $4^{\text {th }}$ edition. McGraw-Hill, Inc. New York, U.S. 407-645.

Santamaria, S., H. Enghoff, and A. S. P. S. Reboleira. 2014. Laboulbeniales on millipedes: Diplopodomyces and Troglomyces. Mycologia. 106(5): 1027-1038.

Schoch, C. L., K. A. Seifert, S. Huhndorf, V. Robert, J. L. Spouge, C. A. Levesque, W. Chen, E. Bolchacova, K. Voigt, P. W. Crous, and A. N. Miller. 2012. Nuclear ribosomal internal transcribed spacer (ITS) region as a universal DNA barcode marker for Fungi. Proceedings of the National Academy of Sciences. 109(16): 6241-6246.

Shear, W. 2011. Class Diplopoda de Blainville in Gervais, 1844. In: Zhang, Z. (ed.) "Animal biodiversity: an outline of higher-level classification and survey of taxonomic richness". Magnolia Press, Auckland, New Zealand, 2011.

Shear, W. A. 2015. The chemical defenses of millipedes (Diplopoda): biochemistry, physiology, and ecology. Biochemical Systematics and Ecology. 61: 78-117.

Shelley, R. M., C. T. McAllister, and T. Tanabe. 2005. A synopsis of the millipede genus Brachycybe Wood, 1864 (Platydesmida: Andrognathidae). Fragmenta Faunistica. 48(2): 137-166. 
Shi, S., E. E. Nuccio, Z. J. Shi, Z. He, J. Zhou, and M. K. Firestone. The interconnected rhizosphere: high network complexity dominates rhizosphere assemblages. Ecology Letters. 19(8): 926-936.

Spatafora, J. W., Y. Chang, G. L. Benny, K. Lazarus, M. E. Smith, M. L. Berbee, G. Bonito, N. Corradi, I. Grigoriev, A. Gryganskyi, and T. Y. James. 2017. A phylum-level phylogenetic classification of zygomycete fungi based on genomescale data. Mycologia. 108(5): 1028-1046.

Srivastava, P. D. and Y. N. Srivastava. 1967. Orthomorpha sp.-a new predatory millipede on Achatina fulica in Andamans. Cellular and Molecular Life Sciences. 23(9): 776.

Tamura, K. 1992. Estimation of the number of nucleotide substitutions when there are strong transition-transversion and $\mathrm{G}+\mathrm{C}$ content biases. Molecular Biology and Evolution. 9: 678-687.

U.S. Environmental Protection Agency. 2013. Level III and IV ecoregions of the continental United States. EPA, National Health and Environmental Effects Research Laboratory, Corvallis, Oregon, U.S.

Vilgalys, R., and M. Hester. 1990. Rapid genetic identification and mapping of enzymatically amplified ribosomal DNA from several Cryptococcus species. Journal of Bacteriology. 172: 4239-4246.

Wagner, L., B. Stielow, K. Hoffmann, T. Petkovits, T. Papp, C. Vágvölgyi, G. S. De Hoog, G. Verkley, and K. Voigt. 2013. A comprehensive molecular phylogeny 
of the Mortierellales (Mortierellomycotina) based on nuclear ribosomal DNA. Persoonia: Molecular Phylogeny and Evolution of Fungi. 30: 77-93.

White, T. J., T Bruns, S. J. W. T. Lee, and J. W. Taylor. 1990. Amplification and direct sequencing of fungal ribosomal RNA genes for phylogenetics. PCR Protocols: A Guide to Methods and Applications. 18(1): 315-322.

Wilson, H. M. and L. I. Anderson. 2004. Morphology and taxonomy of Paleozoic millipedes (Diplopoda: Chilognatha: Archipolypoda) from Scotland. Journal of Paleontology. 78(1): 169-184.

Wood, W. F., F. J. Hanke, I. Kubo, J. A. Carroll, and P. Crews. 2000. Buzonamine, a new alkaloid from the defensive secretion of the millipede, Buzonium crassipes. Biochemical Systematics and Ecology. 28(4): 305-312.

Wright, K. A. 1979. Trichomycetes and oxyuroid nematodes in the millipede, Narceus annularis. Proceedings of the Helminthological Society of Washington. 46: 213223. 


\section{SUPPLEMENTAL TABLES}

SUPPLEMENTAL TABLE 1: Level III and IV ecoregions used. Source: EPA, 2013.

\begin{tabular}{|l|l|l|}
\hline Number & Level III & Level IV \\
\hline 36B & Ouachita Mountains & Central Mountain Ranges \\
\hline 36C & Ouachita Mountains & Central Hills, Ridges, and Valleys \\
\hline 36D & Ouachita Mountains & Fourche Mountains \\
\hline 37A & Arkansas Valley & Scattered High Ridges and Mountains \\
\hline 45E & Piedmont & Northern Inner Piedmont \\
\hline 66D & Blue Ridge & Southern Crystalline Ridges and Mountains \\
\hline $67 \mathrm{H}$ & Ridge and Valley & Southern Sandstone Ridges \\
\hline $67 \mathrm{I}$ & Ridge and Valley & Southern Dissected Ridges and Knobs \\
\hline $69 \mathrm{D}$ & Central Appalachians & Dissected Appalachian Plateau \\
\hline
\end{tabular}

SUPPLEMENTAL TABLE 2: NCBI reference numbers for reference sequences used in the "aff. Fonsecaea sp." phylogenetic tree.

\begin{tabular}{|l|l|l|l|}
\hline Name & Strain number & ITS & LSU \\
\hline Fonsecaea erecta & CBS 125763 & KC886414.1 & KF155186.1 \\
\hline Fonsecaea minima & CBS 125760 & KC886416.1 & KF155187.1 \\
\hline Fonsecara pedrosoi & CBS 271.37 & NR_130652.1 & KJ930166.1 \\
\hline Fonsecaea monophora & CBS 102243 & EU938579.1 & FJ358247.1 \\
\hline Fonsecaea brasiliensis & BMU 07620 & KJ701015.1 & KJ930163.1 \\
\hline Cladophialophora chaetospira & CBS 491.70 & EU035405.1 & EU035405.1 \\
\hline Phialophora verrucosa & BMU 07676 & KJ701006.1 & KJ930157.1 \\
\hline Phialophora macrospora & BMU 07066 & KF881933.1 & KJ930071.1 \\
\hline Cladophialophora potulentorum & CBS 112222 & EU035409.1 & EU035409.1 \\
\hline Cyphellophora oxyspora & CBS 698.73 & NR_132883.1 & KC455262.1 \\
\hline Capronia pilosella & DAOM 208453 & AF050255.1 & AF050255.1 \\
\hline Exophiala moniliae & CBS 520.76 & NR_111448.1 & KJ930162.1 \\
\hline Capronia leucadendri & CBS 122672 & EU552108.1 & EU552108.1 \\
\hline Rhinocladiella anceps & AFTOL-ID 659 & DQ826740.1 & DQ823102.1 \\
\hline Mucor abundans & CBS 521.66 & JN206110.1 & JN206457.1 \\
\hline Mucor fragilis & CBS 236.35 & JN205979.1 & FN650671.1 \\
\hline & & & \\
\end{tabular}


SUPPLEMENTAL TABLE 3: NCBI reference numbers for reference sequences used in the "Mortierella aff. ambigua" phylogenetic tree.

\begin{tabular}{|l|l|l|l|}
\hline Name & Strain number & ITS & LSU \\
\hline Mortierella ambigua & CBS 521.80 & JX976120.1 & KC018423.1 \\
\hline Mortierella ambigua & YCS-B5 & KP744427.1 & KP744409.1 \\
\hline Mortierella ambigua & MLTB1-2 & KP744425.1 & KP744407.1 \\
\hline Mortierella capitata & CBS 293.96 & JX976123.1 & KC018334.1 \\
\hline Mortierella antarctica & CBS 609.70 & NR_111580.1 & NG_042563.1 \\
\hline Mortierella parvispora & CBS 311.52 & NR_077185.1 & HM849689.1 \\
\hline Mortierella macrocystis & CBS 431.81 & JX975897.1 & KC018437.1 \\
\hline Mortierella sclerotiella & CBS 529.68 & NR_145298.1 & HQ667387.1 \\
\hline Mortierella fatshederae & CBS 388.71 & JX976003.1 & JX976136.1 \\
\hline Mortierella microzygospora & CBS 880.97 & NR_111569.1 & HQ667394.1 \\
\hline Mortierella horticola & CBS 305.52 & NR_111572.1 & NG_042556.1 \\
\hline Mortierella epigama & CBS 489.70 & NR_077210.1 & HQ667367.1 \\
\hline Mortierella parazychae & CBS 868.71 & HQ630283.1 & HQ667362.1 \\
\hline Mortierella polygonia & CBS 685.71 & NR_111562.1 & NG_042546.1 \\
\hline Mortierella pseudozygospora & CBS 779.86 & JX975960.1 & KC018353.1 \\
\hline Mortierella chlamydospora & CBS 120.34 & HQ630354.1 & HQ667430.1 \\
\hline Mortierella beljakovae & CBS 123.72 & NR_111584.1 & NG_042568.1 \\
\hline Mortierella angusta & CBS 293.61 & NR_111555.1 & HQ667358.1 \\
\hline Mortierella stylospora & CBS 211.32 & NR_111556.1 & HQ667359.1 \\
\hline Mortierella rostafinskii & CBS 522.70 & NR_111586.1 & NG_042570.1 \\
\hline Mortierella strangulata & CBS 455.67 & HQ630359.1 & HQ667437.1 \\
\hline Mucor abundans & CBS 521.66 & JN206110.1 & JN206457.1 \\
\hline Mucor fragilis & CBS 236.35 & JN205979.1 & FN650671.1 \\
\hline
\end{tabular}

SUPPLEMENTAL TABLE 4: NCBI reference numbers for reference sequences used in the "aff. Apophysomyces sp." phylogenetic tree.

\begin{tabular}{|l|l|l|l|}
\hline Name & Strain number & ITS & LSU \\
\hline Apophysomyces variabilis & CBS 658.93 & NR_130683.1 & HM849695.1 \\
\hline Apophysomyces elegans & CBS 477.78 & JN206280.1 & JN206536.1 \\
\hline Apophysomyces ossiformis & UTHSC 04-838 & NR_137035.1 & FN554252.1 \\
\hline Apophysomyces trapeziformis & UTHSC 08-1425 & NR_137034.1 & FN554261.1 \\
\hline Saksenaea vasiformis & NRRL 2443 & FR687327.1 & HM776679.1 \\
\hline Saksenaea erythrospora & CBS 138279 & KM102733.1 & KM102734.1 \\
\hline Mucor abundans & CBS 521.66 & JN206110.1 & JN206457.1 \\
\hline Mucor fragilis & CBS 236.35 & JN205979.1 & FN650671.1 \\
\hline Backusella circina & CBS 128.70 & NR_103649.1 & JN206529.1 \\
\hline Backusella recurva & CBS 196.71 & JN206265.1 & JN206523.1 \\
\hline Backusella lamprospora & CBS 118.08 & NR_145291.1 & JN206531.1 \\
\hline
\end{tabular}




\begin{tabular}{|l|l|l|l|}
\hline Cunninghamella echinulata & CBS 656.85 & JN205896.1 & JN206598.1 \\
\hline Cunninghamella elegans & CBS 158.28 & JN205888.1 & JN206602.1 \\
\hline Cunninghamella bertholletiae & CBS 190.84 & JN205878.1 & HM849701.1 \\
\hline Cladophialophora chaetospira & CBS 491.70 & EU035405.1 & EU035405.1 \\
\hline
\end{tabular}

SUPPLEMENTAL TABLE 5: Results of Tukey's HSD post-hoc test comparing the fungal communities between wood hosts where more than one colony was sampled.

\begin{tabular}{|l|l|l|}
\hline Wood host \#1 & Wood host \#2 & Adj. p-value \\
\hline Ulmus sp. & Acer & $0.0000^{*}$ \\
\hline Ulmus sp. & Betula & $0.0000^{*}$ \\
\hline Ulmus sp. & Carya & $0.0000^{*}$ \\
\hline Ulmus sp. & Fagus & $0.0000^{*}$ \\
\hline Ulmus sp. & Liriodendron & $0.0000^{*}$ \\
\hline Ulmus sp. & Pinus & $0.0000^{*}$ \\
\hline Ulmus sp. & Quercus & $0.0000^{*}$ \\
\hline Ulmus alatus & Acer & $0.0000^{*}$ \\
\hline Ulmus alatus & Betula & $0.0000^{*}$ \\
\hline Ulmus alatus & Carya & $0.0000^{*}$ \\
\hline Ulmus alatus & Fagus & $0.0000^{*}$ \\
\hline Ulmus alatus & Fraxinus & $0.0000^{*}$ \\
\hline Ulmus alatus & Liriodendron & $0.0000^{*}$ \\
\hline Ulmus alatus & Pinus & $0.0000^{*}$ \\
\hline Ulmus alatus & Quercus & $0.0000^{*}$ \\
\hline Fagus & Betula & $0.0120^{*}$ \\
\hline Liriodendron & Acer & $0.0338^{*}$ \\
\hline Liriodendron & Fagus & $0.0073^{*}$ \\
\hline Betula & Acer & 0.0596 \\
\hline Carya & Acer & 0.8868 \\
\hline Carya & Betula & 0.7778 \\
\hline Fagus & Acer & 0.9954 \\
\hline Fagus & Carya & 0.3800 \\
\hline Liriodendron & Betula & 1.0000 \\
\hline Liriodendron & Carya & 0.6862 \\
\hline Pinus & Acer & 1.0000 \\
\hline Pinus & Betula & 0.2002 \\
\hline Pinus & Farya & 0.9438 \\
\hline Pinus & Airiodendron & 0.9990 \\
\hline Pinus & 0.1609 \\
\hline Quercus & Caryala & 0.3860 \\
\hline Quercus & Fagus & 0.9443 \\
\hline Quercus & 0.9997 \\
\hline Quercus & & \\
\hline & & \\
\hline
\end{tabular}




\begin{tabular}{|l|l|l|}
\hline Quercus & Liriodendron & 0.8753 \\
\hline Quercus & Pinus & 0.6380 \\
\hline Ulmus sp. & Carpinus & 1.0000 \\
\hline Ulmus sp. & Ulmus alatus & 1.0000 \\
\hline
\end{tabular}




\title{
CHAPTER 3: IDENTIFYING FUNCTIONAL ROLES OF BRACHYCYBE LECONTII- ASSOCIATED FUNGI
}

\begin{abstract}
Brachycybe (Wood) is a genus of fungivorous millipedes, whose fungal associates have only recently been described. The ecology of these fungi and their interactions with $B$. lecontii remain unclear. In an attempt to resolve these relationships, fungal cohort pairings and entomopathogenicity trials were conducted. Of the 156 pairings tested, 67 resulted in competitive interactions. A majority of these interactions involved inhibition or overgrowth by fungi in the Hypocreales and Polyporales, respectively. Results of a series of entomopathogenicity trials indicated that $B$. lecontii was less susceptible to entomopathogenic fungi than an insect model, Galleria mellonella. Conversely, $B$. lecontii exhibited high mortality when challenged with Polyporales, while G. mellonella was unaffected. Recent work involving network analysis shows that a dozen fungal genera play a central role in millipede-fungus associations, and results of this study indicate that individual roles vary in unexpected ways.
\end{abstract}

\section{INTRODUCTION}

Millipedes (Arthropoda: Myriapoda: Diplopoda) are non-insect arthropods with many body segments and two pairs of legs per body segment. The oldest known millipede body fossil, Pneumodesmus newmanii, dates to the Silurian (420-440 million years ago), and presents the earliest evidence for air-breathing in any animal (Wilson and Anderson 2004).

Millipedes are a relatively diverse group of animals, with approximately 12,000 
millipede species described to date, in 16 orders and 140 families (Shear 2011). The majority are detritivores, feeding on dead and decaying plant material and animal waste on the forest floor, though anecdotal evidence supports herbivorous (Marek et al. 2012), fungivorous (Brewer et al. 2012, Marek et al. 2012), and carnivorous lifestyles (Srivastava and Srivastava 1967). Detritivorous millipedes play a crucial role in nutrient cycling, particularly in nutrient-poor areas (Mattson 2012, Lawrence and Samways 2003, Bonkowski et al. 1998). Nearly all millipedes have a subterranean lifestyle, living in decomposing leaf litter, in the soil, or inside wet, rotting wood substrates.

Millipedes are regularly reported in association with fungi, likely due to their detritivorous habit. Most records of fungal-millipede interactions are cases where millipedes occasionally graze on fungi in the environment, or where a parasitic fungus is attacking the millipede (Lilleskov and Burns 2005, Bultman and Mathews 1996, Hodge et al. 2017). Several species of specialist ectoparasitic fungi in the Laboulbeniales have been recorded from millipedes (Santamaria et al. 2014, Enghoff and Santamaria 2015). In the millipede pet trade, fungal infection due to poor animal husbandry is a widespread issue, especially in the most notable pet species, the giant African millipede (Archispirostreptus gigas) (McMonigle 2012). Opportunistic fungi may take advantage of weakened millipedes, but confirmed pathogenicity on healthy animals is uncommon in the literature (Brito 1994, Chitty 2006). At least two species of trichomycetes, obligate arthropod gut-associated fungi, also have been reported from millipedes (Wright 1979).

Brachycybe (Wood) is a genus of millipedes in the family Andrognathidae (Diplopoda: Platydesmida) with eight described species and at least two additional undescribed species awaiting description (Brewer et al. 2012). In the United States, 
there are two species in the Appalachian Mountains and three (plus two undescribed) in northern California. All Brachycybe are small millipedes, with some individuals reaching $4 \mathrm{~cm}$ in length (pers. obs.). They are one of the few groups of arthropods that exhibit paternal care of their offspring (Kudo et al. 2011). Brachycybe are most frequently found living on rotten logs and branches with visible fungal growth (Shelley et al. 2005). They exhibit various social behaviors including overlapping adult generations and reproductive division of labor. They also form pinwheel-like multigenerational colonies around resupinate fungi underneath downed woody substrates (Gardner 1975). All members of the millipede subterclass Colobognatha, which includes Brachycybe, are believed to be strict fungivores (Gardner 1975), as evidenced by their diminutive mouthparts (Paul Marek, pers. comm.) their clustering around fungi, and the visual damage (i.e. divots) they leave behind on fungi.

The known geographic range of Brachycybe lecontii extends across 13 states from eastern Oklahoma to western South Carolina, south to Louisiana, and north to southern West Virginia (Shelley et al. 2005, Brewer et al. 2012). Their range encompasses five Level III and nine Level IV Ecoregions (as defined in 2013 report from U.S. EPA). The five Level III Ecoregions include: "Ouachita Mountains" (AR, OK), "Arkansas Valley" (AR), "Piedmont" (SC), "Blue Ridge" (GA, SC), "Ridge and Valley" (VA), and "Central Appalachians" (TN, VA, WV). The nine Level IV Ecoregions were as follows: "Central Mountain Ranges", "Central Hills, Ridges, and Valleys", and "Fourche Mountains" (“Ouachita Mountains”); "Scattered High Ridges and Mountains" (“Arkansas Valley”); “Northern Inner Piedmont” (“Piedmont”); “Southern Crystalline Ridges and Mountains" ("Blue Ridge"); "Southern Sandstone Ridges" and "Southern Dissected 
Ridges and Knobs" ("Ridge and Valley"); and "Dissected Appalachian Plateau" ("Central Appalachians"). Within this known range, five subpopulations have been identified (Shelley et al. 2005), four of which were recently validated using sequence data (Brewer et al. 2012).

In the previous chapter, we determined that Brachycybe lecontii associates with a large, diverse community of fungi, including at least 183 genera in 40 fungal orders from 4 phyla. This diversity includes Peniophora, the only fungus historically reported in association with Brachycybe (Gardner 1975). A majority of the fungal associates were in five broad morphological classes that encompassed 14 fungal orders. The Hypocreales were the most common order across all $B$. lecontii colonies. Community and diversity analyses confirmed high alpha diversity averaging 83 genera across three B. lecontii clades, and 39 genera across ten wood hosts. Overall, significant differences were found among clades and wood hosts, although twelve genera displayed high connectivity across the whole network. These genera included Fonsecaea and Phialophora (Chaetothyriales), Cosmospora, Trichoderma, Verticillium (Hypocreales), Ramichloridium (Mycosphaerellales), Mortierella (Mortierellales), Mucor (Mucorales), Phanerochaete (Polyporales), Penicillium (Eurotiales), Umbelopsis (Umbelopsidales), and Xylaria (Xylariales). In addition, some fungi were associated with atypical millipede behavior, indicating a sub-optimal fungal community.

The objective of this study is to identify the functional roles of $B$. lecontiiassociated fungi, through laboratory assays of pathogenicity on millipedes, and assays to identify the interactions occurring between co-cultured fungi. 


\section{MATERIALS AND METHODS}

\section{Fungal cohort pairings}

Pairings were conducted at the site level, and only isolates recovered from an individual site were paired with each other. The purpose of this experimental design was to only test interactions between fungi that could interact in nature. Five sites were selected across the study area. Two of these sites were chosen because the millipedes had exhibited atypical behavior (Chapter 2). Representatives of the dominant fungi at each site were paired (Table 1).

TABLE 1: Isolates used in fungal cohort pairings. Asterisk denotes putative new species.

\begin{tabular}{|c|c|c|}
\hline SITE & FUNGAL ORDER & ISOLATE ID \\
\hline \multirow[t]{7}{*}{ TN1 } & Amphisphaeriales & 630-Pestalotiopsis microspore \\
\hline & Chaetosphaeriales & 524-Chaetosphaeria chloroconia \\
\hline & Chaetothyriales & 626-Cladophialophora sp. \\
\hline & Hypocreales & 482-Verticillium insectorum \\
\hline & Mucorales & 556-Mucor fragilis \\
\hline & Polyporales & 523-Irpex lacteus \\
\hline & Umbelopsidales & 529-Umbelopsis angularis \\
\hline \multirow[t]{7}{*}{ SC1 } & Chaetothyriales & 717-Phialophora americana \\
\hline & Hypocreales & 678-Lecanicillium attenuatum \\
\hline & Hypocreales & 701-Verticillium insectorum \\
\hline & Mucorales & 695-Mucor fragilis \\
\hline & Polyporales & 709-Phanerochaete cumulodentata \\
\hline & Umbelopsidales & 702-Umbelopsis isabellina \\
\hline & Umbelopsidales & 683-Umbelopsis ramanniana \\
\hline \multirow[t]{8}{*}{ WV5 } & Amphisphaeriales & 1283-Pestalotiopsis jesteri \\
\hline & Chaetosphaeriales & 1318-Codinaea acacia \\
\hline & Chaetothyriales & 1403-Phialophora americana \\
\hline & Hypocreales & 1310-Verticillium insectorum \\
\hline & Mortierellales & 1349-Mortierella aff. ambigua* \\
\hline & Mucorales & 1285-Mucor circinelloides \\
\hline & Polyporales & 1316-Bjerkandera adusta \\
\hline & Umbelopsidales & 1290-Umbelopsis isabellina \\
\hline \multirow[t]{3}{*}{ AR2 } & Amphisphaeriales & 1217-Pestalotiopsis sp. \\
\hline & Hypocreales & 1163-Metarhizium flavoviride \\
\hline & Hypocrelaes & 1165-Pochonia chlamydosporia \\
\hline
\end{tabular}




\begin{tabular}{l|ll}
\hline AR4 & Hypocreales & $1113-$ Tolypocladium album \\
Hypocrelaes & $1084-$ Verticillium sp. \\
Mucorales & $1001-$ Mucor genevensis \\
Umbelopsidales & $1024-$ Umbelopsis isabellina \\
Amphisphaeriales & $1212-$ Pestalotiopsis jesteri \\
Chaetothyriales & $1091-$ Fonsecaea sp. \\
Chaetothyriales & $1130-$ aff. Fonsecaea sp. \\
Hypocreales & $1172-$ Verticillium insectorum \\
Mortierellales & $1148-$ Mortierella aff. ambigua* \\
Mucorales & $1016-$ Mucor abundans \\
Polyporales & $1143-$ Trametopsis cervina \\
Umbelopsidales & $1023-$ Umbelopsis ramanniana
\end{tabular}

In total, 37 isolates were tested in 156 pairings. Single $0.9-\mathrm{cm}$ diameter plugs were placed $3 \mathrm{~cm}$ from the edge of a potato dextrose agar plate, and the paired isolate placed opposite. Each pairing was done in triplicate. Plates were allowed to grow at $20^{\circ} \mathrm{C}$ for 1 -week intervals for up to 4 weeks total for slow-growing fungi. At the end of each 1-week period, observations of fungal interactions were taken. These interactions included overgrowth of one fungus by another, inhibition of one fungus by another, or no interaction between the paired fungi (Figure 1).

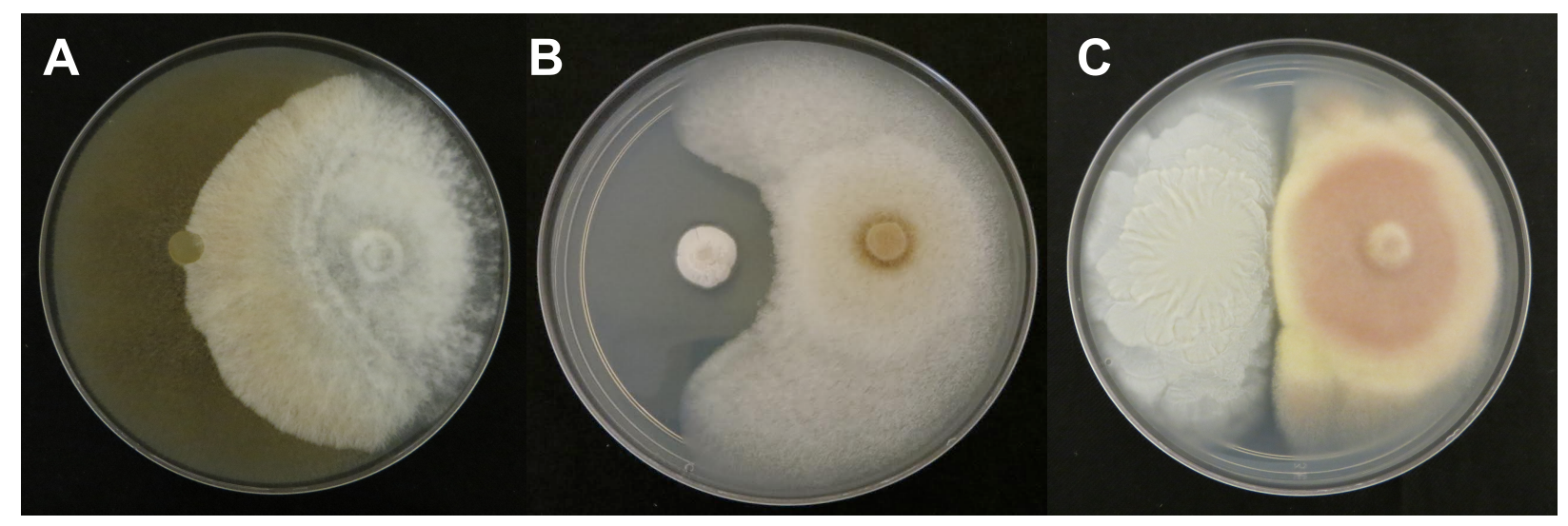

FIGURE 1: Outcomes of fungal-fungal interactions. A: Overgrowth; Mucor fragilis 556 (left) is being overgrown by Irpex lacteus 523 (right). B: Inhibition; Pochonia chlamydosporia 1165 (left) is inhibiting Mucor genevensis 1001 (right). C: Tie/no interaction; "Mortierella aff. ambigua" 1148 (left) has no interaction with Umbelopsis ramanniana 1023 (right). 
Entomopathogenicity testing: live plating

Twenty-two representative isolates (Table 2) were chosen for live-plating entomopathogenicity assays on Galleria mellonella (waxworms, from New York Worms http://www.nyworms.com/) and Brachycybe lecontii (collected in confirmed sampling locations in WV). Waxworms were used in this assay because they are model organisms for studies of pathogenicity/toxicity in arthropods in general (Panaccione and Arnold 2017).

TABLE 2: Isolates used in live plating pathogenicity assays. Asterisk denotes putative new species.

\begin{tabular}{|c|c|}
\hline FUNGAL ORDER & ISOLATE ID \\
\hline Amphisphaeriales & 630-Pestalotiopsis microspora \\
\hline Chaetosphaeriales & 320-Chaetosphaeria myriocarpa \\
\hline Chaetothyriales & 1244-Capronia dactylotricha \\
\hline Chaetothyriales & 1147-aff. Fonsecaea sp.* \\
\hline Chaetothyriales & 1193-Phialophora americana \\
\hline Hypocreales & 678-Lecanicillium attenuatum \\
\hline Hypocreales & 1163-Metarhizium flavoviride \\
\hline Hypocreales & 29-Pochonia bulbillosa \\
\hline Hypocreales & 1216-Trichoderma viride \\
\hline Hypocreales & 482-Verticillium insectorum \\
\hline Mortierellales & 1150-Mortierella aff. ambigua* \\
\hline Mortierellales & 530-Mortierella sp. \\
\hline Mucorales & 1015-aff. Apophysomyces sp.* \\
\hline Mucorales & 1010-Mucor abundans \\
\hline Mycosphaerellales & 329-Ramichloridium anceps \\
\hline Polyporales & 310-Bjerkandera adusta \\
\hline Polyporales & 1158-Ceriporia lacerata \\
\hline Polyporales & 523-Irpex lacteus \\
\hline Polyporales & 494-Trametopsis cervina \\
\hline Umbelopsidales & 529-Umbelopsis angularis \\
\hline Umbelopsidales & 1290-Umbelopsis isabellina \\
\hline Umbelopsidales & 1028-Umbelopsis ramanniana \\
\hline
\end{tabular}


Isolates were grown on glucose yeast extract agar (GYEA) and scraped to generate inoculum suspensions in sterile water. An aliquot of suspension was spread on six GYEA plates per fungus (three for millipedes, three for waxworms). After all plates were covered by fungal growth ( $\sim 3$ weeks), the arthropods were introduced for 7day pathogenicity trials. Five individuals were placed on each plate, for a total of 15 animals of each type for each fungal treatment. For a negative control, animals were placed on clean GYEA plates that were changed each time contaminating fungal growth was observed. Plates required replacement due to inadvertent inoculation by phoretic contaminants and gut community members. Observations were made every 12 hours for the first 36 hours (until mortality began to appear), and every 4 hours for an additional 108 hours until 7 days were complete. At the end of the assay, samples of deceased individuals were preserved for future chemical analyses. Surviving waxworms were euthanized by freezing for 24 hours, and surviving millipedes were placed into laboratory colonies for future studies.

Statistical analysis of survivorship was performed using the "Survival / Reliability" function in JMP 13.1.0. Post-hoc pairwise comparisons to the control treatment were performed in descending order from highest mortality to lowest mortality, for each arthropod type, until such comparisons were no longer significant. Both log-rank and Wilcoxon tests were used. Log-rank tests score mortality at all time points evenly, while Wilcoxon tests score early mortality more heavily. Significance thresholds were Bonferroni-corrected. 
Entomopathogenicity testing: injections

Thirty-one representative isolates (Table 3) were chosen for injection entomopathogenicity assays on Galleria mellonella. Waxworms were used in this assay because they are model organisms for studies of pathogenicity/toxicity in arthropods (Panaccione and Arnold 2017). In addition, Brachycybe lecontii could not be tested due to their small size and the difficulty of injecting through thick cuticle.

TABLE 3: Isolates used in Galleria mellonella larvae injections. Asterisk denotes putative new species.

\begin{tabular}{|c|c|c|}
\hline FUNGAL ORDER & ISOLATE ID & (CONIDIA/ML) \\
\hline Chaetothyriales & 1244-Capronia dactylotricha & $2.5 \times 10^{7}$ \\
\hline Chaetothyriales & 626-Cladophialophora sp. & $3.9 \times 10^{7}$ \\
\hline Chaetothyriales & 325-Cyphellophora sp. & $1.3 \times 10^{7}$ \\
\hline Chaetothyriales & 1091-Fonsecaea sp. & $1.5 \times 10^{7}$ \\
\hline Chaetothyriales & 1147-aff. Fonsecaea sp.* & $3.0 \times 10^{7}$ \\
\hline Chaetothyriales & 1193-Phialophora americana & $2.6 \times 10^{7}$ \\
\hline Chaetothyriales & 1164-Rhinocladiella atrovirens & $2.2 \times 10^{7}$ \\
\hline Hypocreales & 1250-Beauveria caledonica & $1.1 \times 10^{7}$ \\
\hline Hypocreales & 678-Lecanicillium attenuatum & $3.5 \times 10^{7}$ \\
\hline Hypocreales & 1163-Metarhizium flavoviride & $2.5 \times 10^{7}$ \\
\hline Hypocreales & 587-Pochonia chlamydosporia & $6.2 \times 10^{7}$ \\
\hline Hypocreales & 17-Pochonia suchlasporia & $1.9 \times 10^{7}$ \\
\hline Hypocreales & 1070-Purpureocillium lilacinum & $3.6 \times 10^{7}$ \\
\hline Hypocreales & 1113-Tolypocladium album & $3.4 \times 10^{7}$ \\
\hline Hypocreales & 1216-Trichoderma viride & $4.8 \times 10^{7}$ \\
\hline Hypocreales & 488-Verticillium fungicola & $3.5 \times 10^{7}$ \\
\hline Hypocreales & 482-Verticillium insectorum & $2.9 \times 10^{7}$ \\
\hline Hypocreales & 1005-Verticillium insectorum & $3.6 \times 10^{7}$ \\
\hline Mortierellales & 1150-Mortierella aff. ambigua* & $6.2 \times 10^{6}$ \\
\hline Mortierellales & 530-Mortierella sp. & $4.3 \times 10^{7}$ \\
\hline Mucorales & 1015-aff. Apophysomyces sp.* & 0 ** \\
\hline Mucorales & 1267-Backusella circina & $1.7 \times 10^{7}$ \\
\hline Mucorales & 1044-Cunninghamella elegans & $1.2 \times 10^{6}$ \\
\hline Mucorales & 1010-Mucor abundans & $4.4 \times 10^{7}$ \\
\hline Mucorales & 1029-Mucor qenevensis & $5.2 \times 10^{7}$ \\
\hline
\end{tabular}

\section{CONIDIA} CONCENTRATION (CONIDIA/ML) 


\begin{tabular}{l|cc} 
Mucorales & 1009-Mucor luteus & $1.4 \times 10^{6}$ \\
Mycosphaerellales & 329-Ramichloridium anceps & $4.8 \times 10^{7}$ \\
Polyporales & 305-Bjerkandera adusta & $4.7 \times 10^{7}$ \\
Umbelopsidales & 529-Umbelopsis angularis & $1.7 \times 10^{7}$ \\
Umbelopsidales & $1290-$ Umbelopsis isabellina & $4.7 \times 10^{7}$ \\
Umbelopsidales & $1028-$ Umbelopsis ramanniana & $2.4 \times 10^{7}$
\end{tabular}

**"aff. Apophysomyces sp." did not produce spores in culture, but the suspension generated contained enough hyphal fragments to attempt the trial.

Selected isolates were grown on GYEA and scraped to generate spore suspensions in sterile distilled water. Spore concentrations were checked via hemocytometer and diluted to a concentration between $1 \times 10^{7}$ and $5 \times 10^{7}$ conidia/mL, except for four Mucoromycotan isolates that did not produce enough conidia and were assayed at the concentrations given in Table 3. Due to the use of conidia for inoculum, several groups of non-sporulating isolates could not be tested, most notably many Polyporales. Injections were performed with a disposable 29.5-gauge hypodermic needle, and a fresh needle was used for each treatment. In each treatment, 20 waxworms were injected behind the left rear proleg with $20 \mu \mathrm{L}$ of conidial suspension supplemented with $10 \mu \mathrm{g} / \mathrm{mL}$ rifampicin, an antibiotic to combat wound infections (Panaccione and Arnold 2017). For a negative control, 20 worms were injected with only sterile water and rifampicin. To test for a negative effect from injections, the negative control group was compared to 20 non-injected worms. Observations were made every four hours for the first 48 hours, and every 12 hours for an additional 96 hours, for a total of 144 hours. At the end of the assay, samples of deceased individuals were preserved for future chemical analyses. Surviving waxworms were euthanized by freezing for 24 hours. 
Injections were performed in three separate batches of 7 to 16 treatments, and each batch had a water + rifampicin injection treatment and a no-injection treatment as independent controls.

Statistical analysis of survivorship was performed using the "Survival / Reliability" function in JMP 13.1.0. Waxworms that pupated during the studies were censored. Post-hoc pairwise comparisons to the control treatment were performed in descending order from highest mortality to lowest mortality, for each arthropod type, until such comparisons were no longer significant. Both log-rank and Wilcoxon tests were used. Log-rank tests score mortality at all time points evenly, while Wilcoxon tests score early mortality more heavily. Significance thresholds were Bonferroni-corrected.

\section{RESULTS}

\section{Fungal cohort pairings}

A majority of cohort pairings did not result in inhibition. There were 156 pairings, and of these, 49 resulted in one fungus overgrowing another, and 18 resulted in one fungus inhibiting the growth of another (Figure 2).

Of the 42 pairings involving entomopathogenic Hypocreales (excluding Hypo. X Hypo. pairings), one overgrew the other fungus and eight inhibited the paired nonHypocreales isolate. In AR2, six Hypo. X Hypo. interactions were tested and four of six resulted in inhibition. In these pairings, a pattern of inhibition emerged: Pochonia chlamydosporia inhibited Verticillium sp., which inhibited Tolypocladium album, which inhibited Metarhizium flavoviride (Figure 2). 
Of the 40 pairings involving a dematiaceous yeast (Chaetothyriales or Chaetosphaeriales, and excluding Dem. X Dem. pairings), zero overgrew the other fungus and four inhibited the other non-dematiaceous-yeast isolate. Only three Dem. X Dem. interactions were tested and two of three had no interaction. In the interacting pair, Cladophialophora sp. inhibited Chaetosphaeria chloroconia (Figure 2).

Of the 62 pairings involving a zygomycete (Umbelopsis, Mucor, or Mortierella, and excluding zygo. X zygo. pairings), 14 overgrew the other fungus, and one inhibited the other non-zygomycete isolate. Eleven zygo. $X$ zygo. interactions were tested and six resulted in no interaction. In all five other cases, a Mucor sp. overgrew the other fungus (Umbelopsis or Mortierella) (Figure 2).

Of the 46 pairings involving a white filamentous fungus (Amphisphaeriales and Polyporales, and excluding W.F.F. X W.F.F. pairings), 28 overgrew the other fungus, and zero inhibited the other non-white-filamentous isolate. Only three W. F. F. x W. F. F. interactions were tested, and one of three had no interaction. The remaining two interactions involved overgrowth: in one, Pestalotiopsis jesteri overgrew Bjerkandera adusta, and in the other, Pestalotiopsis jesteri was overgrown by Trametopsis cervina (Figure 2). 

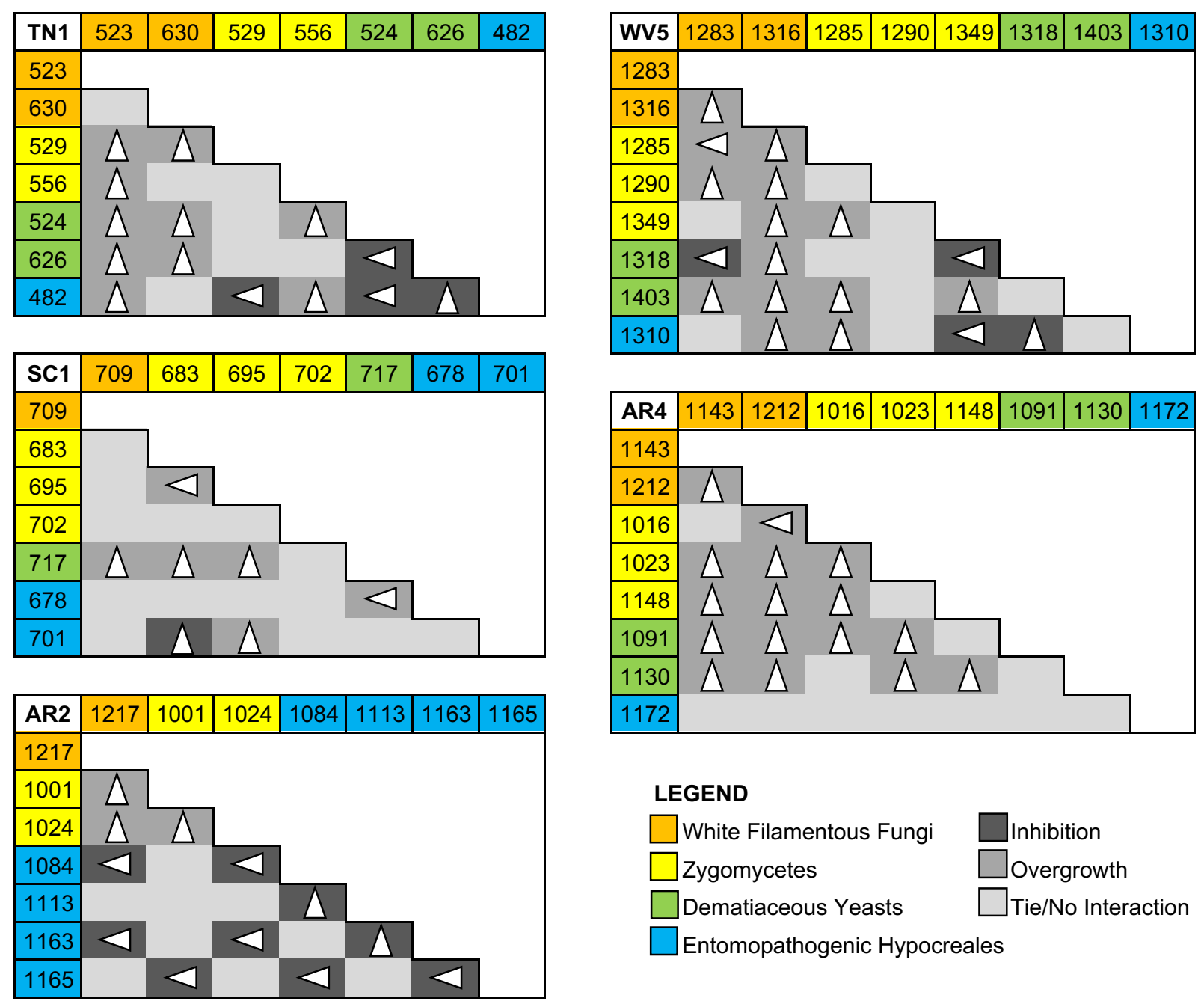

FIGURE 2: Interaction tables showing the results of fungal cohort pairings, by site. The color of each isolate label indicates its fungal morphotype, and the shade of grey inside the chart indicates if the interaction resulted in inhibition, overgrowth, or a tie/no interaction. Arrows indicate the "winners" of inhibition or overgrowth interactions.

\section{Entomopathogenicity testing: live plating}

A majority of the fungi used in live plating entomopathogenicity tests did not cause significant mortality in Galleria mellonella or Brachycybe lecontii. For B. lecontii, only treatments that are significantly different from the control are shown in the survivorship curve in Figure 3. 


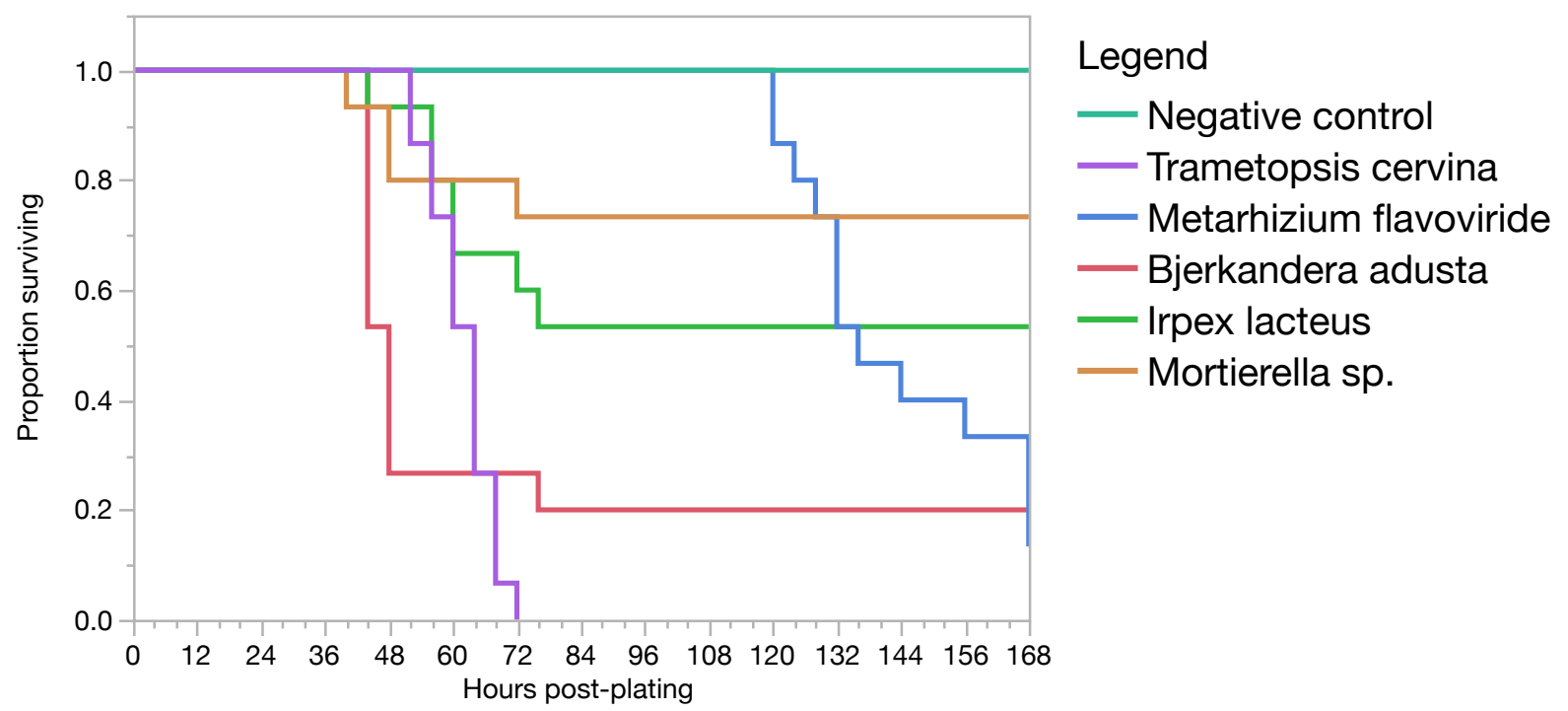

FIGURE 3: Survivorship curves for Brachycybe lecontii live-plating trials. Only fungal treatments that were significantly different from the control are shown.

In Brachycybe lecontii, white filamentous fungi caused the most severe damage, with $50 \%$ mortality at 48 hours post-plating for Bjerkandera adusta and at 64 hours postplating for Trametopsis cervina. In addition to the white filamentous fungi, one entomopathogenic Hypocrealean fungus, Metarhizium flavoviride, caused $50 \%$ mortality at 136 hours post-plating. No other treatment reached $50 \%$ mortality. Fungi from all other groups did not appear to have any negative effect on Brachycybe.

A survival analysis was performed for the live-plating assay on Brachycybe lecontii. Of the 345 millipedes used in this study, 266 were unaffected by fungi. Both log-rank and Wilcoxon tests were performed to determine if the treatment received had an effect on survivorship. Both tests yielded a p-value less than 0.0001 . All millipedes in the control treatment (plating with no fungus) survived, in addition to all millipedes in the 13 following treatments: Chaetosphaeria myriocarpa, "Mortierella aff. ambigua", "aff. Fonsecaea sp.", "aff Apophysomyces sp.", Verticillium insectorum, Lecanicillium 
attenuatum, Umbelopsis ramanniana, Mucor abundans, Capronia dactylotricha, Umbelopsis isabellina, Pochonia bulbillosa, Ramichloridium anceps, and Ceriporia lacerata. Three additional treatments lost no more than two of 15 millipedes over the course of the experiment. The remaining six treatments, Trametopsis cervina, Metarhizium flavoviride, Bjerkandera adusta, Irpex lacteus, Mortierella sp., and Pestalotiopsis microspora lost 15, 13, 12, seven, four, and three millipedes, respectively. Pairwise comparisons were made for treatments starting with those that resulted in the most severe mortality. Comparisons were halted after the first nonsignificant comparison.

Four fungal treatments, Trametopsis cervina, Metarhizium flavoviride, Bjerkandera adusta, and Irpex lacteus, were significantly different from the control based on Log-rank and Wilcoxon tests (Supplemental Table 1).

In Galleria mellonella, entomopathogenic Hypocreales caused the most severe damage, with $50 \%$ mortality at 44 hours post-plating for Metarhizium flavoviride, and at 132 hours post-plating for Pochonia bulbillosa. No other treatment reached 50\% mortality (Figure 4), but the other treatments in the entomopathogenic Hypocreales (Lecanicillium attenuatum, Verticillium insectorum) resulted in dermal lesions with active sporulation. Fungi from all other groups did not appear to have any effect on Galleria. 


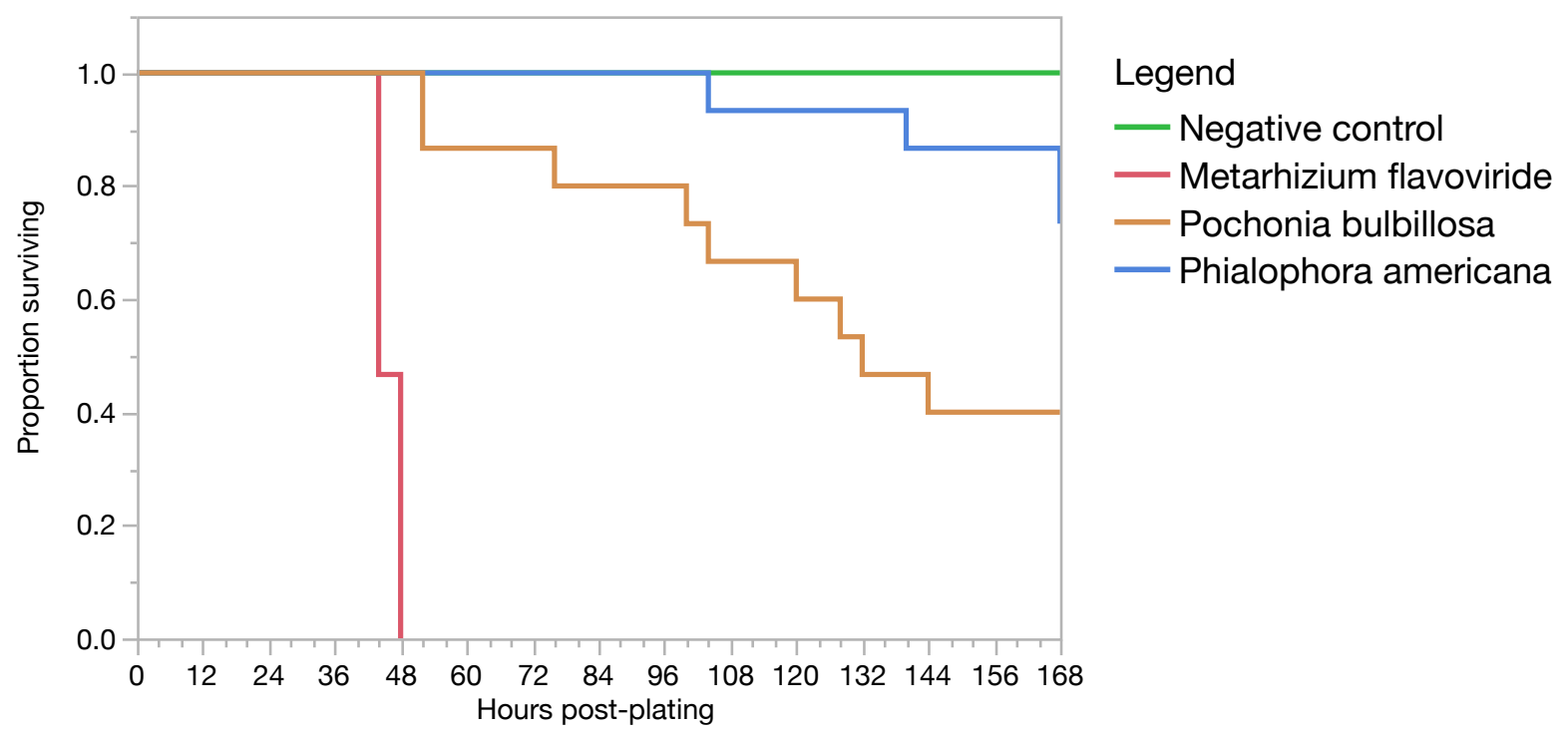

FIGURE 4: Survivorship curves for Galleria mellonella live-plating trials. Only fungal treatments that were significantly different from the control are shown.

A survival analysis was performed for the live-plating assay on Galleria mellonella. Of the 345 waxworms used in this study, 299 were unaffected by fungi or had pupated by the end of the study. Both log-rank and Wilcoxon tests were performed to determine if the treatment received had an effect on survivorship. Both tests yielded a p-value less than 0.0001 . All waxworms in the control treatment (plating with no fungus) survived, in addition to all waxworms in "aff. Fonsecaea sp.", Pestalotiopsis microspora, Irpex lacteus, Ramichloridium anceps, and Bjerkandera adusta. Fourteen additional treatments lost no more than two waxworms over the course of the experiment. The remaining three treatments, Metarhizium flavoviride, Pochonia bulbillosa, and Phialophora americana, lost 15, nine, and four waxworms, respectively. Two fungal treatments, Metarhizium flavoviride and Pochonia bulbillosa, were significantly different from the control based on Log-rank and Wilcoxon tests (Supplemental Table 2). 


\section{Entomopathogenicity testing: injections}

Most fungi used in injection entomopathogenicity tests were harmful to Galleria mellonella (Figure 5). Only 8 of 31 treatments did not cause at least $50 \%$ mortality.

The Mucorales had the most rapid effect, causing complete melanization of the larvae within two hours of injection and $50 \%$ mortality by $24-60$ hours post-injection. The only Mucorales without this effect was aff. Apophysomyces sp., which did not reach $50 \%$ mortality by the end of the experiment (Figure 5).

The dematiaceous yeasts exhibited the same larval melanization effect as the Mucorales but did not always result in severe mortality. Only five of eight treatments involving dematiaceous yeasts resulted in 50\% mortality by the end of the assay (Figure $5)$.

Among all Hypocreales treatments, nine of 10 resulted in $50 \%$ mortality by the end of the study, and all nine were from families of known entomopathogenic Hypocreales. Among these treatments, $50 \%$ mortality was reached by $28-72$ hours post-injection (mean and median $44 \mathrm{HPI}$ ) (Figure 5).

The remaining treatments in orders Umbelopsidales and Mortierellales did not cause significant mortality by the end of the study (Figure 5).

A survival analysis was performed for the injection assays on Galleria mellonella. The injection assay was performed in three separate batches, each with their own controls, so survival analysis was performed for each batch separately. Of the 740 waxworms used in injection trials, 279 were unaffected by fungi. 

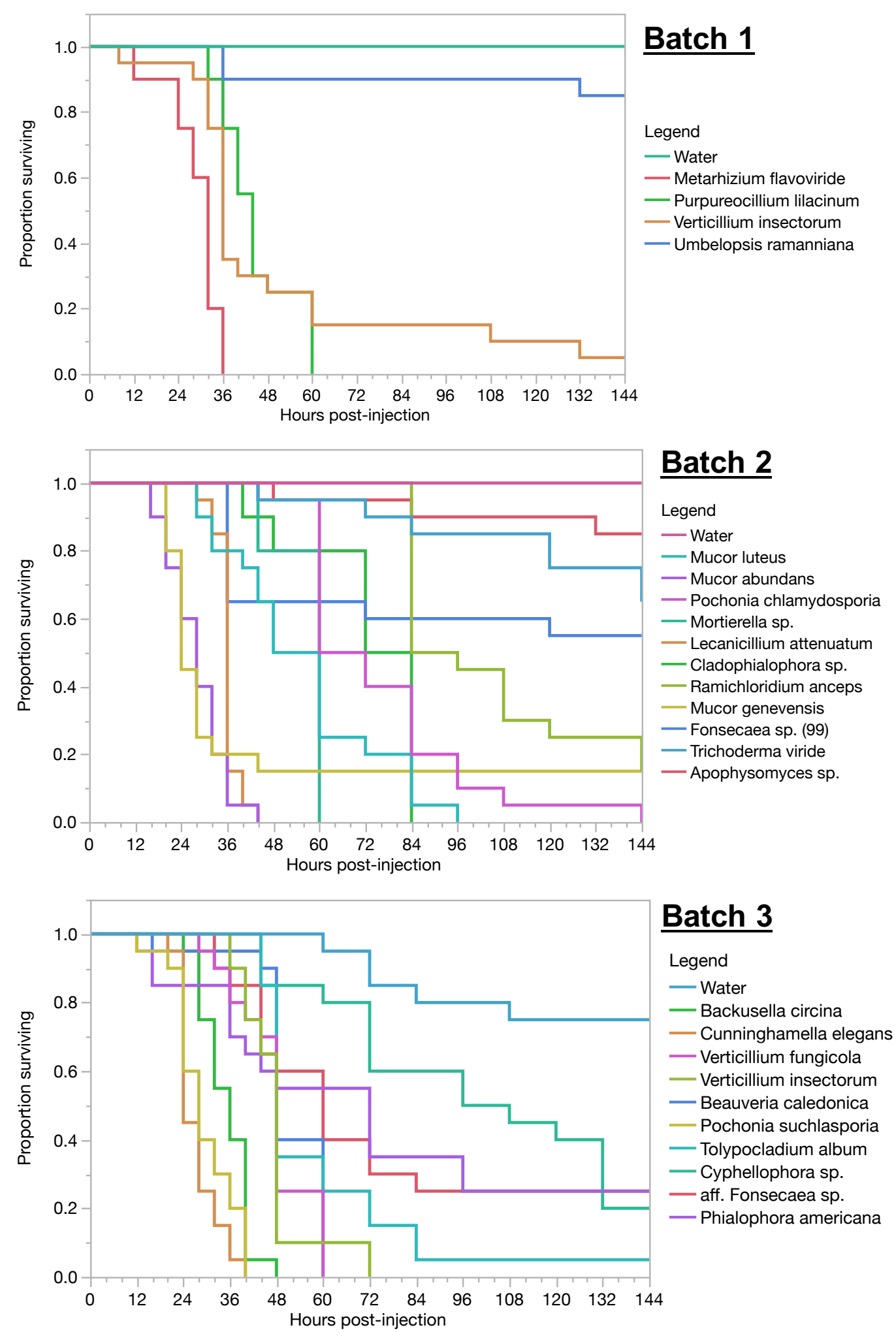

FIGURE 5: Survivorship curves for Galleria mellonella injection trials, grouped by the batch in which each fungus was tested. Only fungal treatments that were significantly 
different from the control are shown.

Batch 1 had four fungal treatments and the two controls (no injection, water injection+antibiotic). Only the control groups had no mortality. Both log-rank and Wilcoxon tests were performed to determine if the treatment received had an effect on survivorship. Both tests yielded a p-value less than 0.0001 . The four treatments, $M$. flavoviride, P. lilacinum, V. insectorum, and U. ramanniana, lost 20, 20, 19, and three waxworms, respectively (Figure 5). Since there was no mortality recorded in the control groups (no injection, water + antibiotic), they were not statistically compared. Fungal treatments were then only compared to the water + antibiotic control. Three fungal treatments, $M$. flavoviride, $P$. lilacinum, and $V$. insectorum were significantly different from the control based on Log-rank and Wilcoxon tests (Supplemental Table 3).

Batch 2 had fourteen fungal treatments and the two controls. No mortality was observed in the control groups and in "Mortierella aff. ambigua." Both log-rank and Wilcoxon tests were performed to check for differences between all treatments. Both tests yielded a $p$-value less than 0.0001 . Only eight of the fourteen treatments lost at least 10 waxworms by the end of the trial: Mucor luteus (20 waxworms deceased), Ramichloridium anceps (17), Mucor abundans (20), Pochonia chlamydosporia (20), Mortierella sp. (20), Mucor genevensis (17), Lecanicillium attenuatum (20), and Cladophialophora sp. (20) (Figure 5). Similar to Batch 1, there was no mortality recorded in either control group (no injection, water + antibiotic), so fungal treatments were then only compared to the water + antibiotic control. Ten fungal treatments, Mucor luteus, Mucor abundans, Pochonia chlamydosporia, Mortierella sp., Lecanicillium attenuatum, Cladophialophora sp., Ramichloridium anceps, Mucor genevensis, 
Fonsecaea sp., and Trichoderma viride were significantly different from the control based on Log-rank and Wilcoxon tests (Supplemental Table 4).

Batch 3 had thirteen fungal treatments and the two controls. The control groups had mild mortality: the no-injection treatment lost one worm by the end of the trial, and the water + antibiotic treatment lost five. No treatment had all worms surviving at the end of the trial. Both log-rank and Wilcoxon tests were performed to determine if the treatment received had an effect on survivorship. Both tests yielded a significant $\mathrm{p}$ value. Twelve of the thirteen fungal treatments lost at least 10 waxworms by the end of the trial: Cyphellophora oxyspora (16), Backusella circina (20), Cunninghamella elegans (20), Umbelopsis angularis (10), Verticillium fungicola (20), Verticillium insectorum (20), Beauveria caledonica (20), Pochonia suchlasporia (20), Tolypocladium album (19), "aff. Fonsecaea sp." (15), Phialophora americana (15), and Capronia dactylotricha (12) (Supplemental Table 5). Because mortality was observed in both control groups, they were statistically compared but were not significantly different. Only the water + antibiotic control was used for pairwise comparisons with fungal treatments. Nine fungal treatments, Backusella circina, Cunninghamella elegans, Verticillium fungicola, Beauveria caledonica, Pochonia suchlasporia, Tolypocladium album, Cyphellophora oxyspora, aff. Fonsecaea sp., and Phialophora americana were significantly different from the control based on Log-rank and Wilcoxon tests (Supplemental Table 5). 


\section{DISCUSSION}

\section{Fungal cohort pairings}

Overall, most fungi paired up in cohort pairings did not inhibit or overgrow other fungi. Out of 156 pairings, $12 \%$ resulted in one fungus inhibiting the growth of another, and $31 \%$ resulted in one fungus overgrowing another.

Entomopathogenic Hypocrealean fungi displayed the most inhibitory effects on other fungi (17\%) and amongst each other (66\%), followed by dematiaceous yeasts (10\% for other / $33 \%$ amongst each other), zygomycetes $(2 \%$ / $0 \%)$, and white filamentous fungi $(0 \% / 0 \%)$. White filamentous fungi displayed the most overgrowth in response to competition ( $61 \%$ / $66 \%)$, followed by zygomycetes $(23 \% / 45 \%)$, entomopathogenic Hypocreales (2\% / 0\%), and dematiaceous yeasts $(0 \% / 0 \%)$.

Based on these results, entomopathogenic Hypocreales invest in the competitive strategy of chemical warfare, where they produce diffusible compounds into their growth substrate that prevent or slow the growth of other fungi. Several studies have characterized numerous secondary metabolites that inhibit the growth and reproduction of other fungi (Molnar et al. 2010, Vicente et al. 2016, Schulz et al. 2002). Some dematiaceous yeasts may also invest in this strategy to a lesser degree. It has been hypothesized previously (Shear 2015) that millipedes may sequester chemicals that they then use for their own defenses, and it is possible that the preference $B$. lecontii displays for entomopathogenic Hypocreales (17\% of all CFUs, Chapter 2 ) is a result of this. Another possibility is that $B$. lecontii selectively harbors and inoculates substrate with entomopathogenic Hypocrealean fungi, which help prevent the growth of fungi that are not desired. Having wood substrate preferentially filled with entomopathogenic fungi 
may also help keep the worst $B$. lecontii predators (ants) and competitors (termites) away (Kudo et al. 2011). If this hypothesis is correct, resistance to entomopathogenic fungi in B. lecontii would offer evidence to support this assertion.

Zygomycetes and white filamentous fungi (especially Irpex lacteus), however, invest in a completely different strategy, physical overgrowth of the competition. These fungi rapidly colonize all available substrates, and will overgrow other fungi that are present, killing them and using them as a food source (Kasson et al. 2015, Mikeskova et al. 2012). These fungi represent $8 \%$ and $7 \%$ of all CFUs identified in Chapter 2 , respectively, and may represent preferred fungal community members. However, it is also possible that these fungi are "weeds" to $B$. lecontii. This is unlikely for white filamentous fungi, since $B$. lecontii are nearly always observed in the field on or near fruiting Polyporalean fungi (Chapter 2). However, in contrast, white filamentous fungi were only identified from $48.3 \%$ of $B$. lecontii colonies (Chapter 2). Members of the Polyporales are also known to produce many secondary metabolites (Yao et al. 2016), and it is possible that $B$. lecontii sequesters those compounds and uses them for their own purposes. If any of these hypotheses are correct, the absence of pathogenicity in B. lecontii would offer evidence to support this assertion.

\section{Entomopathogenicity testing: live plating}

Galleria mellonella live plating trials were used to determine which fungi isolated from $B$. lecontii can be considered general entomopathogens. Most fungal treatments resulted in no mortality over 7-day trials, except for the entomopathogenic Hypocreales. M. flavoviride and $P$. bulbillosa caused mortality in $>60 \%$ of all tested individuals. No 
other treatment reached $50 \%$ mortality, but the other treatments in the entomopathogenic Hypocreales ( $L$. attenuatum, V. insectorum) resulted in dermal lesions with active sporulation on a majority of individuals. These results indicate that, as expected, only entomopathogenic Hypocrealean fungi are general entomopathogens.

When the same fungi were tested in $B$. lecontii, however, very different results were obtained. Only one entomopathogenic Hypocrealean fungus caused $100 \%$ mortality in B. lecontii (Metarhizium flavoviride). The most severe mortality came from white filamentous fungi, especially the Polyporales Bjerkandera adusta (50\% mortality at 48 hours post-plating) and Trametopsis cervina (50\% mortality at 64 hours postplating). This result was highly unexpected, given the abundance of Polyporales in the field and the apparent behavioral preference for them. It is possible that the life stage of these fungi may affect their toxicity/pathogenicity to B. lecontii (Lu et al. 2014, Calvo et al. 2002), though a similar pattern ought to have appeared in the waxworm trials, since they were exposed to fungi at the same life stage. When a Polyporalean fungus first enters a log, it must actively compete with other fungi already present in the log (Kasson et al. 2016, Ottosson et al. 2015). This competition may result in the production of chemicals that inadvertently harm millipedes. In the field, $B$. lecontii is seen in association with fungal fruiting bodies. If a fungus has grown enough to be able to produce a fruiting body, it is possible that these harmful chemicals may no longer be produced. To a fungus, an uncolonized agar plate may more closely resemble the early stages of growth in a log, causing it to produce harmful compounds. 
Entomopathogenicity testing: injections

In addition to live platings, Galleria mellonella fungal injection trials were used to determine ability of fungi isolated from $B$. lecontii to opportunistically colonize arthropods. The body wall provides a strong defense against pathogens for all animals, so injection of spores through the body wall could permit weakly pathogenic fungi to cause disease. Conversely, if direct injection of spores does not result in disease, this may rule out pathogenicity all together (Kasson et al. 2015).

Most fungi ( 23 of 31 treatments) caused at least $50 \%$ mortality in waxworms by the end of the 6-day pathogenicity trials. The Mucorales and the dematiaceous yeasts caused a melanization response within 2 hours of injection, indicating that the fungi were recognized by the larval immune system as attackers (Loh et al. 2013). All Mucorales except "aff. Apophysomyces sp." caused 50\% mortality within 24-60 hours post-injection. The result for "aff. Apophysomyces sp." is not unexpected, since few to no conidia were present in the inoculum (Table 3). This pattern of rapid colonization is consistent with the results from the fungal co-plate assays, where Mucoralean fungi overgrew their competition in $26 \%$ of interactions with other fungi.

While dematiaceous yeasts did cause melanization, they did not always cause mortality. Only 5 of 8 treatments involving dematiaceous yeasts resulted in $50 \%$ mortality by the end of the study, and this mortality all occurred near the end of the study. These results indicate that even following injection, waxworms are able to hold off attacks from dematiaceous yeasts, at least for a time.

As expected, all entomopathogenic Hypocrealean fungi tested resulted in $50 \%$ mortality by the end of the study, within 28-72 hours post-injection. 
The remaining treatments in Umbelopsidales and Mortierellales did not cause significant mortality in waxworms, even following direct injections. Future work should investigate potential positive effects for these fungi, especially since results from Chapter 2 place these fungi in the core of the preferred $B$. lecontii fungal community. 


\section{LITERATURE CITED}

Bonkowski, M., S. Scheu, and M. Schaefer. 1998. Interactions of earthworms (Octolasion lacteum), millipedes (Glomeris marginata), and plants (Hordelymus europaeus) in a beechwood on a basalt hill: implications for litter decomposition and soil formation. Applied Soil Ecology. 9(1): 161-166.

Brewer, M. S., C. L. Spruill, N. S. Rao, and J. E. Bond. 2012. Phylogenetics of the millipede genus Brachycybe Wood, 1864 (Diplopoda: Platydesmida:

Andrognathidae): patterns of deep evolutionary history and recent speciation. Molecular Phylogenetics and Evolution. 64(1): 232-242.

Bultman, T. L. and P. L. Mathews. 1996. Mycophagy by a millipede and its possible impact on an insect-fungus mutualism. Oikos. 75(1): 67-74.

Calvo, A. M., R. A. Wilson, J. W. Bok, and N. P. Keller. 2002. Relationship between secondary metabolism and fungal development. Microbiology and Molecular Biology Reviews. 66(2): 447-459.

Enghoff, H. and S. Santamaria. 2015. Infectious intimacy and contaminated cavesthree new species of ectoparasitic fungi (Ascomycota: Laboulbeniales) from blaniulid millipedes (Diplopoda: Julida) and inferences about their transmittal mechanisms. Organisms Diversity \& Evolution. 15(2): 249-263.

Gardner, M. R. 1975. Revision of the millipede family Andrognathidae in the Nearctic region. Memoirs of the Pacific Coast Entomological Society. 5: 19-38.

Hodge, K. T., A. E. Hajek, and A. Gryganskyi. 2017. The first entomophthoralean killing millipedes, Arthrophaga myriapodina n. gen. n. sp., causes climbing before host death. Journal of Invertebrate Pathology. 149: 135-140. 
JMP, Version 13.1.0. SAS Institute Inc., Cary, NC, 1989-2007.

Kasson, M. T., E. S. O'Neal, and D. D. Davis. 2015. Expanded host range testing for Verticillium nonalfalfae: potential biocontrol agent against the invasive Ailanthus altissima. Plant Disease. 99(6): 823-835.

Kasson, M. T., K. L. Wickert, C. M. Stauder, A. M. Macias, M. C. Berger, D. R. Simmons, D. P. Short, D. B. DeVallance, and J. Hulcr. 2016. Mutualism with aggressive wood-degrading Flavodon ambrosius (Polyporales) facilitates niche expansion and communal social structure in Ambrosiophilus ambrosia beetles. Fungal Ecology. 23: 86-96

Kudo, S. I., Y. Akagi, S. Hiraoka, T. Tanabe, and G. Morimoto. 2011. Exclusive male egg care and determinants of brooding success in a millipede. Ethology. 117(1): 19-27.

Lawrence, J. M. and M. J. Samways. 2003. Litter breakdown by the Seychelles giant millipede and the conservation of soil processes on Cousine Island, Seychelles. Biological Conservation. 113(1): 125-132.

Lilleskov, E. A. and T. D. Burns. 2005. Spore dispersal of a resupinate ectomycorrhizal fungus, Tomentella sublilacina, via soil food webs. Mycologia. 97(4): 762-769.

Loh, J. M. S., N. Adenwalla, S. Wiles, and T. Proft. 2013. Galleria mellonella larvae as an infection model for group A streptococcus. Virulence. 4(5): 419-428.

Lu, M. J., W. Fan, W. Wang, T. Chen, Y. Tang, F. Chu, T. Chang, S. Y. Wang, M. Y. Li, Y. H. Chen, and Z. S. Lin. 2014. Genomic and transcriptomic analyses of the 
medicinal fungus Antrodia cinnamomea for its metabolite biosynthesis and sexual development. Proceedings of the National Academy of Sciences. 111(44).

Marek, P., W. Shear, and J. Bond. 2012. A rediscription of the leggiest animal, the millipede Illacme plenipes, with notes on its natural history and biogeography (Diplopoda, Siphonophorida, Siphonorhinidae). ZooKeys. 241: 77-112.

Mattson, W. J. (Ed.) 2012. The role of arthropods in forest ecosystems. Springer Science \& Business Media, New York, U.S. 96-97.

McMonigle, O. 2012. Millipeds in captivity: diplopodan husbandry and reproductive biology. Coachwhip Publications, Ohio, U.S.

Mikeskova, H, C. Novotny, and K. Svobodova. 2012. Interspecific interactions in mixed microbial cultures in a biodegradation perspective. Applied Microbiology and Biotechnology. 95(4): 861-870.

Molnár, I., D. M. Gibson, and S. B. Krasnoff. 2010. Secondary metabolites from entomopathogenic Hypocrealean fungi. Natural Product Reports. 27(9): 12411275.

Ottosson, E., A. Kubartová, M. Edman, M. Jönsson, A. Lindhe, J. Stenlid, and A. Dahlberg. 2015. Diverse ecological roles within fungal communities in decomposing logs of Picea abies. FEMS Microbiology Ecology. 91(3).

Panaccione, D. G. and S. L. Arnold. 2017. Ergot alkaloids contribute to virulence in an insect model of invasive aspergillosis. Scientific Reports. 7.

Santamaria, S., H. Enghoff, and A. S. P. S. Reboleira. 2014. Laboulbeniales on millipedes: Diplopodomyces and Troglomyces. Mycologia. 106(5): 1027-1038. 
Schulz, B., C. Boyle, S. Draeger, A. Römmert, and K. Krohn. 2002. Endophytic fungi: a source of novel biologically active secondary metabolites. Mycological Research. 106(9): 996-1004.

Shear, W. 2011. Class Diplopoda de Blainville in Gervais, 1844. In: Zhang, Z. (ed.) "Animal biodiversity: an outline of higher-level classification and survey of taxonomic richness". Magnolia Press, Auckland, New Zealand, 2011.

Shear, W. A. 2015. The chemical defenses of millipedes (Diplopoda): biochemistry, physiology, and ecology. Biochemical Systematics and Ecology. 61: 78-117.

Shelley, R. M., C. T. McAllister, and T. Tanabe. 2005. A synopsis of the millipede genus Brachycybe Wood, 1864 (Platydesmida: Andrognathidae). Fragmenta Faunistica. 48(2): 137-166.

Srivastava, P. D. and Y. N. Srivastava. 1967. Orthomorpha sp.-a new predatory millipede on Achatina fulica in Andamans. Cellular and Molecular Life Sciences. 23(9): 776 .

U.S. Environmental Protection Agency. 2013. Level III and IV ecoregions of the continental United States. EPA, National Health and Environmental Effects Research Laboratory, Corvallis, Oregon, U.S.

Vicente, F., F. Reyes, and O. Genilloud. 2016. Fungal secondary metabolites as source of antifungal compounds. In: Fungi: applications and management strategies. CRC Press, New York, U.S. 80-102.

Wilson, H. M. and L. I. Anderson. 2004. Morphology and taxonomy of Paleozoic millipedes (Diplopoda: Chilognatha: Archipolypoda) from Scotland. Journal of Paleontology. 78(1): 169-184. 
Wright, K. A. 1979. Trichomycetes and oxyuroid nematodes in the millipede, Narceus annularis. Proceedings of the Helminthological Society of Washington. 46: 213223.

Yao, L., L. Zhu, X. Xu, L. Tan, M. Sadilek, H. Fan, B. Hu, X. T. Shen, J. Yang, B. Qiao, and S. Yang. 2016. Discovery of novel xylosides in co-culture of basidiomycetes Trametes versicolor and Ganoderma applanatum by integrated metabolomics and bioinformatics. Scientific Reports. 6. 


\section{SUPPLEMENTAL TABLES}

SUPPLEMENTAL TABLE 1: Results of pairwise comparisons for $B$. lecontii live-plating trials. All listed fungal isolates are compared to the negative control.

\begin{tabular}{|l|l|l|l|}
\hline Fungal isolate & Log-Rank $\mathbf{P}$ & Wilcoxon $\mathbf{P}$ & $\begin{array}{l}\text { Bonferroni-corrected } \\
\text { significance threshold }\end{array}$ \\
\hline Trametopsis cervina & $<.0001^{*}$ & $<.0001^{*}$ & 0.05 \\
\hline Metarhizium flavoviride & $<.0001^{*}$ & $<.0001^{*}$ & 0.025 \\
\hline Bjerkandera adusta & $<.0001^{*}$ & $<.0001^{*}$ & 0.0167 \\
\hline Irpex lacteus & $0.0028^{*}$ & $0.0031^{*}$ & 0.0125 \\
\hline Mortierella sp. & 0.0346 & 0.035 & 0.01 \\
\hline
\end{tabular}

SUPPLEMENTAL TABLE 2: Results of pairwise comparisons for G. mellonella liveplating trials. All listed fungal isolates are compared to the negative control.

\begin{tabular}{|l|l|l|l|}
\hline Fungal isolate & Log-Rank P & Wilcoxon $\mathbf{P}$ & $\begin{array}{l}\text { Bonferroni-corrected } \\
\text { significance threshold }\end{array}$ \\
\hline Metarhizium flavoviride & $<.0001^{*}$ & $<.0001^{*}$ & 0.05 \\
\hline Pochonia bulbillosa & $<.0004^{*}$ & $.0005^{*}$ & 0.025 \\
\hline Phialophora americana & 0.0348 & 0.0351 & 0.0167 \\
\hline
\end{tabular}

SUPPLEMENTAL TABLE 3: Results of pairwise comparisons for G. mellonella injection trials (Batch 1). All listed fungal isolates are compared to the water + antibiotic negative control.

\begin{tabular}{|l|l|l|l|}
\hline Fungal isolate & Log-Rank P & Wilcoxon P & $\begin{array}{l}\text { Bonferroni-corrected } \\
\text { significance threshold }\end{array}$ \\
\hline Metarhizium flavoviride & $<.0001^{*}$ & $<.0001^{*}$ & 0.05 \\
\hline Purpureocillium lilacinum & $<.0001^{*}$ & $<.0001^{*}$ & 0.025 \\
\hline Verticillium insectorum & $<.0001^{*}$ & $<.0001^{*}$ & 0.0167 \\
\hline Umbelopsis ramanniana & 0.0753 & 0.0755 & 0.0125 \\
\hline
\end{tabular}


SUPPLEMENTAL TABLE 4: Results of pairwise comparisons for G. mellonella injection trials (Batch 2). All listed fungal isolates are compared to the water + antibiotic negative control.

\begin{tabular}{|l|l|l|l|}
\hline Fungal isolate & Log-Rank P & Wilcoxon P & $\begin{array}{l}\text { Bonferroni-corrected } \\
\text { significance threshold }\end{array}$ \\
\hline Mucor luteus & $<.0001^{*}$ & $<.0001^{*}$ & 0.05 \\
\hline Mucor abundans & $<.0001^{*}$ & $<.0001^{*}$ & 0.025 \\
\hline Pochonia chlamydosporia & $<.0001^{*}$ & $<.0001^{*}$ & 0.0167 \\
\hline Mortierella sp. & $<.0001^{*}$ & $<.0001^{*}$ & 0.0125 \\
\hline Lecanicillium attenuatum & $<.0001^{*}$ & $<.0001^{*}$ & 0.01 \\
\hline Cladophialophora sp. & $<.0001^{*}$ & $<.0001^{*}$ & 0.0083 \\
\hline Ramichloridium anceps & $<.0001^{*}$ & $<.0001^{*}$ & 0.0071 \\
\hline Mucor genevensis & $<.0001^{*}$ & $<.0001^{*}$ & 0.0063 \\
\hline Fonsecaea sp. & $0.0007^{*}$ & $0.0008^{*}$ & 0.0056 \\
\hline Trichoderma viride & $0.004^{*}$ & $0.0041^{*}$ & 0.005 \\
\hline aff. Apophysomyces sp. & 0.0754 & 0.0756 & 0.0045 \\
\hline
\end{tabular}

SUPPLEMENTAL TABLE 5: Results of pairwise comparisons for G. mellonella injection trials (Batch 2). All listed fungal isolates are compared to the water + antibiotic negative control.

\begin{tabular}{|l|l|l|l|}
\hline Fungal isolate & Log-Rank P & Wilcoxon P & $\begin{array}{l}\text { Bonferroni-corrected } \\
\text { significance threshold }\end{array}$ \\
\hline (No injection) & 0.011 & 0.1025 & 0.05 \\
\hline Backusella circina & $<.0001^{*}$ & $<.0001^{*}$ & 0.025 \\
\hline Cunninghamella elegans & $<.0001^{*}$ & $<.0001^{*}$ & 0.0167 \\
\hline Verticillium fungicola & $<.0001^{*}$ & $<.0001^{*}$ & 0.0125 \\
\hline Beauveria caledonica & $<.0001^{*}$ & $<.0001^{*}$ & 0.01 \\
\hline Pochonia suchlasporia & $<.0001^{*}$ & $<.0001^{*}$ & 0.0083 \\
\hline Tolypocladium album & $<.0001^{*}$ & $<.0001^{*}$ & 0.0071 \\
\hline Cyphellophora oxyspora & $0.0011^{*}$ & $.0026^{*}$ & 0.0063 \\
\hline aff. Fonsecaea sp. & $.0003^{*}$ & $.0001^{*}$ & 0.0056 \\
\hline Phialophora americana & $0.0005^{*}$ & $0.0003^{*}$ & 0.005 \\
\hline Capronia dactylotricha & 0.0312 & 0.0402 & 0.0045 \\
\hline
\end{tabular}




\section{Appendix A: Media Used}

$\begin{array}{cc}\text { Glucose Yeast Extract Agar with Antibiotics (GYEA): } \\ \text { Agar } & 20 \mathrm{~g} \\ \text { Dextrose } & 10 \mathrm{~g} \\ \text { Yeast extract } & 2 \mathrm{~g} \\ \mathrm{KH}_{2} \mathrm{PO}_{4} & 1 \mathrm{~g} \\ \mathrm{MgSO}_{4} & 0.5 \mathrm{~g} \\ \text { Thiamine } & 50 \mu \mathrm{g} \\ \text { Biotin } & 10 \mu \mathrm{g} \\ \text { Microelements } & 500 \mu \mathrm{g} \\ \mathrm{Fe}^{3+} & 439 \mu \mathrm{g} \\ \mathrm{Mn}^{2+} & 154 \mu \mathrm{g} \\ \mathrm{Zn}^{2+} & 1 \mathrm{~L}\end{array}$

Autoclave 22 minutes, cool to $\sim 50 \mathrm{C}$, add antibiotics, mix \& pour Tetracycline hydrochloride $100 \mathrm{mg}$ Streptomycin sulfate $\quad 10 \mathrm{mg}$

\section{Potato Dextrose Agar (PDA):}

Difco ${ }^{\circledR}$ potato dextrose agar $\quad 39 \mathrm{~g}$

Distilled water

Autoclave 22 minutes, cool to $\sim 50 \mathrm{C}$, pour

\section{Appendix B: DNA Extraction Protocol}

1. Harvest mycelium and dry between filter paper. Transfer to $1.5 \mathrm{~mL}$ Eppendorf tubes.

2. Add $600 \mu \mathrm{L}$ Nuclei Lysis Solution, macerate.

3. Incubate at $65 \mathrm{C}$ for 15 minutes, vortex for 10 seconds, and incubate for another 15 minutes.

4. Cool to room temperature for 5 minutes.

5. Add $200 \mu \mathrm{L}$ Protein Precipitation Solution, vortex for 20 seconds, and centrifuge at $13000 \mathrm{xg}$ for 3 minutes.

6. Transfer supernatant to a new $1.5 \mathrm{~mL}$ Eppendorf tube containing $600 \mu \mathrm{L}$ isopropanol. Mix by inversion and centrifuge at $13000 \mathrm{xg}$ for 1 minute.

7. Decant supernatant and add $600 \mu \mathrm{L} 70 \%$ ethanol. Centrifuge at $13000 x \mathrm{~g}$ for 1 minute. Decant supernatant.

8. For extra purification, repeat step 7.

9. Air-dry the pellet for approximately 30 minutes. Add $100 \mu \mathrm{L}$ Elution Buffer and store in freezer. 